\title{
Feeding competition in wild female Assamese macaques (Macaca assamensis)
}

\author{
Dissertation \\ for the award of the degree \\ "Doctor rerum naturalium" (Dr.rer.nat.) \\ of the Georg-August-Universität Göttingen \\ within the doctoral program Biology \\ of the Georg-August University School of Science (GAUSS) \\ submitted by \\ Marlies Heesen \\ from Valkenswaard, The Netherlands
}

Göttingen, 2014 
Thesis Committee

Prof. Dr. Julia Ostner, Junior Research Group Social Evolution in Primates, Courant Research Centre Evolution of Social Behaviour

Prof. Dr. Peter Kappeler, Behavioral Ecology and Sociobiology Unit, German Primate Center GmbH

Dr. Oliver Schülke, Junior Research Group Social Evolution in Primates, Courant Research Centre Evolution of Social Behaviour

\section{Members of the Examination Board}

First Reviewer:

Prof. Dr. Julia Ostner

Second Reviewer:

Prof. Dr. Peter Kappeler

\section{Further members of the Examination Board:}

Dr. Oliver Schülke, Junior Research Group Social Evolution in Primates, Courant Research Centre Evolution of Social Behaviour

Prof. Dr. Julia Fischer, Cognitive Ethology Lab, German Primate Center GmbH

Prof. Dr. Eckhard Heymann, Behavioral Ecology and Sociobiology Unit, German Primate Center GmbH Dr. Bernhard Fink, Junior Research Group Evolutionary Psychology, Courant Research Centre Evolution of Social Behaviour 
This thesis is dedicated to the memory of my mother Elizabeth Vergeer 



\section{Table of Contents}

Zusammenfassung.

Summary

Chapter 1 - General introduction.

Chapter 2 - Food abundance affects energy intake and reproduction in frugivorous female Assamese macaques.

With Sebastian Rogahn, Julia Ostner and Oliver Schülke

Chapter 3 - Predictors of food related aggression in wild Assamese macaques and the role of conflict avoidance .

With Sebastian Rogahn, Sally Macdonald, Julia Ostner and Oliver Schülke

Chapter 4 - Ecological and social determinants of group cohesiveness and within-group spatial position in wild Assamese macaques.

With Sally Macdonald, Julia Ostner and Oliver Schülke

Chapter 5 - General discussion

Bibliography. 



\section{Zusammenfassung}

Nahrung ist eine der wichtigsten Ressourcen um die Tiere konkurrieren. Um die Anpassung von lebenden Organismen zu verstehen ist es daher von großem Interesse festzustellen, wie Individuen um solche limitierenden Ressourcen konkurrieren. Bei Säugetieren wird erwartet, dass Weibchen intensiver um Nahrungsressourcen konkurrieren als Männchen, da Weibchen im Allgemeinen geringere Fortpflanzungsraten haben, und ihre Fertilität und Fortpflanzung stärker durch ihren Ernährungszustand beeinflusst werden. Zusätzlich zu dem Einfluss von Nahrungsressourcen auf das Überleben und die Reproduktion von Individuen, schlagen sozio-ökologische Modelle vor, dass die Eigenschaften von Nahrungsressourcen die Nahrungskonkurrenz und sozialen Interaktionen zwischen Individuen und Gruppen beeinflussen, und so zu voraussagbaren Unterschieden in der Sozialstruktur von Weibchen führen. Die Validität dieser Modelle wird momentan diskutiert, da Modellvorhersagen und empirische Daten häufig voneinander abweichen. Es wird allerdings argumentiert, dass diese Unstimmigkeiten hauptsächlich daraus resultieren, dass Modellvorhersagen nur ungenau oder unvollständig überprüft und wichtige Faktoren, wie zum Beispiel konkurrenzreduzierende Mechanismen und Konkurrenz um andere limitierende Ressourcen, ausgelassen werden.

Das Ziel dieser Doktorarbeit war, unser Verständnis der Zusammenhänge zwischen Nahrungseigenschaften, proximaten Mechanismen der Nahrungskonkurrenz und weiblicher Fitness zu erweitern, indem Aggression, Energieaufnahme und Reproduktion innerhalb einer Gruppe wilder Assam-Makaken (Macaca assamensis) mit Nahrungseigenschaften in Verbindung gebracht wurde. Um dieses Ziel zu erreichen, habe ich mehrere Faktoren berücksichtigt, von denen behauptet wurde, dass sie die Vorhersagekraft von sozio-ökologischen Modellen verbessern könnten. Dazu gehören Energieaufnahme und Fitness, sowie Nahrungskonkurrenz innerhalb einzelner Nahrungsquellen (food patches), konkurrenzreduzierende Mechanismen und Konkurrenz um Sicherheit.

Ich habe die ultimaten Folgen der Nahrungskonkurrenz erforscht, in dem ich den Einfluss von Nahrungsverfügbarkeit auf die Energieaufnahme von Weibchen, sowie den Einfluss deren Ranges auf die Energieaufnahme, Aktivität und Reproduktion untersucht habe. Um einen Einblick in die proximaten Mechanismen der Nahrungskonkurrenz zu gewinnen, habe ich dann die Nahrungskonkurrenz innerhalb einzelner Nahrungsquellen untersucht, um den Einfluss von sozialen und ökologischen Faktoren auf die nahrungsbezogene Aggressionsrate zu erforschen. Zusätzlich habe ich Strategien untersucht, die Weibchen nutzen könnten um direkte Konflikte um Nahrung zu vermeiden. Des Weiteren habe ich untersucht, inwiefern die räumliche Verteilung von Individuen von der Gruppenaktivität und ökologischen Bedingungen abhängt, um zu beurteilen wie die Gruppe ihre 
Kohäsion anpassen könnte, um das beste mögliche Verhältnis zwischen Kosten und Nutzen des Lebens in einer Gruppe zu erreichen. Schlussendlich habe ich erforscht, wie Dominanzrang und Reproduktionszustand den Abstand eines Weibchen zum Mittelpunkt der Gruppe beeinflusst.

Für diese Studie wurden Daten über eine Gruppe wilder Assam-Makaken im Phu Khieo Wildlife Sanctuary im Nordosten Thailands über zwei einjährige Beobachtungszeiträume erhoben (Zeitraum 1: Oktober 2007 bis September 2008; Zeitraum 2: Mai 2010 bis April 2011). Die Gruppe bestand aus insgesamt 53 Individuen, davon 12 adulte Weibchen (Zeitraum 1), bzw. aus insgesamt 49 Individuen, davon 15 adulte Weibchen (Zeitraum 2). Es wurden Fokusbeobachtungen von allen adulten Weibchen durchgeführt, und so insgesamt über 2100 Stunden Beobachtungen von Fressverhalten, Energieaufnahme, und Aktivitätsbudget erhoben, die durch Daten über Nahrungseigenschaften, weibliche Fortpflanzung, physische Verfassung und räumliche Positionen ergänzt wurden. Zusätzlich habe ich 355 Fokusbaumbeobachtungen durchgeführt, die simultane Beobachtungen aller Individuen beim Fressen in einem patch erlaubten und detaillierte Informationen über Ressourceneigenschaften, Aggressionen und die Gruppenzusammensetzung beim Fressen lieferten.

Meine Studie zeigte, dass die Studienpopulation sich hauptsächlich frugivor ernährt und dass die Verfügbarkeit von Früchten sowohl die Energieaufnahme als auch die Empfängnisraten der Weibchen beeinflusst. Dies lässt darauf schließen, dass Nahrung tatsächlich eine limitierende Ressource ist. Der Einfluss des Ernährungszustandes auf die weibliche Fitness war besonders offensichtlich während der Stillperiode, welche als energieaufwändigster Teil des Reproduktionszyklus weiblicher Säugetiere betrachtet wird. Während dieses Zeitraums haben weibliche Assam-Makaken eine energiesparende Strategie verfolgt, und verlängerte Ruhezeiten gegen verkürzte Zeiten der Nahrungsaufnahme abgewogen. Der Grad, zu dem Weibchen in der Lage waren die Kosten der Laktation zu kompensieren, beeinflusste, ob sie in ausreichend guter physischer Verfassung blieben, um in der folgenden Paarungszeit erneut tragend zu werden. Dies weißt darauf hin, dass die Nahrungsverfügbarkeit während energetisch anspruchsvoller Perioden, wie z.B. der Hauptstillzeit, die weibliche Reproduktion beschränken kann. Trotz ihrer hauptsächlich frugivoren Ernährung und dem Fakt, dass Weibchen eine strikt lineare Dominanzhierarchie aufweisen, zeigen Weibchen überraschenderweise keine Rangabhängigkeit in der Energieaufnahme, des Aktivitätsbudgets oder der Reproduktion. Außerdem veränderte sich der Einfluss des Ranges eines Weibchen weder auf ihre Energieaufnahme noch auf ihre Aktivität, abhängig von der Gesamtverfügbarkeit von Früchten, Nahrungsqualität, Größe einer Nahrungsressource oder Dichte des meist verzehrten Nahrungstyps.

Die Frequenz von nahrungsbezogener Aggression in Nahrungspatches erhöhte sich mit zunehmender Gruppengröße beim Fressen und abnehmender Anzahl von Futterstellen innerhalb des patches (patch 
size), während sie nicht durch ökologische Variablen, die den Wert von Ressourcen messen, beeinflusst wurde. Interessanterweise scheinen Weibchen mehrere Mechanismen zu nutzen, die direkte Konflikte vermeiden. Dazu gehören die Nutzung alternativer Futterstellen innerhalb von Nahrungspatches, das Speichern von Nahrung in Backentaschen und das Fressen in der Nähe von Individuen mit enger sozialer Bindung. Distanzen zwischen Individuen waren größer wenn die Gruppe fraß als wenn sie hauptsächlich ruhte, sozial interagierte oder sich bewegte. Dies beruht wahrscheinlich darauf, dass die Kosten auf Grund der Nahrungskonkurrenz mit der Nähe zunehmen. Unter den adulten Weibchen besetzten höherrangige Individuen zentralere Positionen innerhalb der Gruppe, während niederrangige Weibchen eher außen zu finden waren.

Zusammenfassend vereint diese Doktorarbeit Erkenntnisse über die Zusammenhänge zwischen Ressourceneigenschaften, Verhaltensmechanismen der Nahrungskonkurrenz und Fitnesskonsequenzen in weiblichen Assam-Makaken, und gibt somit einen detaillierten Einblick in die sozialen und ökologischen Einflüsse auf Nahrungskonkurrenz und Fitness von Weibchen. Basierend auf Ressourceneigenschaften wurde vorhergesagt, dass Weibchen innerhalb der Gruppe direkte Nahrungskonkurrenz (contest competition) zeigen. Obwohl Weibchen Aggression im Zusammenhang mit Nahrung zeigen, waren die Aggressionsraten niedriger als vorhergesagt. Dies war wahrscheinlich bedingt durch den Fakt, dass Weibchen konfliktreduzierende Mechanismen nutzen, und dadurch, dass Aggressionsraten stärker durch die Größe eines Nahrungsquelles (patch size) und der Gruppengröße beim Fressen beeinflusst wurden, als durch die Dichte, die Qualität und die Verteilung der Nahrung. Weibchen haben keine Rangabhängigkeit in Hinsicht auf Energieaufnahme und Fitness gezeigt, die mit direkter Nahrungskonkurrenz innerhalb der Gruppe in Verbindung gebracht wird. Hier sind erneut die konkurrenzreduzierenden Mechanismen wichtig, da sie es niedrigrangigen Weibchen erlauben ihren Zugang zu Nahrungsressourcen zu verbessern. Dies könnte mit anderen Nachteilen verbunden sein. Niedrigrangige Weibchen besetzten zum Beispiel eher äußere Positionen, die voraussichtlich Störungen bei der Nahrungsaufnahme reduzieren, welche aber auch mit erhöhtem Prädationsrisiko verbunden sind. Dies deutet an, dass die Konkurrenz um sichere Positionen mit der Nahrungskonkurrenz interagiert und die individuelle Fitness beeinflussen kann. Um die interne Widerspruchsfreiheit von sozio-ökologischen Modellen grundlegend zu überprüfen, sind weitere Studien notwendig die detaillierte Messungen von Ressourceneigenschaften, Energieaufname und Fitness miteinbeziehen, und die konkurrenzvermeidenden Anpassungen und Konkurrenz um sonstige limitierende Ressourcen berücksichtigen. 


\section{Summary}

Food is one of the most important resources animals compete over and assessing the way individuals compete over such limiting resources is fundamental to our understanding of the adaptations of living organisms. In mammals, females are predicted to compete more intensively for access to food resources than males as females generally have lower potential reproductive rates and female fertility and reproduction are more strongly influenced by nutritional status. In addition to affecting individual survival and reproduction, socio-ecological models propose that food resource characteristics influence feeding competition and social interactions between individuals and groups, leading to predictable differences in female social structure. The validity of these models is currently under debate due to the many discrepancies found between model predictions and empirical data. However, it is argued that these mismatches mainly result from inaccurate or incomplete testing of model predictions and from ignoring important factors such as competition reducing mechanisms and competition for other limiting resources.

The overall aim of this thesis was to broaden our understanding of the relationships between food characteristics, proximate mechanisms of feeding competition and female fitness by linking food characteristics to aggression, energy intake and reproduction in a group of wild Assamese macaques (Macaca assamensis). To achieve this I incorporated several factors that have been suggested to improve the predictive value of socio-ecological models, including measures of energy intake and fitness, measures of feeding competition at the level of individual food patches, competition reducing mechanisms and competition for safety.

I investigated the ultimate consequences of feeding competition by examining the influence of food availability on female energy intake and reproduction as well as the influence of female rank on energy intake, activity and reproduction. To gain insight into the proximate mechanisms of feeding competition I then examined feeding competition at the level of individual food patches, investigating the impact of social and ecological factors on rates of food related aggression. Additionally, I examined strategies females may use to avoid direct conflicts over food. Finally, I related group activity and ecological conditions to inter-individual spacing behaviour to assess how group cohesiveness may be adjusted to mediate the costs and benefits of group living and I investigated how dominance rank and reproductive state affect a female's distance from the centre of the group.

Data for this study were collected on a group of wild Assamese macaques at Phu Khieo Wildlife Sanctuary in north-eastern Thailand over two 1-year sampling periods (period 1: October 2007September 2008; period 2: May 2010-April 2011). During these sampling periods the group consisted

vi 
of a total of 53 individuals, 12 of which were adult females (period 1) and 49 individuals, 15 of which were adult females (period 2). Focal data were collected on all adult females, resulting in over 2,100 hours of data on feeding behaviour, energy intake, and activity budgets which were combined with data on resource characteristics, female reproduction, physical condition and spatial position. In addition, I conducted 355 focal tree observations which allowed for the simultaneous observation of all individuals feeding in a food patch, proving detailed information on resource characteristics, aggression, and feeding party composition.

My study revealed that the study population has a highly frugivorous diet and fruit availability affected both female energy intake and conception rates, indicating that food is indeed a limiting resource. The influence of nutritional status on female fitness was especially apparent during the lactation period which is considered to be one of the most energetically costly parts of the reproductive cycle in female mammals. During this period female Assamese macaques followed an energy conserving strategy, trading-off an increase in time spent resting for reduced feeding time. The degree to which females were able to compensate for the costs of lactation affected whether they were able to attain a high enough physical condition to conceive again the following mating season. This suggests that food availability during energetically demanding periods such as peak lactation can constrain female reproduction. Surprisingly, despite their highly frugivorous diet and the fact that females exhibited strict linear dominance hierarchies, females did not display a rank related skew in energy intake, activity budgets or reproduction. In addition, the relationships between female rank and either energy intake or activity did not change depending on overall fruit abundance or the nutritional quality, patch size or density of the most consumed food items.

The frequency of food related aggression in feeding patches increased with increasing feeding group size and decreasing number of feeding sites inside patches (patch size) while it was not affected by ecological variables representing resource value. Interestingly, females appear to employ several mechanisms to avoid direct conflicts, including the use of alternative feeding sites within food patches, storing food in cheek pouches and co-feeding with closely bonded individuals. Inter-individual distances were greater when the group was feeding compared to when the main group activity was resting, engaging in social behaviour or moving. This is likely due to the high costs of proximity associated with feeding competition. Among adult females, higher ranking individuals occupied more central positions within the group while lower ranking females were more peripheral.

In sum, this thesis unites information on the relationships between resource characteristics, behavioural mechanisms of feeding competition and fitness consequences in female Assamese macaques, creating a detailed picture of the social and ecological influences on female feeding 
competition and fitness. Based on resource characteristics, females were predicted to exhibit withingroup contest competition over food. Although females did exhibit food related aggression, aggression rates were lower than predicted. This was probably due to the fact that females employ conflict reducing mechanisms and that aggression rates may be more strongly affected by patch size and feeding group size than by food density, quality and distribution per se. Females did not exhibit the rank related skew in energy intake and fitness that is associated with within-group contest competition. Here, again, competition reducing mechanisms are important as they can enable low ranking females to enhance their access to food resources although this may come at a cost. For example, low ranking females occupy more peripheral positions which are likely to reduce feeding interference but which are also associated with increased predation risk. This suggests that competition for safe positions can interact with feeding competition to affect individual fitness. For true tests of the internal consistency of socio-ecological models more studies are needed which incorporate detailed measurements of resource characteristics as well as energetic and fitness measures and which take into account conflict reducing adaptations and competition for limiting resources other than food. 


\section{Chapter 1}

\section{General introduction}

Assessing the way individuals compete to survive and reproduce is fundamental to our understanding of the adaptations of living organisms (Darwin 1859). Among animals food is one of the most important resources individuals compete over as feeding is essential to survival and resource acquisition efficiency will therefore have a great impact on individual fitness (Chapman et al. 2012). Thus, it is not surprising that foraging behaviour plays a central role in the field of behavioural ecology (Krebs and Davies 1987) which has its focus on the current adaptive value of behavioural traits and their development over evolutionary time. Its main premise is that natural selection favours behaviour patterns which will maximise an individual's fitness with the most optimal behaviour depending on both the physical and social environment (Davies et al. 2012; Simmons 2014).

Competition for scarce resources within and between species constitutes an important part of this social environment and this thesis focuses specifically on feeding competition among group-living animals. While group living offers benefits such as reduced predation risk and the communal defence of resources, it is also likely to result in increased feeding competition due to the simultaneous exploitation of scarce resources (Alexander 1974; Krause and Ruxton 2002). The different strategies individuals use to balance these costs and benefits have resulted in a wide variety of animal social systems, including differences in group size, composition and cohesion, patterns of social interactions among individuals (social structure) and mating systems (Kappeler and van Schaik 2002). In this thesis I focus specifically on the relationship between food resource characteristics, feeding competition and female social structure (Kappeler and van Schaik 2002). Most research in this area is based upon the framework provided by socio-ecological models which propose that a limited number of environmental factors such as food resource characteristics influence feeding competition and social interactions between individuals and groups, leading to predictable differences in female social structure (Wrangham 1980; van Schaik 1989; Sterck et al. 1997; Isbell and Young 2002).

The validity of these models is currently under debate due to the many discrepancies found between model predictions and empirical data (Thierry 2008; Clutton-Brock and Janson 2012). However, it is argued that these mismatches mainly result from inaccurate or incomplete testing of model predictions and from ignoring important factors such as competition reducing mechanisms and competition for limiting resources other than food (Koenig and Borries 2006; Koenig and Borries 2009; 
Schülke and Ostner 2012). I therefore aim to contribute to a better understanding of the relationship between food resource characteristics, proximate mechanisms of feeding competition and individual fitness by conducting a detailed investigation of the mechanisms of female feeding competition in a group of wild Assamese macaques (Macaca assamensis).

In the following general introduction I will first provide a theoretical background on foraging and feeding competition (section 1.1), followed by a description of the strategies individuals may use to balance the costs and benefits of group living and how these depend on the distribution of risks and resources in the environment (section 1.2). I then focus on primate social systems, how they are affected by ecological conditions and more particularly how female social structure is predicted to result from variation in food resource characteristics and feeding competition (section 1.3). This is followed by an overview of the current debate on the validity of socio-ecological models including methods that have been suggested to improve these models (section 1.4). Finally, I briefly describe the study species (section 1.5) followed by an outline of the overall aim of my thesis as well as the individual studies conducted to achieve this aim (section 1.6).

\subsection{Feeding competition}

Animals are generally predicted to forage in a way which will maximise their energy intake while expending the least amount of time or energy (optimal foraging: Emlen 1966; MacArthur and Pianka 1966). All optimal foraging models are based on the assumption that an animal's fitness is a function of its foraging efficiency, measured in terms of some "currency" (Schoener 1971), usually energy, and that natural selection has resulted in animals foraging in a way that maximises their fitness (Emlen 1966; MacArthur and Pianka 1966). Animals are predicted to either minimise the amount of time needed to obtain a certain amount of energy (time minimisers) or, if an animal has a fixed amount of time to forage, to obtain the maximum amount of energy in the allotted time (energy maximisers) (Schoener 1971). Which category an animal falls into depends on whether factors such as predation or nutritional requirements operate at the same time and conflict with an individual's ability to increase the net rate of energy intake (Pyke et al. 1977). Optimal foraging theory has been applied to predict different aspects of animal foraging behaviour such as diet choice, patch choice, allocation of time to different food patches and movement patterns (Pyke et al. 1977; Perry and Pianka 1997).

Many animals live and forage in social groups, the size and dynamics of which are largely shaped by the pressures of predation risk and feeding competition (Krause and Ruxton 2002). Predation risk is considered to be one of the major factors driving gregariousness as animals in groups typically 
experience a lower predation risk than solitary individuals due to dilution effects (Williams 1966; Hamilton 1971; Duncan and Vigne 1979), improved vigilance (Kenward 1978), predator confusion and communal defence (Kruuk 1964; Andersson and Wicklund 1978). Other benefits of group living include advantages in terms of foraging such as improved food finding, food capture, and communal defence of resources (Davies et al. 2012). At the same time, group living is associated with costs, including increased disease transmission, increased conspicuousness to predators and disturbance of prey (Davies et al. 2012). The most widely acknowledged cost of group living, however, is increased feeding competition resulting from the simultaneous exploitation of limited resources (Skogland 1985; van Schaik 1989; Isbell 1991).

Feeding competition can take different forms, the simplest one of which is exploitation (using up resources). This type of competition is expected to occur in a situation where there is no limit to the number of competitors that can exploit a resource and every individual can choose where to go. The number of individual animals that will aggregate in various habitats or patches is then predicted to be proportional to the amount of resources available so that the rewards per individual are the same in each, assuming that there is no exclusion of weaker competitors by stronger ones and that the animals have complete information about the availability of resources. ("ideal free distribution": Tregenza 1995; Davies et al. 2012). Feeding competition can also take the form of resource defence (interference competition) (Fretwell 1972). This describes a situation where certain individuals are able to defend resources and exclude others from them, thereby reducing the foraging efficiency of the excluded individuals. In this situation, the strongest individuals will be able to occupy the best quality resources, forcing others into low quality areas or excluding them from resources altogether ("despotic distribution": Fretwell and Lucas 1969; Fretwell 1972). In nature, competition is likely to have features of both the ideal free distribution and despotic distribution.

Since resource defence has costs (risk of injury, energy expenditure) as well as benefits (priority of access to resources) it should be favoured by selection when the benefits are greater than the costs (Harper 1982; Parker and Sutherland 1986; Grant et al. 2002). Whether animals will compete for resources by exploitation or resource defence can be predicted by optimality models which focus on the trade-off between the costs and benefits of defending a resource ("economic defendability") (Brown 1964; Emlen and Oring 1977; Grant 1993) as well as by game theoretic approaches which aim predict the occurrence of aggression within populations (Maynard Smith and Price 1973; Maynard Smith 1976; Sirot 2000). Optimality models predict that resource defence increases with increasing economic defendability of resources, for example, when resources are more clumped in space (Grant 1993). One example of a game theoretic approach is that of the hawk-dove game. This approach sets two strategies, one that escalates (hawk) and one that does not (dove), against each other, predicting 
that the nonaggressive dove can only exist as part of a mixed evolutionary stable strategy (ESS) (Maynard Smith and Price 1973). The frequency of hawks in this mixed ESS and therefore the proportion of encounters resulting in escalated fights, depends on the relationship between the value of winning and the cost of losing an aggressive encounter (Sirot 2000). Both approaches are used to predict food related aggression based on factors such as food distribution, food abundance and competitor density (Dubois et al. 2003; Johnson et al. 2004). For social foragers competing for patches of food, patch size and number of competitors are considered to be the key variables that influence whether individuals will use aggression (Grant, 1993).

\subsection{Balancing the costs and benefits of group living}

Due to the contrasting effects of group living on predation risk and feeding competition, individuals face a trade-off between the costs and benefits of gregariousness. One way in which individuals can balance these costs and benefits is by altering (feeding) group size or cohesiveness, depending on factors such as predation risk, the density and distribution of food resources and activity (Wrangham 1980; Isbell 1991; Sogard and Olla 1997; Grant et al. 2002; Krause and Ruxton 2002; Aureli et al. 2008). The costs and benefits of group living not only depend on group size and cohesion, they may also differ between group members (Krause and Ruxton 2002). Many of these differences are related to the spatial distribution of costs and benefits within groups. For example, individuals at the periphery of a group are predicted to experience a higher predation risk compared to central individuals ("marginal predation") due to "selfish herd" effects (Hamilton 1971) and he fact that individuals on the edge will be encountered first by most predators, making them more likely to be the object of an attack (Vine 1971). Individuals will thus benefit from occupying central spatial positions within groups which is supported by both theoretical and empirical studies which have found higher mortality, per capita attack rates and vigilance levels in peripheral compared to central animals (Jennings and Evans 1980; Janson 1990a; Krause 1994; Viscido and Wethey 2002; James et al. 2004; Hirsch and Morrell 2011). Individual positions within a group may also differ in their associated feeding success. The higher density of individuals in the centre of a group can increase feeding interference and therefore reduce food intake in central individuals (Robinson 1981; Janson 1990b; Krause 1994; Di Bitetti and Janson 2001; Krause and Ruxton 2002). Alternatively, especially when food sources are monopolisable, central individuals may be able to occupy the best food sources, leading to a higher food intake in central individuals (Robinson 1981; van Schaik and van Noordwijk 1986; van Schaik and van Noordwijk 1988; Janson 1990a; Barton 1993). 
Due to these varying costs and benefits associated with different spatial positions, animals have to balance a trade-off between feeding and avoiding danger ("risk-sensitive foraging") (Lima and Dill 1990; Miller 2002). The outcome of this trade-off is affected by factors such as resource availability, predation risk, and an individual's hunger state (Milinski and Heller 1978; Heller and Milinski 1979; Werner et al. 1983; Milinski 1984; Miller 2002). Individuals will differ in their vulnerability to predation depending on variables such as age, the presence of infants and habitat use. All these factors will influence an individual's perceived level of risk and thereby its foraging decisions. For example, hungry individuals may occupy more frontal positions where they are the first to encounter food but also more vulnerable to predation while more satiated individuals are more central (Krause 1983; Bumann et al. 1997) Also, juvenile individuals forage at more central positions and avoid open habitats more than adults because they are more vulnerable to predation (Janson 1990a). However, differences in spatial position between individuals are usually not only determined by the associated predation costs and feeding benefits. Within groups that are organized by a dominance hierarchy, high ranking individuals may use their rank to gain access to and exclude lower ranking individuals from preferred positions (Janson 1990b; Krause 1994; Hall and Fedigan 1997; Hirsch 2011)

\subsection{Ecological influences on primate social systems}

The varying costs and benefits associated with group living have resulted in a wide variety of animal social systems across species, within species and even within populations (Crook and Gartlan 1966; Kappeler and van Schaik 2002). This variation can be structured into three aspects of sociality which together form the social system: social organisation (i.e. group size, composition and cohesion), social structure (emerges from dyadic social relationships; i.e. patterns of social interactions and relationships among individuals), and mating system (Kappeler and van Schaik 2002). Although ecological factors such as feeding competition are considered to be important determinants of group dynamics and social systems in many mammalian taxa (e.g. reindeer, Rangifer tardus: Holand et al. (2004), Soay sheep, Ovis aries: Robinson and Kruuk (2007), spotted hyena, Crocuta crocuta: Holekamp and Dloniak (2010), most research in this area is focussed on primates. This is due to the fact that, in contrast to most other mammals, the majority of diurnal primate species live in permanent cohesive social groups of varying sizes displaying a wide range of social systems (Kappeler and van Schaik 2002). Attempts to explain this diversity in primate sociality based on differences in ecology have resulted in the development of what is now known as the socio-ecological model which proposes that a limited number of environmental factors affect population characteristics, leading to predictable differences in social systems. 
The socio-ecological model has developed along different routes, one relating ecological factors to grouping patterns and mating systems (Jarman 1974; Bradbury and Vehrencamp 1977a; Clutton-Brock 1989) and one relating ecological factors to grouping patterns and female social structure (Wrangham 1980; van Schaik 1989; Sterck et al. 1997; Isbell and Young 2002; Isbell 2004). The focus on females is due to the fact that female mammals generally have lower potential reproductive rates than males and are therefore predicted to mainly compete over food resources and safety while males compete over access to receptive females (Clutton-Brock and Parker 1992). In my thesis I will focus on the part of the socio-ecological model which centres on the idea that the abundance density, quality, and distribution of food resources determine the mode and strength of feeding competition females experience which, in turn, is expected to affect female fitness, social relationships and dispersal patterns.

\subsubsection{Factors affecting group living in female primates}

There are several hypotheses about the evolution of gregariousness in primates, starting with Wrangham (1980) who proposed that group living evolved because gregarious females are better at finding and defending resources and would thus be able to improve their access to food. However, the predicted positive relationship between group size and female feeding success has rarely been observed (Janson 2000; Koenig 2002). Another hypothesis states that gregariousness may evolve when females face a risk of male sexual coercion and consequently associate with males to protect them from aggression (Wrangham 1979; van Schaik 1996; Sterck et al. 1997). This pattern has been observed in gorillas and Asian colobines (Gorilla beringei beringei: Watts (1989); Presbytis thomasi: Sterck and Steenbeek (2000)). A third hypothesis, which is thought to account for group living in the majority of primate species, states that female gregariousness evolved as a response to high predation risk (Terborgh 1983; van Schaik 1983; Dunbar 1988; van Schaik 1989; Janson 1998). Regardless of the route via which gregariousness evolved, it is predicted to lead to an increase in female competition over food sources which can take the form of both contest and scramble competition.

\subsubsection{Types of feeding competition}

In behavioural ecology, the concepts of contest and scramble competition are used to describe how animals compete behaviourally and how this competition affects individual access to resources (Parker 2000). Here, the term scramble (indirect or exploitation) competition is used to describe a situation where every individual influences the net energy gain of all other group members by using some 
portion of the food available (Nicholson 1954). In this situation all individuals share the same food supply and no-one is able to obtain more than others by overt behaviour such as excluding others from resources or defending a territory. As a result, the net food intake of all individuals in a population is equally affected by an increase in population density and there is no exclusion of weaker competitors by stronger ones (van Schaik 1989). Contest (direct or interference) competition, on the other hand, describes a situation where a subset of individuals restricts other individuals' access to a resource, either by means of aggressive interactions or avoidance. In this case some individuals, such as dominant individuals, territory owners or winners of agonistic interactions, are able to obtain a greater share of a food source than others (Janson and van Schaik 1988; van Schaik 1989). Both types of competition will occur simultaneously under most natural conditions and can occur both within and between social groups (van Schaik 1989). This led to the establishment of four types of competition within nonhuman primate species: within-group scramble competition (WGS), within-group contest competition (WGC), between-group scramble competition (BGS) and between-group contest competition (BGC) (Janson and van Schaik 1988; van Schaik 1989).

\subsubsection{Food characteristics and modes of feeding competition}

The different modes of competition described above are thought to be the result of different patterns of food distribution, abundance and quality. Within-group contest competition is expected when food is monopolizable and occurs in patches that can be defended by an individual or subset of individuals (van Schaik 1989). This includes food sources with a long depletion time, a high nutritional value, a clumped distribution, and food which occurs in patches that are of intermediate size relative to group size so that they cannot feed all group members at once (Isbell 1991; Sterck et al. 1997; Isbell et al. 1998; Koenig 2002). Within-group contest is also expected when the costs of being excluded from a patch are high (van Schaik 1989). These costs depend on the relative value of a food patch in relation to the alternative patches that are available to an individual without leaving the group (Vogel and Janson 2007). Between-group contest competition is predicted to occur when food quality is high and food patches are large enough to accommodate the entire group and can be economically defended against other groups (van Schaik 1989).

Within-group scramble competition is associated with food resources that are of low quality, highly dispersed or very large so that they are difficult or not valuable enough to monopolize by individuals or small groups (Janson 1988b; van Schaik 1989; Koenig et al. 1998). Scramble competition is also expected when food patches have a short depletion time, for example, because they are very small, contain few food items, or contain food items with a short handling time (Isbell et al. 1998; Pruetz and 
Isbell 2000). Between-group scramble competition is thought to reflect the effect of population density on food intake and since this is not expected to influence female social relationships in primates it is usually not discussed (van Schaik 1989).

\subsubsection{Competitive regimes and their fitness consequences}

In any given situation group living animals will experience a combination of the different modes of competition described above resulting in diverse competitive regimes. Van Schaik (1989) distinguishes four such regimes: 1) predominantly within-group scramble competition, 2) within-group contest competition with a variable intensity of within-group scramble competition, 3) within-group scramble with between-group contest competition and 4) between-group contest competition with a, usually unexpressed, potential for within-group contest competition. The ultimate consequences of different types of feeding competition can be assessed by regressing individual net energy gain on group size and dominance rank (Janson and van Schaik 1988; Koenig 2002). When within-group contest competition prevails, individual energy gain and fitness are expected to be positively related to rank, with high ranking individuals having a higher energy gain and fitness compared to lower ranking individuals. When within-group scramble is the dominant form of competition net energy gain is predicted to be negatively related to group size. On the other hand, when between-group contest is the most dominant form of competition, energy gain and fitness should be positively related to group size as the members of dominant groups are expected to aggressively displace or be avoided by subordinate groups, or because they defend a larger or better territory (Janson and van Schaik 1988; Lomnicki 1988; van Schaik 1989).

\subsubsection{Feeding competition and female social structure}

Female social structure is an emergent property of patterns of dyadic social interactions, including affiliative as well as agonistic behaviours (Hinde 1976; Kappeler and van Schaik 2002). Therefore, as feeding competition affects the frequency, intensity and quality of such social interactions, competitive regimes are predicted to influence not only the social strategies females use to maximize their fitness but also the resulting female social structure (van Schaik 1989; Sterck et al. 1997). An important aspect for social structure is dominance which is a property that results from repeated agonistic interactions. Dominance relationships vary (1) from individualistic to nepotistic, (2) from egalitarian to despotic (Vehrencamp 1983), and (3) from intolerant to tolerant. Nepotistic relationships occur when genetic relatives support each other in agonistic conflict and hierarchies are 
sub-structured into matrilines. Individualistic hierarchies, in which the ranks of female relatives are independent of each other, occur when supporting relatives has no fitness benefits (Sterck et al. 1997). Despotic social structures are marked by clearly established and often formalized dominance relations and dominance hierarchies are usually linear while in egalitarian societies dominance relationships are absent or poorly defined and hierarchies are unclear and non-linear (Sterck et al. 1997). Formal dominance relations are marked by formal submission signals that are unidirectional within dyads. Tolerant relationships are associated with increasing levels of counter-aggression and reconciliation as well as with decreasing severity of aggression (Thierry 1985; de Waal and Luttrell 1989).

When within-group contest competition is strong, females are expected to engage in frequent aggressive interactions because the benefits of gaining access to a resource are high (Janson 1985). As aggression carries costs for all individuals involved in terms of energy expenditure and the risk of injuries, dominance hierarchies are predicted to evolve as a means to regulate aggression (de Waal and Luttrell 1989). Because the benefits of high rank are great, dominance hierarchies are expected to be linear, and stable, with decided, unidirectional aggression within dyads and low frequencies of counter-aggression (van Schaik 1989). In addition, formalised signals of submission or dominance may evolve to avoid escalation of aggression (de Waal 1986a). If food patches can support more than one individual at a time, females are predicted to form coalitions promoted by direct or indirect fitness benefits (van Schaik 1989). Because rank is so influential, females can increase their inclusive fitness by supporting their relatives and consequently related females will be close in rank. These fitness benefits associated with cooperation with kin are also expected promote female philopatry (Wrangham 1980; van Schaik 1989; Sterck et al. 1997; Silk 2002). This so called resident-nepotistic social structure (Sterck et al. 1997) is also associated with well-differentiated relationships among females, including preferential affiliation with kin and reciprocating partners (van Schaik, 1989; van Hooff \& van Schaik, 1992; Sterck et al., 1997).

In situations where within-group scramble is the most predominant form of competition, fitness is primarily influenced by group size and females do not have much to gain from displaying food related aggression. Therefore, rates of aggression are predicted to be low and aggression within dyads is expected to be bidirectional, resulting in hierarchies that are weak, unstable and not necessarily linear. Coalitions, particularly with nonrelatives, should be uncommon or absent. In this situation, hierarchies will be individualistic and females should be able to disperse, although this will not necessarily occur (van Schaik 1989; Sterck et al. 1997). This type of social structure is referred to as dispersal-egalitarian (Sterck et al. 1997). 
When individuals experience strong between-group contest competition in combination with weak within-group contest competition, agonistic relationships are predicted to be similar to those described above for the dispersal-egalitarian social structure. Although success in between-group contest competition is important to all females an individual can withhold her participation in such contests and still benefit from the participation of others. Females can solve this defection problem by living with kin (van Schaik 1989; Sterck et al. 1997). This type of social structure is also referred to as resident-egalitarian (Sterck et al. 1997).

It is also possible that individuals experience both strong within- and between-group contest competition. In this situation high ranking females may risk losing the support of low ranking females in between-group contest competition if they enforce dominance too strongly. Therefore, high ranking individuals are expected to be more tolerant, for example, by allowing low ranking individuals regular access to important resources. As a result, the frequency and intensity of aggression should be lower with high rates of counter-aggression and reconciliation (Thierry 1985; de Waal and Luttrell 1989; Sterck et al. 1997). Females are still expected to be nepotistic because they should prefer relatives as alliance partners (van Schaik 1989). This type of social structure is referred to as resident-nepotistictolerant (Sterck et al. 1997).

\subsection{The current socio-ecological model}

In recent years, the socio-ecological model has been subject to a lot of criticism which has fuelled a general debate about the validity of its assumptions and the accuracy of its predictions. Much of this critique is based on the mismatches which have been found between the predictions of the model and the actual behaviour of nonhuman primates (Thierry 2008). For example, resource characteristics are not always good predictors of aggression rates or competitive regimes (Deutsch and Lee 1991; Sterck and Steenbeek 1997; Koenig 2000) and competitive regimes are not always good predictors of social structure (Borries 1993; Boinski 1999; Cords 2000; Isbell and Young 2002; Koenig 2002). Additionally, it has been argued that, since the socio-ecological model is based on verbal logic, its predictions are difficult to test and test results are difficult to interpret (Thierry 2008; Clutton-Brock and Janson 2012). It has also been suggested that social traits co-evolve and are constrained by a species' phylogenetic history which would mean they cannot be flexibly adjusted to changes in ecological factors (Thierry 2008).

While some authors claim that attempts to relate variation in social behaviour to ecological factors should be abandoned altogether (Thierry 2008), others argue that the existing theory still provides a 
useful framework though it needs refinement (Janson 2000; Snaith and Chapman 2007; Koenig and Borries 2009; Schülke and Ostner 2012; Koenig et al. 2013). It is suggested that many of the mismatches between model predictions and empirical findings are in fact due to imperfect or uncritical testing of these predictions. Imperfect testing is based on incorrect information while in the case of uncritical testing, ecology or behaviour are used as indicators of different forms of competition in the absence of actual measures of competition such as energetic or fitness consequences (Koenig and Borries 2009; Schülke and Ostner 2012). For example, both linear hierarchies and high aggression rates have been used as an indicator of contest competition (Mitchell et al. 1991; Fashing 2001; Wittig and Boesch 2003; Robbins et al. 2005). In both examples predictions of the model have been turned into a factual relationship which renders any test based on these indicators a case of uncritical testing. In fact, few studies to date have incorporated energetic measures although the fitness consequences of behaviours are crucial to the understanding of their ultimate function or survival value (Janson and van Schaik 1988; van Schaik 1989; Koenig and Borries 2009). It should also be mentioned that a conclusive comparative assessment of all model predictions and assumptions is still lacking, partially due to a lack of comparative data.

In addition to a lack of energetic or fitness measures, tests of components of the socio-ecological model also frequently suffer from inaccurate measurement of variables such as diet and resource characteristics, for example by using gross dietary categories to predict levels of competition (Isbell and Young 2002; Koenig and Borries 2006; Snaith and Chapman 2007; Vogel and Janson 2007; Chapman and Rothman 2009; Schülke and Ostner 2012). Resource size, density and distribution are often measured from a botanical perspective without considering the perspective of the animals that are feeding on these resources (Isbell et al. 1998; Koenig and Borries 2006; Koenig et al. 2013). As a potential solution to this problem it has been suggested to take into account the area over which a group can spread out while remaining cohesive (group spread) and to measure feeding competition at the level of individual food patches, combining information on resource characteristics, group spread, and the simultaneous use of resources by different group members (Koenig and Borries 2006; Vogel and Janson 2007).

Besides such methodological refinements, it has been proposed to improve the accuracy of the model by incorporating additional factors such as male resource defence (Janson 2000; Koenig 2002), disease transmission within groups (Nunn and Altizer 2006) and interspecific variation in cognitive abilities (Cunninham and Janson 2007). Additionally, there is a need to consider competition for limiting resources other than food (e.g. mates, safe positions) (Cowlishaw 1997), the influence of paternal relatedness on social tolerance (Schülke and Ostner 2008), constraints on female dispersal (Schülke and Ostner 2012) and adaptations that may compensate for the costs of feeding competition such as 
cheek pouch use in cercopithecoids, extension of the activity period (Janson 1988a), fission-fusion dynamics (Symington 1988; Chapman et al. 1995; Dias and Strier 2003; Asensio et al. 2008) and changes in group spread (Di Fiore 2004; Snaith and Chapman 2008; Schreier and Swedell 2012). When it comes to the influence of phylogenetic constraints it is argued that although phylogeny can be an important influence on social systems and should be included in socio-ecological studies when possible, it does not explain why certain characteristics evolved in the first place and the reasons behind correlated character evolution could be ecological. Additionally, phylogenetic constraints can only be assessed post hoc as they reflect the evolutionary history of a species but not the processes involved (Koenig and Borries 2009)

\subsection{Study site and species}

Macaques are particularly interesting species to investigate links between ecological factors, competition and social structure because, although sharing the basic patterns of social organization (i.e. multimale-multifemale groups, female philopatry, male dispersal), the members of the genus differ greatly in their social structure and inhabit a wide range of different habitats (Thierry 2007; Cords 2012). For this thesis I studied mechanisms of female feeding competition in a wild population of Assamese macaques at Phu Khieo Wildlife Sanctuary in north-eastern Thailand. The study site consists mostly of dry evergreen forest with bamboo stands (Borries et al. 2002) and the climate is highly seasonal with a distinct dry season from November through March (Borries et al. 2011). Vegetation at the study site is dense and the study group spends almost $90 \%$ of their activity time off the ground (Schülke et al. 2011). The study population reproduces seasonally with a mating season between October and January and a birth season between April and July (Fürtbauer et al. 2010).

A preliminary study indicated that the study group is highly frugivorous (Schülke et al. 2011). Since fruit is generally considered to be a high quality, clumped resource, females expected to exhibit high levels of contest competition (Saito 1996; Sterck and Steenbeek 1997; Su and Birky 2007). Several natural predators of Assamese macaques are present in the home range of the study group, including leopards (Pantera pardus), clouded leopards (Neofelis nebulosa) and Asian golden cats (Catopuma temminickii) (Grassman et al. 2005). Although this indicates that females in the study population experience both predation pressure and feeding competition little is known about resource characteristics, mechanisms of feeding competition and their impact on energy intake, reproduction and spatial structure in female Assamese macaques, a gap which my study aims to fill. 


\subsection{Thesis aims}

The overall aim of my thesis is to contribute to a better understanding of the links between food resource characteristics, proximate mechanisms of feeding competition and female fitness. By including measures of energy intake and fitness, investigating feeding competition in individual food patches and by considering both competition reducing mechanisms and competition for safe positions I aim to provide a more detailed and accurate picture of the ecological influences on female feeding competition and fitness as a test of the internal consistency of socio-ecological models (Figure 1).

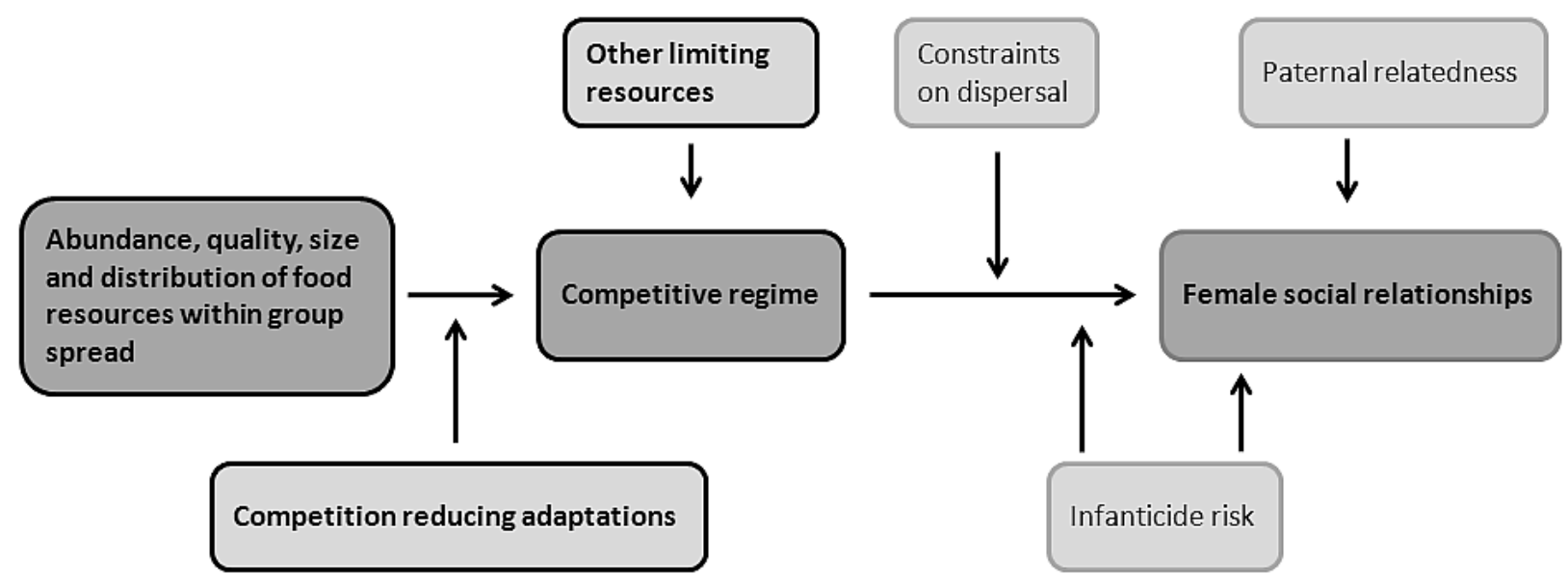

Fig. 1 Representation of the current socio-ecological model. Dark grey parts represent the socio-ecological model of van Schaik (1989) and boxes outlined in black indicate aspects that are addressed in this thesis (adapted from Schülke and Ostner 2012; see also Sterck et al. 1997; van Schaik 1989).

In chapter 2 I investigate the ultimate consequences of feeding competition by examining the influence of female rank on energy intake, activity budgets and reproduction. In order to achieve this I first describe the diet of female Assamese macaques as well as changes in food availability in the home range of the study group over time. Then I examine how food availability affects female energy intake and reproduction to assess whether food is a limiting factor for the study population. I continue by investigating the impact of dominance rank on female energy intake and activity budgets and how these relationships are affected by food availability, density, size and quality. I also investigate the effect of rank on the length of interbirth intervals as an indicator of female fitness. Subsequently, I examine the influence of lactation on female energy intake, activity and physical condition to assess the energetic demands of this period, which are usually great. Then I relate female physical condition 
to the likelihood of conception to shed light on the seasonal reproduction observed in Assamese macaques and how this relates to ecological conditions.

In chapter $\mathbf{3}$ I examine feeding competition at the level of individual food patches, investigating the impact of social and ecological factors on rates of food related aggression, to gain insight into the proximate mechanisms of feeding competition. To achieve this I use a "focal tree method" which allows for the simultaneous observation of all individuals that are feeding together in a patch. This method combines detailed information on resource characteristics at a level that is likely to be relevant to the study animals with information on aggressive interactions within food patches, feeding group composition and feeding group size. More specifically, I examine the influence of feeding group size and ecological factors such as patch size, resource value and the availability of alternative resources on rates of aggression within food patches. Additionally, I investigate strategies females may use to avoid direct conflicts.

Finally, in chapter 4, I relate group activity and ecological conditions to group spread and interindividual distances to assess how group cohesiveness may be adjusted to mediate the costs and benefits of group living. Additionally, I investigate how dominance rank and reproductive state affect a female's distance from the centre of the group and how ecological factors affect these relationships. 


\title{
Chapter 2
}

\section{Food abundance affects energy intake and reproduction in frugivorous female Assamese macaques}

\author{
Marlies Heesen ${ }^{1}$, Sebastian Rogahn ${ }^{1}$, Julia Ostner ${ }^{1}$, Oliver Schülke ${ }^{2}$
}

\footnotetext{
${ }^{1}$ Primate Social Evolution Group, Courant Research Centre Evolution of Social Behaviour, Georg-August University Göttingen, Kellnerweg 6, 37077, Germany

${ }^{2}$ Courant Research Centre Evolution of Social Behaviour, Georg-August University Göttingen, Kellnerweg 6, 37077, Germany
} 


\begin{abstract}
In most mammals female fertility and reproduction are strongly influenced by nutritional status and therefore by foraging conditions. Here we investigate the relationship between food resources, feeding competition, energy intake, and reproduction in a group of wild female Assamese macaques (Macaca assamensis) in north-eastern Thailand. Over 2100 hours of data on feeding behaviour, energy intake, and activity budgets were combined with data on resource characteristics, female reproduction, and physical condition. We found that an increase in food availability had a positive effect on female energy intake and conception rates. In addition, it appeared that females incurred energetic costs during lactation and females with a better physical condition during the mating season were more likely to conceive. The annual birth season occurred a few months before the annual peak in food availability causing peak lactation to coincide with a period of high food availability. This suggests females use the increased food abundance to compensate for the energetic costs of lactation. Neither energy intake rates nor activity budgets were influenced by female dominance rank, even during periods when levels of contest competition were predicted to be high. In line with this we found no evidence for rank related differences in reproduction. The apparently limited influence of feeding competition in female Assamese macaques adds to the debate on the extent to which patterns in feeding competition and fitness can reliably be predicted based on ecological conditions. We suggest this may partially be resolved by including potential competition reducing mechanisms into the predictive framework.
\end{abstract}

Keywords: Assamese macaque, feeding competition, reproduction, energy budget, seasonality, nutrition, ecology 


\section{Introduction}

Nutritional status is one of the most influential factors affecting female fertility and reproduction in mammals, including both humans and nonhuman primates (Sadleir 1969; Gilmore and Cook 1981; Lee 1987; Wade et al. 1996). For example, nutritional status can affect age at menarche, age at first birth, duration of gestation and lactation periods, and the length of interbirth intervals (Bercovitch and Strum 1993; Borries et al. 2001). As a result, female reproductive performance is often constrained by foraging conditions as food provides the energy needed to maintain regular reproductive cycles and reduce the costs of reproduction (Harcourt 1989). This influence of nutritional status on fertility appears to be mainly mediated through the high energetic costs of lactation (Lee 1987). A high abundance of high quality food sources can lead to a shortening of the weaning process and thereby facilitate subsequent conception (Sadleir 1969; Lee 1987). Comparisons between provisioned and unprovisioned primate groups provide further evidence for the influence of food availability on reproductive parameters as provisioned primate groups were found to have higher birth rates, shorter lactation periods, and shorter interbirth intervals compared to unprovisioned groups (Mori 1979; Kuester and Paul 1984; Borries et al. 2001). Variability in reproductive success is not only induced by variability in the foraging environment, it is also affected by the social environment via female feeding competition (van Schaik 1989; Sterck et al. 1997). This study investigates how foraging conditions and feeding competition contribute to within-population variation in energy budgets and reproduction in female Assamese macaques.

For frugivorous primates, fruit abundance often fluctuates which likely affects both reproductive output and the timing of female reproduction. For example, high food availability during or before the mating season can lead to higher birth rates in the following year (Suzuki et al. 1998; Takahashi 2002). In addition, the amount of seasonal variation in ecological variables such as food availability and rainfall directly affects the degree of seasonality in reproductive patterns of primates and other mammals (van Schaik and van Noordwijk 1985; Crockett and Rudran 1987; Di Bitetti and Janson 2000; Carnegie et al. 2011).

The income-capital breeding model, which was first developed to explain breeding patterns in birds (Drent and Daan 1980), has more recently been used to characterise reproductive patterns in nonhuman primates (Richard et al. 2000; Brockman and van Schaik 2005; Janson and Verdolin 2005; Lewis and Kappeler 2005). The original model distinguishes between income breeders, who invest current energy intake in reproduction and use proximal cues such as photoperiod and rainfall to initiate reproductive events, and capital breeders who use previously stored energy reserves to reproduce and respond to endogenous condition thresholds (Stearns 1992). In primates and other 
mammals the entire reproductive cycle (conception, gestation, birth, lactation, and weaning) can take a year or more to complete and as a result the classification of species as capital or income breeders depends on the definition of what constitutes the most essential reproductive period (Lewis and Kappeler 2005). It is important therefore to be clear as to what stage of the cycle is being modelled when predicting a reproductive pattern within the income-capital framework (Janson and Verdolin 2005; Lewis and Kappeler 2005). In an attempt to predict the diversity of seasonal birth patterns seen among nonhuman primates the original dichotomous income-capital model has been modified in several ways. Most importantly, it has been suggested to view the model as a range of strategies as opposed to a strict dichotomy (Di Bitetti and Janson 2000; Brockman and van Schaik 2005; Janson and Verdolin 2005).

One of the main adjustments includes the division of income breeders into income-I and income-II breeders. Income-I breeders are characterized by small body mass and low adult survival. They time births such that infant weaning will coincide with the peak in food abundance, thereby maximising infant survival by reducing energetic stress on infants during weaning. Income-Il breeders have a larger body mass and a long adult lifespan and births in these species are timed to occur just before the mean peak in food abundance, which allows for the period of mid-to-late lactation to coincide with this peak (Janson and Verdolin 2005). This strategy maximises maternal survival by minimising energetic stress during lactation which is considered to be the most energetically costly part of the reproductive cycle (Altmann 1980; Coelho 1986; Loudon and Racey 1987). The "income-capital continuum model" is a similar modification of the original model except that income-II breeders are referred to as relaxed income breeders. This relaxed income strategy is characterised by reproductive patterns that overlap those found among income and capital breeders, including conceptions that are cued by both exogenous environmental stimuli, e.g., photoperiod, which in turn may indicate impending food production, and endogenous maternal condition thresholds (Brockman and van Schaik 2005).

In addition to seasonal fluctuations in food abundance, other resource characteristics such as the distribution and quality of food sources are expected to affect nutritional status and reproduction in group-living females through their impact on feeding competition (van Schaik 1989; Sterck et al. 1997; Isbell and Young 2002). Different resource characteristics are associated with different types of feeding competition which impact individual energy intake and fitness in different ways. Scramble competition is an indirect form of competition where some individuals remove limited food sources from an area before other individuals have the opportunity to feed. In this situation there is no exclusion of weaker competitors by stronger ones (Lomnicki 1988; van Schaik 1989). Scramble competition is thought to be associated with food sources that are difficult or not valuable enough to 
be monopolised by individuals or small groups (van Schaik 1989; Koenig 2002). This includes food sources with a short depletion time, very large patch size, low nutritional value or a dispersed distribution in relation to group spread (Isbell et al. 1998; Koenig et al. 1998; Pruetz and Isbell 2000). Contest competition in contrast is a direct form of competition where certain individuals monopolise access to resources thereby restraining the food and energy intake of others (Lomnicki 1988; van Schaik 1989). Contest competition is associated with food that can be, and is valuable enough to be monopolised, thus making it profitable for females to behave competitively toward each other (Wrangham 1980; Janson and van Schaik 1988; van Schaik 1989; Isbell 1991). This includes food sources with a long depletion time, relatively small patch size, high nutritional value, or a clumped distribution in relation to group spread (Isbell 1991; Sterck et al. 1997; Isbell and Pruetz 1998; Koenig 2000).

Scramble and contest competition differ in the way they affect individual energy gain and fitness; an effect which is mediated through the influence of competition on individual foraging efficiency (Janson 1988a). Scramble competition affects all females in a group equally and an increase in scramble competition, e.g. due to an increase in group size, will lower energy gain and fitness for all females in the group (Lomnicki 1988; van Schaik and van Noordwijk 1988; van Schaik 1989). Contest competition, on the other hand, is associated with rank related differences in foraging efficiency with high ranking females having a higher foraging efficiency and energy intake compared to lower ranking females (Whitten 1983; Janson 1985; Barton and Whiten 1993; Saito 1996; Vogel 2005). It is also possible, however, that low ranking females try to compensate for a reduced foraging efficiency by increasing their time spent feeding or foraging (Saito 1996; Koenig 2002), or by feeding on high quality resources away from the main group. A disadvantage of the latter strategy is that it may decrease a female's fitness by increasing predation risk (Robinson 1981; Janson 1985; van Noordwijk and van Schaik 1987). Ultimately, if rank related differences in energy intake are present they are expected to translate into a rank related skew in fitness (Barton 1993). For example, high ranking females may have shorter interbirth intervals and reach maturity at a younger age compared to lower ranking females (Whitten 1983; Bulger and Hamilton 1987; van Noordwijk and van Schaik 1987; Altmann et al. 1988; Altmann and Alberts 2003).

In this paper we investigate the relationship between ecological variables, feeding competition, energy intake, and reproduction in a group of wild naturally feeding female Assamese macaques at Phu Khieo Wildlife Sanctuary in north-eastern Thailand. This population is particularly interesting for this type of study as both climatic conditions and reproduction patterns are highly seasonal (Kumsuk et al. 1999; Grassman et al. 2005; Fürtbauer et al. 2010). The climate is characterised by an annual rainy season which takes place between April and October (Kumsuk et al. 1999; Grassman et al. 2005). 
At the same time the study group exhibits a strictly seasonal reproduction pattern with a mating season between October and early February, followed by a birth season between April and July (Fürtbauer et al. 2010).

Assamese macaques are highly frugivorous (Schülke et al. 2011) and are therefore expected to exhibit high levels of contest competition since specialised fruit eaters have often been observed to compete directly over food (Saito 1996; Sterck and Steenbeek 1997; Su and Birky 2007). Females in this population either have a 1-year or a 2-year interbirth interval and the probability a female conceives in two consecutive years is linked to early parturition within the birth season (Fürtbauer et al. 2010). This suggests females incur energetic costs during lactation and the likelihood a female conceives is affected by her nutritional status. Rainy seasons are often associated with an increase in food availability (Barton et al. 1992) which could indicate that Assamese macaques align the costly peak lactation period to a period of high energy availability. In combination with their strictly seasonal reproduction, which is usually associated with endogenously cued conceptions, this suggests that female Assamese macaques are income-II or relaxed income breeders. If this is the case we would expect the annual peak in food availability to take place after the start of the birth season.

The first aim of this study was to examine the impact of fruit abundance on female nutritional status (measured as energy intake) and how this relationship is affected by feeding competition. We therefore investigated the relationship between female dominance rank and energy intake and how this relationship changes depending on the abundance, distribution, size, and quality of food sources available in the environment. Additionally, we addressed the possibility that females are compensating for a reduced foraging efficiency by examining the relationship between rank and activity budget and how this relationship changes depending on food characteristics. The second aim was to investigate how fruit abundance and feeding competition affect female reproduction and how changes in fruit abundance relate to reproductive seasonality. Firstly, we examined the relationship between fruit abundance and overall conception rates and the relationship between rank and reproductive success. In addition, we looked at the impact of lactation on energy intake and activity budgets to assess the energetic costs of lactation and we investigated the relationship between female nutritional status and conception. Lastly, we examined the link between patterns in fruit abundance and reproductive seasonality.

\section{Methods}

Study site and subjects 
This study was conducted at Phu Khieo Wildlife Sanctuary in north-eastern Thailand $\left(16^{\circ} 5^{\prime}-35^{\prime} \mathrm{N}\right.$, $\left.101^{\circ} 20^{\prime}-55^{\prime} \mathrm{E}\right)$. The sanctuary covered an area of $1573 \mathrm{~km}^{2}$ at elevations of $300-1300 \mathrm{~m}$ above sea level and is part of the $6500 \mathrm{~km}^{2}$ contiguous Western Isaan Forest Complex, which has the highest nature reserve protection status in Thailand (Koenig et al. 2004). Phu Khieo Wildlife Sanctuary is home to a diverse animal community including Asian elephants, Asian forest bisons, clouded leopards, Asian golden cats, raptors, pythons, and 7 diurnal primate species (Kumsuk et al. 1999; Borries et al. 2002; Grassman et al. 2005). The study site within the sanctuary, “Huai Mai Sot Yai” $\left(16^{\circ} 27^{\prime} \mathrm{N}, 101^{\circ} 38^{\prime} \mathrm{E}\right)$, is situated at elevations of 600-800 $\mathrm{m}$ above sea level and consists mostly of dry evergreen forest with bamboo stands (Borries et al. 2002). The annual rainfall averages 1,444 $\mathrm{mm}$ with a distinct dry season from November through March. Mean annual temperature is $21.3^{\circ} \mathrm{C}$ (mean minimum temperature= $18.4^{\circ} \mathrm{C}$, mean maximum temperature $=25.5^{\circ} \mathrm{C}$ ) (Borries et al. 2011).

\section{Behavioural data collection}

Behavioural data were collected from a fully habituated group of wild Assamese macaques over two one-year sampling periods (period 1: October 2007 - September 2008; period 2: May 2010 - April 2011). During these sampling periods the group consisted of a total of 53 individuals, 12 of which were adult females (period 1) and 49 individuals, 15 of which were adult females (period 2). All adult females were included as subjects in this study. All adult females were subject to regular focal observations and an effort was made to distribute these observations evenly across both time of day and individuals. Original focal sample duration was 20 minutes however this was extended to 30 minutes during sampling period 1 , and remained 30 minutes throughout sampling period 2. In total, $841 \mathrm{hrs}$ of focal data were collected during sampling period 1 with an average of $70 \pm 7 \mathrm{hrs}$ per female and $1,340 \mathrm{hrs}$ of focal data were collected during sampling period 2 with an average of $91 \pm 4.6 \mathrm{hrs}$ per female.

All affiliative, aggressive, submissive, sexual, solitary, and child directed behaviours as well as facial displays and vocalisations shown by or directed at the focal female were recorded using continuous recording (Altmann 1974). In addition, instantaneous records were collected at 1 minute intervals $(137,427$ data points for both data collection periods combined) including information on positional behaviour (lay, sit, stand, walk, trot, run, climb up, climb down, hang, swing) and activity (rest, travel, feed, social, other). We also calculated the proportion of time a female spent in locomotion by combining the data points an individual was walking, trotting, running, swinging, or climbing. Behaviour was recorded as feeding when an individual was ingesting food items, chewing and/or reaching for, or handling food items. Feeding from cheek pouches was not recorded as feeding. If an 
individual was feeding on plant matter, species, part, and age were recorded and if a plant species was unknown a sample was collected for later identification.

\section{Dominance hierarchy}

A female dominance hierarchy was established for each sampling period separately in order to accommodate for a large number of changes in the number and identity of the adult females in the group between the two sampling periods, i.e. two deaths and five juvenile females reaching full maturity. The female dominance hierarchies were established using only decided, dyadic agonistic interactions (i.e. bouts of aggression with only aggression on one side and submission on the other or spontaneous signals of submission) recorded during both continuous focal observations and ad libitum sampling (for details see Ostner et al. 2008). A winner/loser matrix of these interactions was reordered using the I\&SI method as implemented in MATMAN ${ }^{\mathrm{TM}}$ 1.1.4 (Noldus 2003) to give the final female rank order for each sampling period. Female dominance hierarchies for both data collection periods were significantly linear with a high Directional Consistency Index (period 1: 249 interactions, $h^{\prime}=0.92, D C l=0.96,10.6 \%$ unknown relationships, $p<0.001$; period 2: 393 interactions, $h^{\prime}=0.83$, $\mathrm{DCl}=0.96,12.4 \%$ unknown relationships, $\mathrm{p}<0.001$ ). Ranks for both data collection periods were standardised to range from 1 (lowest ranking) to 2 (highest ranking), with all females spaced evenly between these two values to enable comparison between the two years.

\section{Ecological sampling}

A total of 44 botanical plots were established within the home range of the study group: $3150 \times 50 \mathrm{~m}$ plots and $13100 \times 100 \mathrm{~m}$ plots, covering a total area of 20.75 ha of forest $(4.41 \%$ of the home range of the study group). All trees $\geq 10 \mathrm{~cm}$ DBH and climbers $\geq 5 \mathrm{~cm}$ DBH (11,508 trees and climbers in total) within these plots were identified and their DBH was recorded. Data on the abundance of foliar items (leaf buds, young leaves, mature leaves) and reproductive items (flower buds, flowers, young fruit, mature fruit, old fruit) were collected in the middle of each month by monitoring up to 650 trees, shrubs, and climbers spread over 20 botanical plots. These included 57 important food species covering on average $68.8 \%$ of monthly feeding time on plant matter and $76.7 \%$ of monthly feeding time on fruit. An attempt was made to include at least 10 individuals per species (median=12). Abundance of the different items was estimated visually using binoculars and scored on a logarithmic scale (1=1-9, 2=10-99, 3=100-999, 4=1000-9999, 5=10000-99999) (Janson and Chapman 1999a). 
Based on this information an index of fruit availability was calculated for each calendar month using the following formula:

$$
F A=\sum_{i}^{n}(A i \times D i)
$$

Where:

$F A=$ total fruit availability index for $n$ species in the sample

$A_{i}=$ mean fruit abundance score for species $i$

$D_{i}=$ mean density of species i per hectare (based on 44 botanical plots)

The index was based on fruit items only because Assamese macaques are highly frugivorous and fruit availability is expected to have a strong impact on levels of contest competition. Information on fruit availability was available for the period between October 2007 and December 2011.

In order to identify months during which females were expected to experience high levels of contest competition we calculated monthly values for different food resource characteristics which were predicted to influence levels of contest competition. These included nutritional quality (energy yield in kJ per minute feeding (Schülke et al. 2006)), density (mean density of a species per hectare based only on plots where the species was present), and DBH (used as a measure of patch size). An increase in food quality was predicted to increase levels of contest competition while an increase in density or patch size was expected to decrease the potential for contest competition. Monthly values were based on food items (including fruit, leaves, flowers, and flower buds) that made up at least $5 \%$ of the feeding time on plant matter for that month. Mean density and DBH were calculated based on 1 ha botanical plots as this was considered a good approximation of the group spread of the study group. Values for the different food items were then weighed by the percentage of monthly feeding time made up by each of the items so that food items the monkeys fed on more had a greater impact. The weighted values were then summed to generate a monthly value for each variable.

\section{Plant nutritional content and energy intake}

Samples of frequently consumed food items were collected preferably from trees in which the monkeys had been observed feeding. We only included items which were similar in size and maturation stage to the food items consumed by the Assamese macaques and parts of the items the 
monkeys did not consume were not included in the samples. These samples were deep-frozen at $-20^{\circ} \mathrm{C}$ and transported to the Department of Animal Science (Kasetsart University, Bangkok) where they were freeze dried and analysed for nutritional content (neutral detergent fibre (NDF), protein, ash, moisture, and lipids). Crude Protein was determined by using the Kjeldahl procedure for total nitrogen and multiplying by 6.25 (Pierce and Haenisch 1947). The neutral detergent fibre fraction was determined using the detergent system of fibre analysis (Goering and Van Soest 1970) as modified by Van Soest and Robertson (1980), and total lipid was measured by petroleum spirit extraction in a Soxhlet apparatus. The total proportion of non-structural carbohydrates (TNC) was determined by subtraction (100 - (\% protein $+\%$ fat $+\%$ ash $+\%$ NDF)). An NDF coefficient of $52.0 \%$ was used to estimate the amount of fibre available as energy due to hindgut fermentation. This value was based on that found for Japanese macaques fed on a $37.5 \%$ NDF diet (Sawada et al. 2011) which is comparable to the mean percentage of NDF in food items consumed by the study group. The total energy content in kilojoules per gram dry mass $(E)$ was calculated for each food item as: $E=(0.1674 \times$ $(\%$ dry mass TNC $)+0.1674 \times(\%$ dry mass protein $)+0.3766 \times(\%$ dry mass fat $)+0.1674 \times(0.52 \times \%$ dry mass NDF). These values are the standards taken from the human literature, converted to $\mathrm{kJ} / \mathrm{g}$ from $\mathrm{kcal} / \mathrm{g}$, thereby giving an estimate of metabolisable energy (National Research Council, 1989). Energy yield per minute was estimated for different plant food items based on the product of 1 ) the number of items ingested per minute, 2) the weight per item (g dry mass), and 3) kJ/g dry mass, to yield kilojoules of energy ingested per minute feeding. These energy yield values were available for 58 food items belonging to 51 species and covering $74.9 \%$ of the average feeding time on plant items.

Ingestion rates were recorded by counting the number of bites taken from a large item, the number of complete items (e.g., whole leaves, flowers or fruit), or the number of handfuls of very small items (e.g. bunches of leaves) ingested during one minute of continuous feeding behaviour using the definition of feeding given above. Due to limited visibility it was not possible to record a sufficiently large number of ingestion rates for each individual female for each food item and ingestion rates were therefore averaged per food item. On average we collected 82 ingestion rates per food item. For 11 food items we collected $\geq 10$ ingestion rates per female for $\geq 10$ females and based on these items we tested whether ingestion rate was correlated with dominance rank. As ingestion rate was not correlated with rank in any of these food items (spearman correlation: rho $<0.09, p>0.5$ for all 11 food items), combining ingestion rates for different females was not expected to mask any potential rank related differences in energy intake. In a similar analysis we excluded the possibility that lactating females had different ingestion rates compared to non-lactating females, using food items with at least 5 ingestion rates for both lactating and non-lactating females (Wilcoxon signed rank test: $V=74.5$, $p=0.940, n=17$ food items). Mean wet weight per bite was determined by weighing fresh samples 
similar in size to one bite (item or handful) after removal of parts of the items the monkeys did not consume (i.e. seeds or husk). Dry weight per item was calculated based on wet weight and percent moisture derived from the nutritional analysis.

Individual energy intake rates per female were calculated on a monthly basis to match the monthly fruit availability index. For each female we calculated the mean number of minutes spent feeding per food item per hour and this was multiplied by the energy yield per minute for the respective food items when available. Values for all food items consumed during a certain month were added up to produce a mean energy intake rate (kJ per hour) per female per calendar month. Intake rates per hour were used as a proxy for daily energy intake as changes in day length were minimal at the study site.

\section{Physical condition}

Energy status could not be measured directly and was therefore estimated by visually assessing female physical condition as previous studies found this to be a good indicator of female nutritional status (Berman and Schwartz 1988; Koenig et al. 1997). Physical condition of all adult females was recorded in the middle of each month by the same observer. Females were scored based on the shape and size of muscle mass on arms (0: none, 1: a little, 2: a lot) and shoulders (0: no, 1: yes), and the amount of visible body fat around the waist line (0: none, 1: a little, 2: a lot) as indicators of good condition, and the degree to which shoulder blades (0: no, 1: yes) and hip bones (0: no, 1: a little, 2: a lot) stick out and the number of visible ribs and vertebrae (spine and tail) as indicators of bad condition (Koenig et al. 1997). The sum of scores for indicators of good condition was weighed against sum of scores for bad condition indicators plus 1 to generate a single score for physical condition per female per month that ranged from 0 (very bad condition) to 6 (very good condition). Physical condition data were collected between July 2007 and September 2011.

\section{Reproduction}

Demographic data were available from May 2006 through August 2012. A total of 51 infants were born in the study group during this period. Birth dates were either known exactly (65\% of cases) or determined as the midpoint of the period between the last day a female was seen without an infant and the first day she was seen with infant (mean $\pm S D=6.6 \pm 4.1$ days).

Fruit availability and conception rates 
In order to examine the relationship between fruit availability and conception rates we calculated the mean fruit availability score for the period between the start of the birth season and the start of the mating season (April-September), and plotted this against both the overall conception rate (no. of conceptions/no. of adult females) and the conception rate for the females who gave birth that same year (no. of conceptions in females who gave birth that year/no. of females who gave birth that year). This information was available for 4 years (2008-2011).

\section{Statistical analyses}

To assess how mean energy intake per hour (response variable) was influenced by female dominance rank, fruit availability, and lactation we used a linear mixed model (LMM, Baayen 2008). Besides rank, fruit availability, and lactation status (yes/no, with lactation defined as the first 6 months after parturition), we included the following interaction terms: rank and fruit availability, rank and food density, rank and food quality, and rank and DBH as fixed effects. In addition, we included data collection period and female ID as random effects. The interactions terms were included in the model because a priori fruit availability, density, quality and DBH could be expected to influence the strength of the relationship between rank and energy intake through their impact on contest competition (Whitten 1983; van Schaik 1989; Barton and Whiten 1993; Sterck et al. 1997; Koenig 2000).

In addition, we conducted a non rank-based analysis of the impact of contest competition on energy intake to address the possibility that rank may only have a linear effect on energy intake at the extreme ends of the dominance hierarchy. We ran a multiple linear regression with the coefficient of variation of energy intake across females per calendar month as the response variable, and fruit availability, food quality, food density, and DBH as predictor variables. The coefficient of variation is expected to increase with increasing levels of contest competition as differences in energy intake among individuals become greater.

Because information on nutritional content was not available for all food items in the diet and monthly energy intake rates were calculated by summing up energy intake for all items with known energy content, monthly energy intake rates may depend on the proportion of time a female spent feeding on food types with known energetic value. A female's monthly energy intake rate was therefore only included in the analysis if at least $60 \%$ of her monthly feeding time on plant items was spent feeding on items with known energy content. At this $60 \%$ cut-off point monthly energy intake rates were no longer correlated with the proportion of feeding time a female fed on food items with known energetic value (Spearman correlation: rho $=0.07, p=0.267$ ). 
In order to test whether the proportion of time females spent feeding or moving was influenced by dominance rank or lactation, and whether the relationship between rank and activity was influenced by fruit availability, food density, food quality, or DBH, we used LMM's including the same fixed and random factors as described above. Separate models were run with the following response variables: proportion of time spent in locomotion and proportion of time spent feeding on plant matter.

An additional model was run to test whether lactation influenced female physical condition. This model included female physical condition score as a response variable, lactation status, rank, and fruit availability as fixed effects, and data collection period and female ID as random effects. All LMM's mentioned above were fitted with Gaussian error structure and identity link function. To investigate whether average female physical condition score during the mating season had an effect on the probability of conception we ran a GLMM with binomial error structure and logit link function. In this model we included conception (yes/no) as a dependent variable, physical condition score as a fixed effect, and mating season and female ID as a random effects.

All (G)LMM's were fitted in $R$ ( $R$, version 2.14.2, $R$ Development Core Team 2012) using the function Imer of the R-package Ime4 (Bates et al. 2012). Regarding significance testing for all models we first determined the significance of the full model (including fixed effects, interaction terms, and random effects) as compared to the corresponding null model (including random effects and potential control predictors) using a likelihood ratio test (Burnham and Anderson 2002). P-values of main effects were considered only if these effects were not included in a significant interaction. Likelihood ratio tests were calculated using the R function anova. For the LMM's with Gaussian error structure P-values for the individual effects were based on Markov Chain Monte Carlo sampling (Baayen 2008) and derived using the functions pvals.fnc and aovlmer.fnc of the R package language $(B a a y e n$ 2011). For the binomial GLMM the significance of the individual fixed effects was determined based on the $z$ - and $p$ values provided by Imer. All appropriate assumptions (homogeneity of error variances, multicollinearity, influential cases) were tested for and met in each analysis.

To test whether females who gave birth early during the birth season were more likely to conceive again that same year, and thereby achieve a 1-year interbirth interval (IBI), we used a binary logistic regression with the number of days between the start of the birth season and the birth of the infant as the predictor variable, and the factor 1-year IBI (yes/no) as the dependent variable. Whether dominance rank influenced the length of interbirth intervals was tested by conducting a survival analysis based on birth data for 16 females. All IBI's were calculated in days and females were assigned a rank class (low, middle, high) based on their rank at the start of each IBI. Intervals following the death of an infant were not included in the analysis $(n=5)$. Of the 46 intervals included, 16 were 
incomplete (censored), either because the previous infant was born before the start of data collection, no subsequent birth occurred to close the interval prior to the end of the study period, or because the female died. The remaining 30 intervals were complete (uncensored). The data were analysed using the Kaplan-Meier SURVIVAL analysis in Statistica (version 10.0, StatSoft), which uses both censored and uncensored intervals, and corrects for censoring. In addition, we tested for a correlation between mean interbirth interval and mean female dominance rank using uncensored data only. $\mathrm{P}$ was set at 0.05 for all analyses and all tests were two-tailed.

\section{Results}

Diet and fruit availability

On average female Assamese macaques spent $59.1 \%$ of their feeding time feeding on fruit (including seeds), $12.8 \%$ feeding on leaves, and $23.6 \%$ feeding on animal matter (including mammals, birds, reptiles, amphibians, spiders, insects, and molluscs). The remaining $4.5 \%$ was comprised of flowers, bark, mushrooms and unknown items. During instantaneous sampling females fed on 165 known plant items belonging to 118 species ( $88.3 \%$ of total feeding time on plant matter). In both data collection periods the 10 most consumed food items combined made up about $50 \%$ of the total annual feeding time on plant items. Only 4 items were included in the top 10 most consumed food items in both data collection periods, indicating only moderate overlap in the most consumed food items between years. Characteristics of the food items used to calculate monthly values for food density ( $n=37)$, quality $(n=34)$ and DBH $(n=38)$ are shown in Table 1.

Table 1 Descriptive statistics of food resource characteristics used to assess the potential for within group contest competition. Values are given for all food plant species included in the monthly calculations of food density $(n=37)$, quality ( $n=34)$ and DBH ( $n=38)$ for both data collection periods combined. Medians were calculated across species. Measures are based on information derived from 13 botanical plots of 1 ha each

\begin{tabular}{lrrr}
\hline Variable & Median (interquartile range) & Minimum & Maximum \\
\hline Density $(\mathrm{n} / \mathrm{ha} \text { if } \mathrm{n}>0)^{\mathrm{a}}$ & $5.50(2.1-13.2)$ & 1.0 & 34.9 \\
Quality $(\mathrm{kJ} / \mathrm{min})$ & $12.29(7.0-36.0)$ & 1.9 & 72.8 \\
$\mathrm{DBH}^{\mathrm{b}}(\mathrm{cm})$ & $18.60(12.7-26.8)$ & 1.0 & 179.2 \\
& & & \\
${ }^{\mathrm{a}} \mathrm{n}>0$ in $55.8 \%$ of plots (mean for all species) & & \\
\end{tabular}


Monthly variation in the fruit availability index between October 2007 and December 2011 is shown in Fig. 1. Fruit availability varied over the course of the years but no clear seasonal pattern appeared to be present. In the first three years the month with the highest fruit availability occurred around the same time of year however (2008: June; 2009: July; 2010: August), and in all years fruit availability was lowest during the last month of the dry season (March). Fruit availability was generally higher during the second data collection period and the period of high availability was longer.

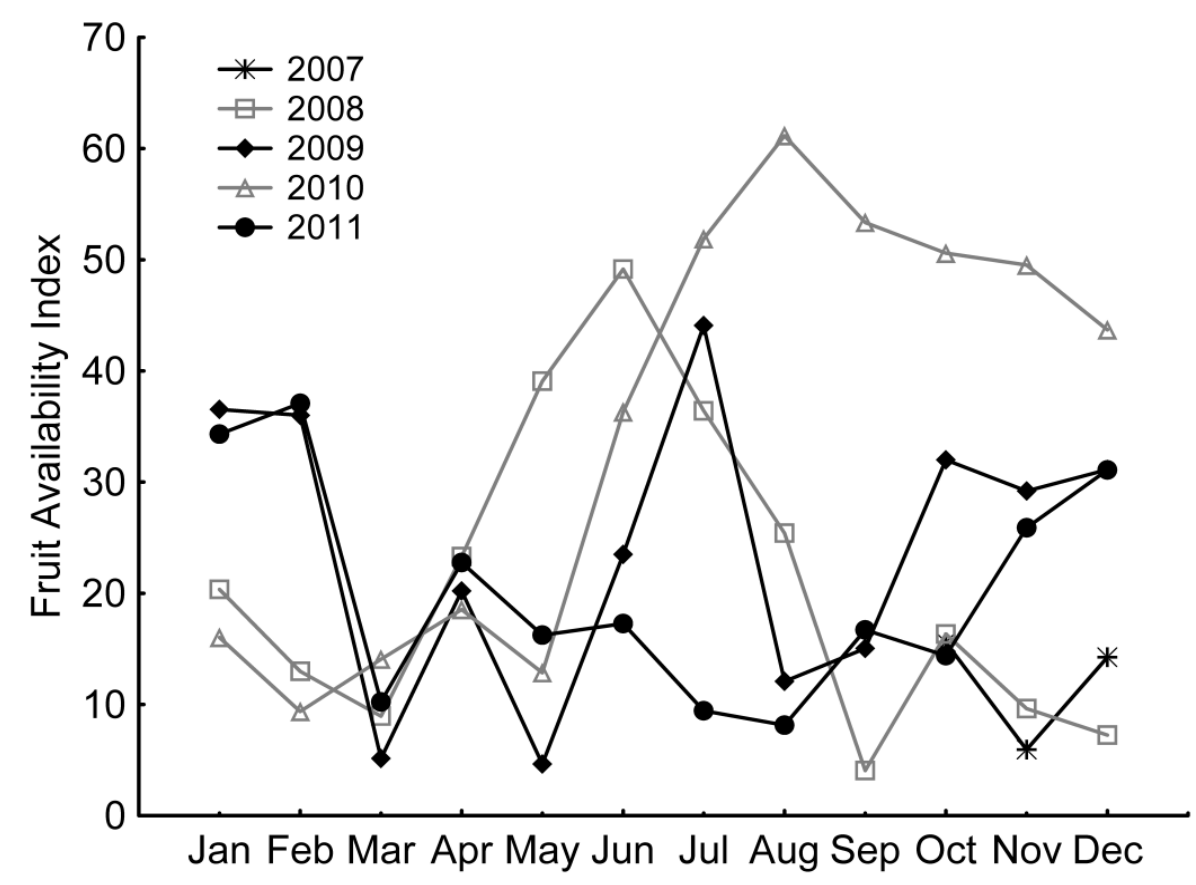

Fig. 1 Monthly variation in the fruit availability index for the period between October 2007 and December 2011. Behavioural data collection period 1: October 2007-September 2008, behavioural data collection period 2: May 2010-April 2011

Fruit availability, rank, lactation, and energy intake

The relationship between rank and energy intake was not affected by fruit availability, food density, food quality, or DBH (interaction rank and food availability: $t=-1.62, p=0.128$; interaction rank and density: $t=-0.50, p=0.604$; interaction rank and quality: $t=-0.27, p=0.802$; interaction rank and $\mathrm{DBH}: \mathrm{t}=-$ $0.81, p=0.417)$. For this reason all interaction terms were removed from the model as well as food quality, density, and DBH because we were only interested in their effect on the relationship between 
rank and energy intake and not in their impact on energy intake per se. Fruit availability had a positive influence on energy intake while female dominance rank did not have a significant impact on energy intake rates (Table 2; Fig. 2). In addition we found a trend towards a lower energy intake in lactating compared to non-lactating females (Table 2). Multiple linear regression revealed no significant influence of fruit availability, food quality, food density, and DBH on the coefficient of variation of energy intake $\left(F_{4,17}=1.03, p=0.419\right)$.

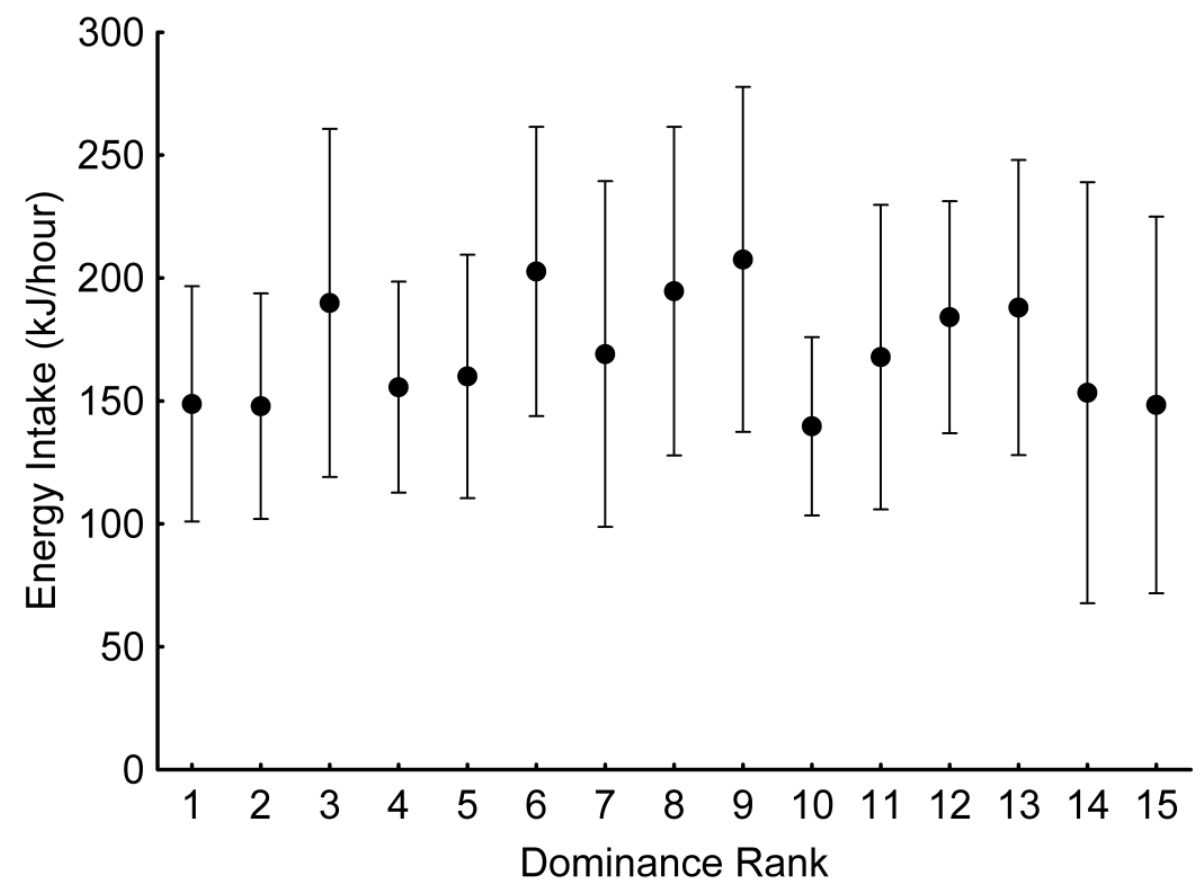

Fig. 2 Mean energy intake for females of decreasing dominance rank (1=highest rank, 15=lowest rank). Values are means \pm SE across all observation months. The same rank position can be occupied by different individuals in data collection period 1 and 2 
Table 2 Energy intake ( $\mathrm{kJ} / \mathrm{hour}$ ) is predicted by fruit availability but not rank and lactating females tend to have lower energy intake. Results of a LMM with monthly values $(n=256)$ and $z$-transformed predictors: test of the full model against the null model including data collection period and female ID as random factors $\left(\chi^{2}=7.23(3)\right.$, $p=0.065$ )

\begin{tabular}{lrrrr}
\hline Independent variable & Estimate & SE & t-value & p-value \\
\hline Intercept & 12.75 & 0.73 & 17.51 & 0.056 \\
Fruit availability & 0.68 & 0.28 & 2.40 & 0.010 \\
Rank & -0.24 & 0.24 & -1.02 & 0.346 \\
Lactation & -1.05 & 0.62 & -1.70 & 0.072 \\
\hline
\end{tabular}

Rank, lactation, and activity

On average females spent $20.7 \pm 8.3 \%$ of their active daytime feeding on plant matter and $29.2 \pm 6.6$ $\%$ moving. Since the latter category was calculated based on positional behaviour instead of activity it is separate from the other elements of the activity budget. The relationship between rank and the time a female spent feeding was not affected by either fruit availability, food density, food quality, or DBH (interaction rank and food availability: $t=-0.06, p=0.949$; interaction rank and density: $t=0.70$, $\mathrm{p}=0.490$; interaction rank and quality: $\mathrm{t}=0.04, \mathrm{p}=0.950$; interaction rank and $\mathrm{DBH}: \mathrm{t}=-0.70, \mathrm{p}=0.497$ ). Similarly, the relationship between rank and the time a female spent moving was not affected by either fruit availability, food density, food quality, or DBH (interaction rank and food availability: $t=0.32, p=0.464$; interaction rank and density: $t=0.34, p=0.204$; interaction rank and quality: $t=0.32$, $\mathrm{p}=0.925$; interaction rank and $\mathrm{DBH}: \mathrm{t}=-0.34, \mathrm{p}=0.428)$. Therefore the interaction terms were removed from both models and the results discussed below refer to models including rank, lactation, and fruit availability. Female dominance rank did not influence the time a female spent either feeding or moving. At the same time, lactating females spent less time feeding compared to non-lactating females whilst they did not differ from non-lactating females in terms of time spent moving (Table 3 ). 
Table 3 Time spent feeding (\% of daily activity time) is predicted by lactation but not dominance rank and time spent in locomotion is not affected by lactation or dominance rank. Results are reported for LMMs with monthly values ( $n=320$ ) and z-transformed predictors: tests of the full model against the null model including data collection period and female ID as random factors (Feeding: $\chi^{2}=13.54(3), p=0.004$; locomotion: $\chi^{2}=18.64(3)$, $p<0.001)$

\begin{tabular}{llrrrr}
\hline Dependent variable & Independent variable & Estimate & SE & t-value & $p$-value \\
\hline Feeding & Intercept & 21.21 & 0.79 & 26.74 & 0.092 \\
& Rank & -0.85 & 0.63 & -1.35 & 0.183 \\
& Lactation & -2.70 & 1.12 & -2.41 & 0.013 \\
& Fruit availability & -2.70 & 1.12 & -2.41 & 0.053 \\
Locomotion & Intercept & 29.87 & 2.70 & 11.07 & $<0.001$ \\
& Rank & -0.77 & 0.65 & -1.18 & 0.217 \\
& Lactation & -0.47 & 0.80 & -0.59 & 0.541 \\
& Fruit availability & 1.50 & 0.35 & 4.25 & $<0.001$ \\
\hline
\end{tabular}

Fruit availability and conception rates

Years with a higher mean fruit availability during the period between the start of the birth season and the start of the mating season were also marked by higher conception rates, both overall and among females who had given birth that same year (Fig. 3). 


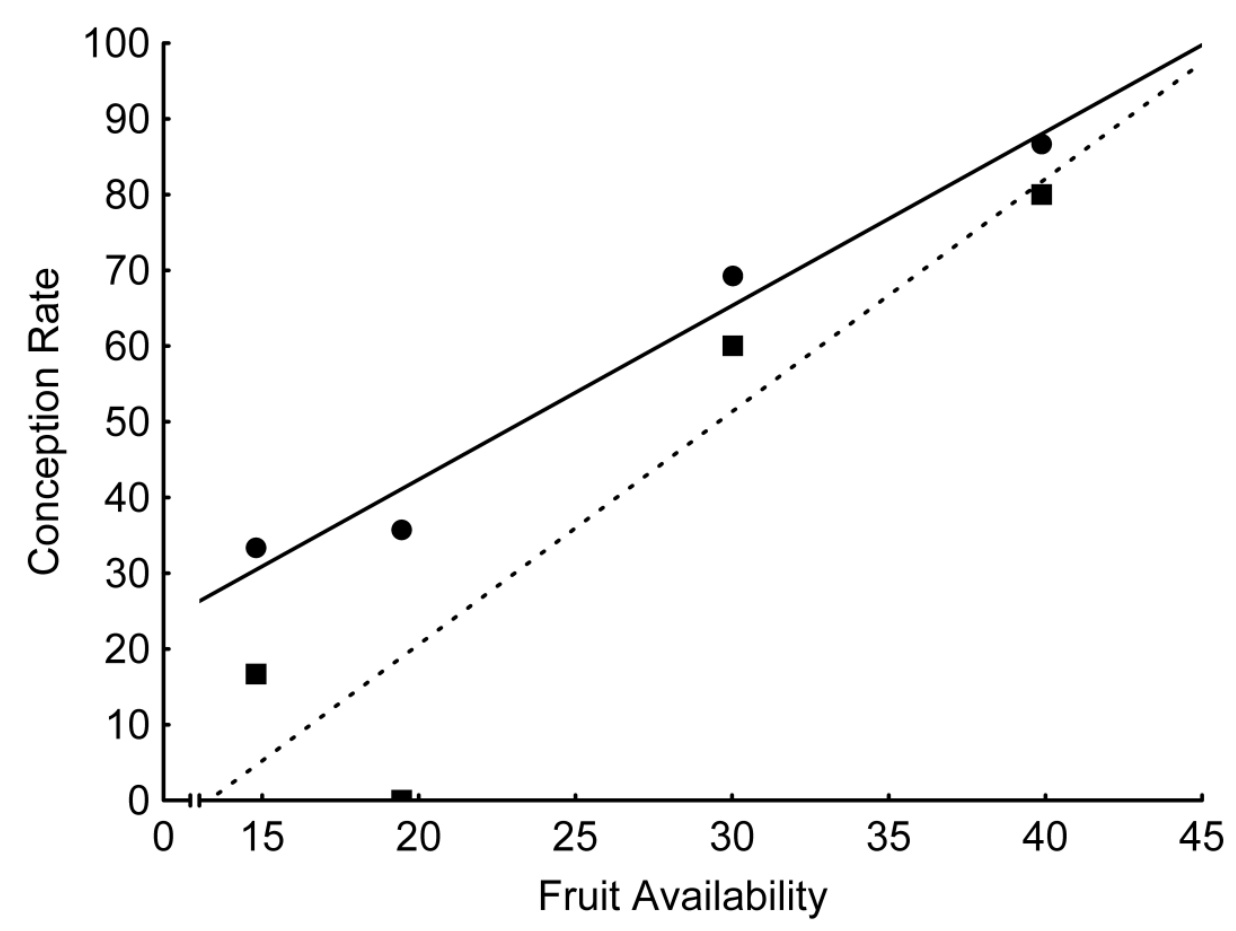

Fig. 3 Mean fruit availability score for the period between the start of the birth season and the start of the mating season (April-September) and conception rates during the mating season for all females (circles, solid line) and for females who gave birth the same year (squares, dotted line; $n=4$ mating seasons: 08/09, 09/10, 10/11, 11/12). Lines represent potential relationships which need to be confirmed with statistical analysis on larger datasets

\section{Physical condition and conception}

Binomial regression revealed that 1-year IBI's were associated with females that gave birth early during the birth season $(n=30, z=-2.51, p=0.012)$. At the same time we found that lactating females had a lower physical condition compared to non-lactating females ( $n=282$, full model: $\chi^{2}=9.1(1)$, $\mathrm{p}=0.003$; lactation: estimate $\pm \mathrm{SE}=-0.18 \pm 0.06, \mathrm{t}=-3.065, \mathrm{p}=0.002$ ). In addition, a binomial GLMM revealed a strong trend indicating that a females with a higher physical condition score during the mating season were more likely to conceive $(n=54, z=1.90, p=0.058$, Fig. 4). 


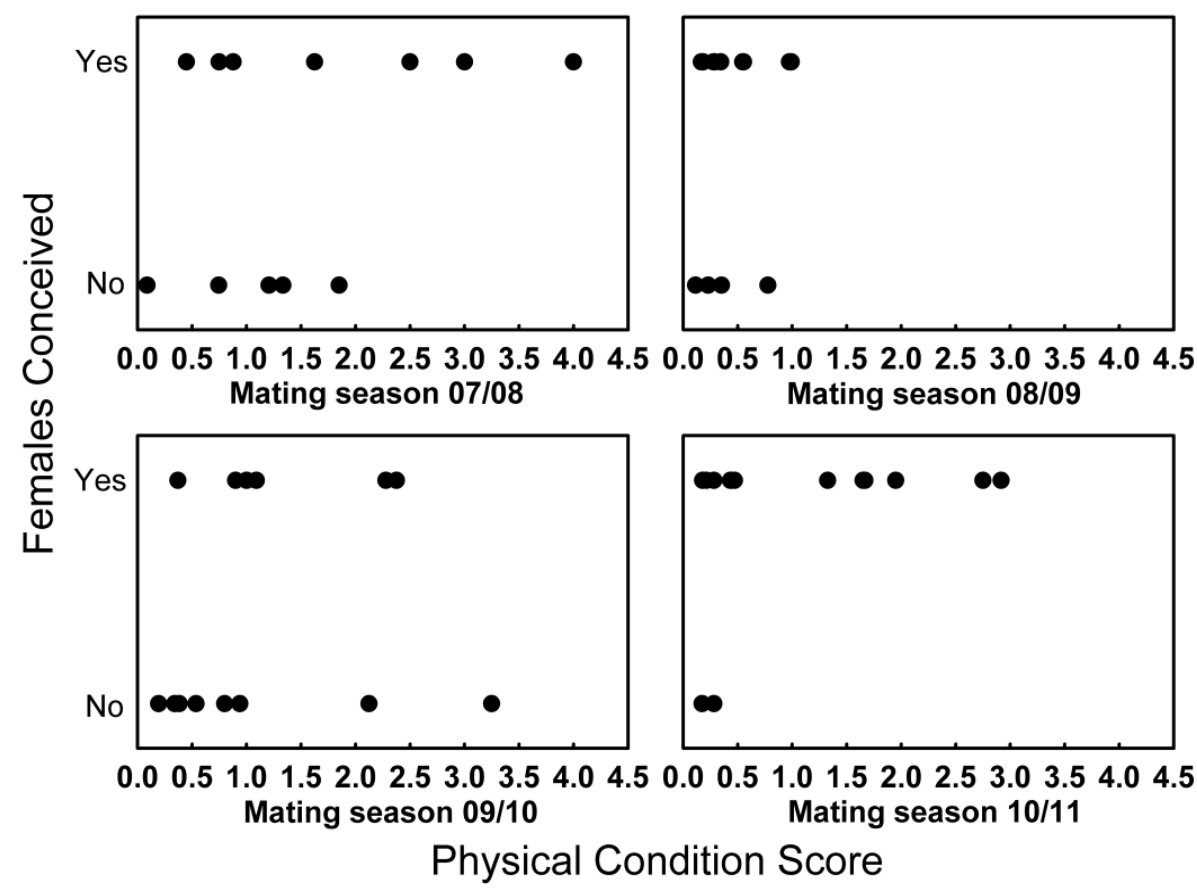

Fig. 4 Mean female physical condition scores during the mating season (October-January) for females that conceived $(n=35)$ and females that did not conceive $(n=19)$ across four mating seasons. Binomial GLMM: dependent variable $=$ conception (yes/no), fixed factor= physical condition score, random factors= mating season (4 levels), female ID (17 levels). Physical condition: $z=1.90, p=0.058$

\section{Rank and reproduction}

The distribution of complete IBI's followed a bimodal pattern with females either having a 1-year IBI (467.5 \pm 118.3 days, 11 cases) or a 2-year IBI (701.4 \pm 27.5 days, 19 cases). Survival analysis did not reveal a difference in IBI length between low, middle, or high ranking females $\left(\chi^{2}=1.29, p=0.524\right.$, Fig.5). Correlation also did not reveal a significant relationship between mean dominance rank and mean IBI (Spearman correlation: $r h o=0.31, p=0.300$ ). 


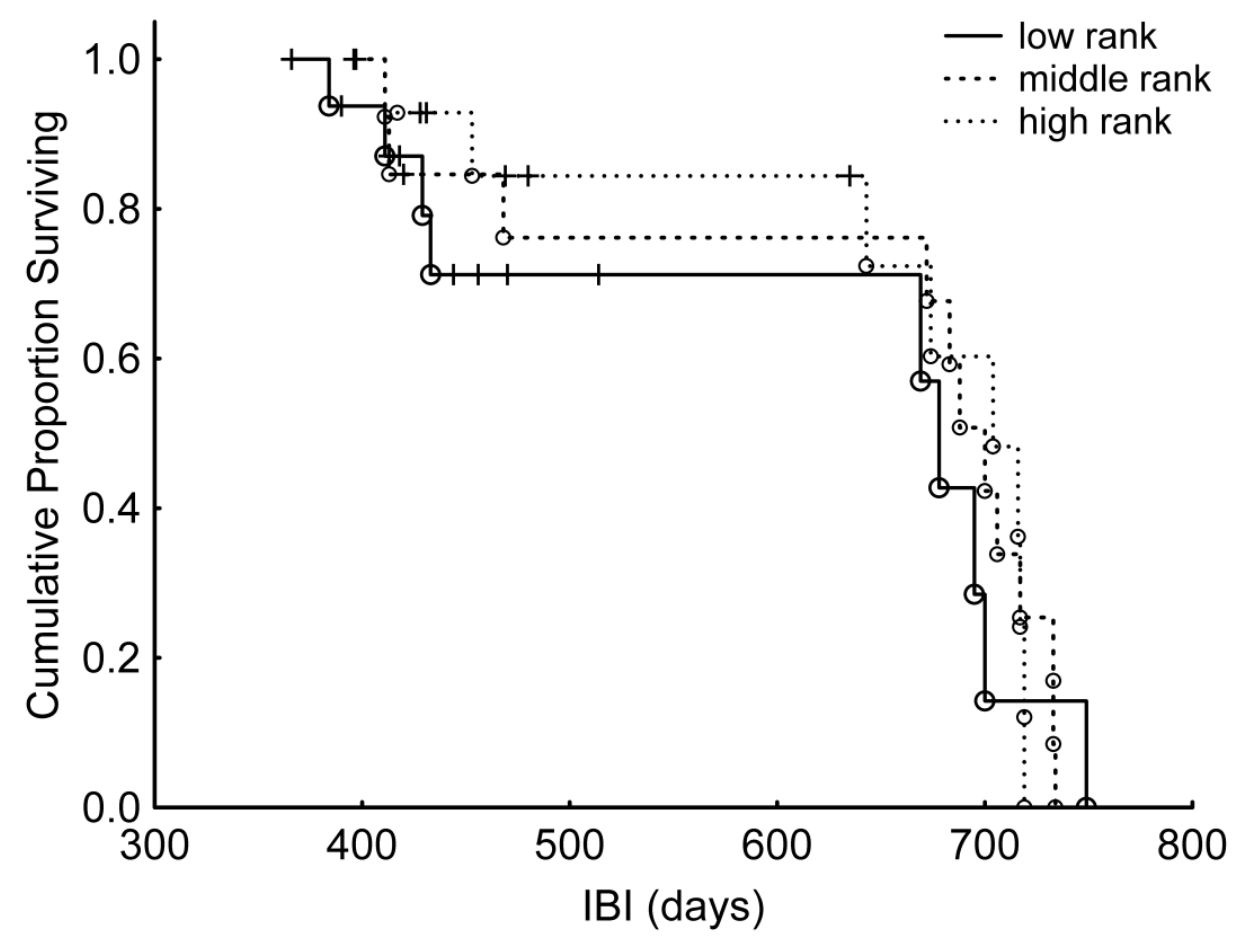

Fig. 5 Cumulative proportion of interbirth intervals (IBI) depending on the rank of the female at the start of the IBI $(n=46)$. Low ranking females (solid line), middle ranking females (hatched line) and high ranking females (dotted line), + = censored IBIS $(n=16), o=$ uncensored IBIS $(n=30)$. There was no significant difference in IBI length between low, middle, and high ranking females $\left(\chi^{2}=1.29, p=0.524\right)$

\section{Discussion}

The results of our study suggest that ecological conditions have a strong influence on nutritional status and reproduction in female Assamese macaques while at the same time we did not find evidence for an effect of direct feeding competition on energy gain rates or fecundity in this population of highly frugivorous macaques. As predicted, female energy intake responded positively to an increase in food availability, supporting the hypothesis that female nutritional status is influenced by the foraging environment. Nutritional quality, patch size (DBH), and tree density of the most consumed food items as well as overall fruit abundance varied widely between months. Despite this variation, energy intake rates did not appear to be influenced by female dominance rank, even during periods when the characteristics of the most consumed food items predicted high levels of competition. This is in contrast to many other primate species where the relationship between rank and energy intake was 
more pronounced or only present in ecological conditions that are associated with high levels of contest competition (Whitten 1983; Janson 1985; Barton 1993; Gore 1993; Koenig 2000).

There are more primate studies, however, that did not find a relationship between female dominance rank and feeding success (Deutsch and Lee 1991; White et al. 2007; meta-analysis: Majolo et al. 2012). As a possible explanation for this effect it is suggested that low ranking individuals may be able to compensate for a lower feeding efficiency by increasing the time they devote to feeding and/or searching for food (van Noordwijk and van Schaik 1987; Soumah and Yokota 1991; Koenig 2002; Murray et al. 2006). In Assamese macaques this does not seem to be the case as lower ranking females did not spend more time feeding or moving compared to high ranking females and this pattern did not change during periods where food characteristics predicted high levels of contest competition. These findings indicate that low ranking female Assamese macaques are able to attain the same energy intake as high ranking females without having to adjust their activity budget.

The positive relationship between fruit abundance and energy intake also translated into the predicted differences in conception rates, which increased in line with the amount of fruit available during the period prior to the mating season. A similar pattern has been observed in other primate species where changes in birth rate corresponded well with relative food abundance (Strum and Western 1982; Suzuki et al. 1998; van Noordwijk and van Schaik 1999; Takahashi 2002), or environmental factors that correspond with food abundance such as rainfall (Dunbar 1980).

Our finding that the occurrence of 1-year IBI's was significantly linked to early parturition within the birth season corroborates earlier findings on the same study population (Fürtbauer et al. 2010). This suggests that, like most mammals, female Assamese macaques incur energetic costs during lactation (Coelho 1986; Loudon and Racey 1987; Gittleman and Thompson 1988). Females can compensate for these costs by increasing food consumption (Altmann 1980; Dunbar and Dunbar 1988; Koenig et al. 1997), mobilising stored energy reserves (Bercovitch 1987; Pereira 1993), reducing the energy invested in other activities (Barrett et al. 2006), or adopting mixed strategies (Roberts et al. 1985; Nievergelt and Martin 1999).

During peak lactation female Assamese macaques spent less time feeding compared to females in other stages of the reproductive cycle. This decrease in feeding time corresponds with a trend indicating lactating females may also have a lower energy intake compared to non-lactating females. Instead of increasing their food intake it appears that female Assamese macaques mainly follow an energy-conserving strategy (Dasilva 1992), which is also seen in several other primate species (van Schaik and van Noordwijk 1985; Barrett et al. 2006; Miller et al. 2006; Lappan 2009). This is supported by the fact that lactating females did not change the time they spent moving, indicating feeding time 
was traded-off against resting rather than moving. At the same time, lactating females had lower physical condition scores compared to non-lactating females, suggesting that energy conservation was not sufficient and some of the energetic costs of lactation were likely met by metabolising stored energy reserves.

The positive relationship between early parturition within the birth season and the chance a female conceived again the same year suggests that female Assamese macaques may need to attain a certain threshold body condition in order to be able to conceive. The trend we found, indicating that the probability a female conceived may be positively affected by her physical condition during the mating season, provides further support for this theory. This link between physical condition and conception is also seen in other primate species and underlines the importance of nutritional status with regard to reproduction (Koenig et al. 1997; Richard et al. 2000). Although fruit abundance and nutritional status seem to clearly influence reproduction we found no evidence for rank related differences in interbirth intervals which could be related to the fact that we did not find evidence for a relationship between rank and energy intake or activity in our study group. Additionally, the months between the start of the birth season and the mating season appear to be most important in terms of reproduction and as these months are usually marked by a relatively high fruit availability, levels of contest competition during this period may be low.

Fruit availability at the study site was highly variable, both within and between years. Assamese macaques have a very broad diet and feed on a large number of different fruit items for considerable amounts of time in different months. Most items are only consumed for a short period of time and different items are important in different years. This means that looking only at species that make up a large part of the annual feeding budget would ignore many important resources. For this reason we included a large number of fruit species in the availability index to give a more complete picture of the availability of important food sources throughout the years. Despite the large variability, some patterns were repeated most years, including a period of very low food availability at the end of the dry season and a peak in food availability a few months after the start of the birth season. The latter could be related to the onset of the rainy season in April.

The timing of the birth season a few months before the annual peak in fruit availability causes the peak lactation period to overlap with a period of high food abundance, supporting the hypothesis that Assamese macaques are Income-II or relaxed income breeders (Brockman and van Schaik 2005; Janson and Verdolin 2005). The higher availability of fruit may enable females to better cope with the energetic demands of lactation despite their reduced feeding time. In other respects, Assamese macaques also show a mixture of reproductive responses derived from both income and capital 
breeding tactics which is typical for relaxed income breeders (Brockman and van Schaik 2005). Like typical income breeders they are strictly seasonal and females exhibit no ovarian cyclicity outside the mating season (Fürtbauer et al. 2010). At the same time, the probability a female conceived appeared to be condition dependent, indicating that conception is timed by both exogenous (income breeding) and endogenous (capital breeding) cues, and unlike in strict income breeders, birth rates varied between years depending on food availability (Brockman and van Schaik 2005).

In summary, this study found strong evidence that, in our study group, ecological conditions affect both female energy intake and reproduction. We also found that lactation is energetically costly and female physical condition may have a positive effect on the probability a female conceives. As a result of this, food availability, especially during peak lactation, can constrain female reproduction as it affects how well females can compensate for the costs of lactation and thereby attain a high enough physical condition to be able to conceive again. This suggests that in strictly seasonal species, ecological conditions have a much larger impact on reproduction during certain parts of the year than during others, which is important to take into consideration when investigating links between ecology and reproduction. Based on their reproductive strategy, Assamese macaques would be classified as relaxed income breeders (Brockman and van Schaik 2005). This supports the idea that income and capital breeding are opposite ends of a continuum and many species follow intermediate strategies.

If additional studies corroborate our current findings that there is no evidence for a link between ecological conditions, feeding competition, and female energy budgets or reproduction in our study group this would add to the on-going debate on the extent to which ecological conditions can reliably predict patterns in feeding competition and female fitness (Thierry 2008; Koenig and Borries 2009; Clutton-Brock and Janson 2012). Several studies have stressed the importance of using detailed measures of resource characteristics and pointed out that inconsistencies between observed variation in primate social behavior and the predictions of socioecological theory may be due to a lack of energetic or fitness measures and the use of inadequate measures of resource characteristics such as gross dietary categories (Koenig and Borries 2001; Snaith and Chapman 2007; Chapman and Rothman 2009). Our study reinforces this point as based on their highly frugivorous diet Assamese macaques would have been expected to face high levels of within group contest competition. However, our detailed study of resource characteristics, fitness, and energy intake did not reveal any significant rank related effects of resource contestability on energy intake or activity.

Another possibility is that female Assamese macaques are in fact experiencing contest competition and subordinates are able to avoid the energetic costs of direct competition for food resources by spacing out and finding enough food away from the center of the group. A disadvantage of this 
strategy is that predation risk is often higher at the edge of the group (Robinson 1981; van Schaik and van Noordwijk 1988; Murray et al. 2006). If female Assamese macaques follow this strategy we would expect to see rank related differences in spatial position within the group with low ranking females being more peripheral. If this is the case a high dominance rank may provide benefits in terms of safety rather than food intake.

Additional insight into the process of feeding competition in Assamese macaques may be provided by studying competition at the level of individual food items or even food trees which could offer a way to assess what different individuals are doing at the same time which would give a more complete picture of the dynamics of feeding competition (Vogel 2005; Vogel and Janson 2007). In addition, there is a need to investigate ways in which females may be compensating for a lower feeding efficiency and how this could affect their fitness, for example by looking at the link between female rank and spatial position within the group (Schülke and Ostner 2012).

\section{Acknowledgements}

We thank the National Research Council of Thailand (NRCT) and the Department of National Parks, Wildlife and Plant Conservation (DNP) for permission (No. 0004.3/3618; 0002.3/2647) to conduct this study. We are grateful to J. Prabnasuk, K. Nitaya, M. Kumsuk, and K. Kreetiyutanont (Phu Khieo Wildlife Sanctuary) for their cooperation and permission to carry out this research. We thank A. Koenig and C. Borries (Stony Brook University), who developed the field site at Huai Mai Sot Yai. We are very thankful to N. Juntuch, N. Ponganan, D. Bootros, S. Jomhlotwong, T. Kilawit, T. Wisate, P. Saisawatdikul and especially M. Swagemakers for their help in the field. We are also very grateful to W. Nuagchiyo, A. Chunchaen and S. Macdonald for their help with data collection. We thank N. Bhumpakphan, W. Eiadthong (Kasetsart University), and W. Brockelman (Mahidol University) for their support and cooperation. Furthermore we would like to thank Dr. Marie Charpentier and two anonymous reviewers for helpful comments on an earlier draft of the manuscript. This project was supported with funds from the Max Planck Society, the National Geographic Society, and the University of Göttingen through funding from the German Initiative of Excellence.

\section{Conflict of interest}

The authors declare that they have no conflict of interest. 


\section{Ethical standards}

Approval and permission to conduct research was granted by the authorities of Thailand (permit no. 0004.3/3618 and 0002.3/2647), and all research was undertaken in strict accordance with the laws set forth by the National Research Council of Thailand and the regulations of the Department of National Parks, Wildlife and Plant Conservation, Bangkok, as well as the guidelines of the involved institutes. 


\title{
Chapter 3
}

\section{Predictors of food related aggression in wild Assamese macaques and the role of conflict avoidance}

\author{
Marlies Heesen ${ }^{1}$, Sebastian Rogahn ${ }^{1}$, Sally Macdonald ${ }^{1}$, Julia Ostner ${ }^{1}$, Oliver Schülke ${ }^{2}$
}

${ }^{1}$ Primate Social Evolution Group, Courant Research Centre Evolution of Social Behaviour, Georg-August University Göttingen, Kellnerweg 6, 37077, Germany

${ }^{2}$ Courant Research Centre Evolution of Social Behaviour, Georg-August University Göttingen, Kellnerweg 6, 37077, Göttingen, Germany 


\section{Abstract}

The quality, availability, and distribution of food resources and their influence on types and levels of feeding competition play a central role in ecological models of female social structure in mammals. Here we investigate the impact of social and ecological factors on rates of food related aggression and the use of potential conflict avoidance mechanisms in wild Assamese macaques (Macaca assamensis) in north-eastern Thailand. These questions were addressed by examining feeding competition at the level of individual food patches which provides detailed information on resource characteristics, aggression, and feeding party composition. Results suggest that the frequency of aggression in food patches increases with increasing feeding group size and decreasing patch size, but is not affected by ecological variables representing resource value (abundance and nutritional value of food items in patch). Interestingly, females appear to employ several mechanisms to avoid direct conflicts, including the use of alternative feeding sites within food patches, storing food in cheek pouches, and co-feeding with individuals they share strong social bonds with. Conflict avoidance may be partially responsible for the absence of a rank related skew in female energy intake in this population and may explain other cases where empirical data do not fit the predictions of socio-ecological theory. Our findings also inform the debate about the mechanisms generating fitness benefits from strong social bonds by suggesting that by increasing feeding tolerance, social bonds may enhance resource acquisition, reduce the risk of injuries and lower levels of agonism related stress.

Keywords: aggression, feeding competition, Assamese macaque, socio-ecology, social bonds, cheek pouch use 


\section{Introduction}

Competition for access to food resources can have profound effects on individual survival and reproduction and plays an important role in shaping different aspects of animal social systems, such as group size and composition, patterns of social interactions and mating systems (Crook and Gartlan 1966; Trivers 1972; Clutton-Brock 1974; Jarman 1974; Bradbury and Vehrencamp 1977b; Emlen and Oring 1977; Lee 1987). In particular, the idea that the quality, availability, and distribution of food resources shape relationships among females, both within and between groups, has been central to ecological models of female social structure among primates and other mammals (Wrangham 1980; van Schaik 1989; Sterck et al. 1997; Isbell and Young 2002; Clutton-Brock and Janson 2012). Evaluations of these models have suffered from uncritical testing (Koenig and Borries 2009) based on unsupported assumptions about resource characteristics of frugivores versus folivores (Snaith and Chapman 2007; Wheeler et al. 2013). Here, we present empirical data to investigate the effects of social (feeding group size) and ecological factors (abundance and quality of food items in patches, patch size) on the rate of aggression in food patches as predicted by socio-ecological models.

According to socio-ecological theory, within-group contest competition is expected to occur when food resources are of high nutritional quality and have a clumped distribution or occur in patches of intermediate size relative to group size. In these situations one or more individuals will be able to monopolize access to food resources to the exclusion of others (Sterck et al. 1997; Isbell et al. 1998; Koenig 2002). On the other hand, when resources are of low quality, highly dispersed or occur in patches that are large relative to group size, within-group contest competition is not expected to occur (van Schaik 1989; Koenig et al. 1998; Koenig 2002). Because access to resources can depend on both the outcome of concurrent and prior agonistic interactions, contest competition is generally associated with higher rates of agonism and predicted to result in a higher net energy gain for more dominant individuals. This, in turn, is expected to favour female philopatry, the formation of consistent, linear dominance relationships, and the defence of resources by groups of related, natal, females (Wrangham 1980; Janson and van Schaik 1988; Lomnicki 1988; van Schaik 1989; Sterck et al. 1997; Koenig 2002; Koenig and Borries 2006). Several field studies have confirmed this link between the use of clumped or high quality resources, high levels of contest competition and the predicted effects on social structure and dispersal patterns (Whitten 1983; Borries 1993; Barton et al. 1996; Saito 1996; Sterck and Steenbeek 1997; Goldberg et al. 2001; Grant et al. 2002; Su and Birky 2007).

However, inconsistencies between theoretical expectations and observed patterns have also been found, as resource characteristics are not always good predictors of contest competition (Deutsch and Lee 1991; Gore 1993; Boinski 1999; Koenig 2000), rates of aggression do not always match 
competitive regimes (Sterck and Steenbeek 1997; Pruetz and Isbell 2000), and competitive regimes are not always good predictors of social structure (Borries 1993; Cords 2000; Isbell and Young 2002; Koenig 2002). These discrepancies have fuelled a general debate on the validity of the assumptions of socio-ecological theory and the accuracy of its predictions. While some authors claim that attempts to relate variation in social behaviour to ecological factors should be abandoned altogether (Thierry 2008), others argue that the existing theory still provides a useful framework though it needs refinement (Janson 2000; Koenig and Borries 2009; Schülke and Ostner 2012; Koenig et al. 2013).

In an attempt to increase the model's validity, a call for a more specific definition and more accurate measurement of resource characteristics has been made (Isbell and Young 2002; Koenig and Borries 2006; Snaith and Chapman 2007; Vogel and Janson 2007; Schülke and Ostner 2012). Resource size, density and distribution are often measured from a botanical perspective without considering the animals that are feeding on these resources while factors such as body size and group spread may greatly influence what type of competition a particular resources elicits (Isbell et al., 1998, Koenig and Borries, 2006, Koenig et al., 2013). One potential solution to this problem may be to measure feeding competition at the level of individual food patches, combining information on resource characteristics, group spread, and the simultaneous use of resources by different group members (Koenig and Borries 2006; Vogel and Janson 2007; Vogel and Janson 2011).

Studies investigating food related agonism in individual feeding patches found that the frequency of agonism increases with decreasing food abundance, increasing food quality, and a decreasing number of feeding sites available in patches. Additionally, rates of agonism increased with the number of individuals feeding in a patch and with the amount of time individuals occupy a patch (Saito 1996; Vogel and Janson 2007; Hanya 2009).

An additional aspect that may be able to explain some of the discrepancies between empirical data and the predictions of the socio-ecological model is the influence of conflict avoidance mechanisms. Contest competition can be costly as it may lead to escalated aggression which can result in injuries (van Schaik 1989; Janson 1992; Koenig 2002). Additionally, escalated aggression can lead to increased social stress resulting from uncertainty about renewed attacks, as well as ecological stress resulting from a decrease in foraging time due to exclusion from the contested resource or the need to increase social vigilance (Aureli et al. 1989; Aureli 1992; Aureli et al. 2002). Considering these potential costs associated with escalated aggression, animals are expected, where possible, to employ mechanisms to reduce the risk of food related conflicts.

One way in which cercopithecine primates, including macaques, could avoid food related aggression is by using their cheek pouches (Hill 1966; Murray 1973). By storing food, instead of masticating and 
ingesting it, cheek pouches can allow individuals to leave feeding patches before agonism occurs, without having to reduce their food intake (Lambert 2005). Increased cheek pouch use has indeed been observed in situations of increased contest competition, for example when animals feed on provisioned or more contestable food. In addition, cheek pouch use has been found to increase with decreasing dominance rank, possibly because lower-ranking individuals are more likely to receive aggression during feeding (Lambert and Whitham 2001; Lambert 2005).

Individuals may also be able to actively avoid conflict by being selective about who they feed with. For example, individuals may prefer to share a food patch with group-mates they share a strong social bond with or with those who are close to them in rank (de Waal 1991; King et al. 2009; King et al. 2011). There is a growing body of evidence that social bonds have a positive impact on fitness in a range of taxa, from mice to humans (Berkman and Glass 2000; Silk et al. 2003; Silk 2007a; Smith and Christakis 2008; Yee et al. 2008; Cameron et al. 2009; Silk et al. 2010b). However, it remains unclear exactly how strong social bonds function to enhance fitness (Alberts 2010). Benefits from reduced aggression during feeding may provide one of the missing links between sociality and fitness via improved resource acquisition, stress reduction and lower costs from wounding.

In this paper, we aim to investigate covariates of food related aggression in wild Assamese macaques and mechanisms females may use to avoid food related conflicts. These questions were addressed by examining feeding competition at the level of individual food patches, in this case feeding trees, using the "focal tree method" (Vogel and Janson 2007). Food is a limiting resource for females in the study population as fruit availability affects both female energy intake and reproduction. Surprisingly, despite their highly frugivorous diet and their steep linear dominance hierarchies, no evidence for a rank related bias in female metabolizable energy intake was found (Heesen et al. 2013). Investigation of feeding competition at the level of individual food patches may help explain this unexpected finding. For an overview of the main questions addressed below with the associated predictions see Table 1.

First, we investigated whether patches were being depleted, as contest competition may only be detectable in patches that are depleted over residence time. We predicted to find a slowed intake rate coupled with a constant or increasing feeding effort over time. In addition, we predicted both feeding bout duration and feeding group size to increase with the number of food items available in patches (Snaith and Chapman 2005).

Rates of aggression in food patches are expected to be influenced by both social factors, affecting the opportunity for aggression to occur, and ecological variables, representing the benefits of gaining access to a resource or the opportunity for individuals to avoid conflict by using alternative feeding 
locations (Vogel and Janson 2007). To assess the influence of social factors on aggression, we investigated the impact of the number of individuals in a food patch and predicted that the frequency of aggression would increase with feeding group size (Vogel and Janson 2007). With regard to ecological variables representing the benefits of gaining access to a food patch, we examined patch size, crown energy (see Methods), and the nutritional value of the food items in the patch. We predicted that if the ecological value of a food patch is higher, the frequency of aggression will increase because the benefits of gaining access to the resource are greater (Maynard Smith 1974). Ecological variables may also represent the opportunity for individuals to avoid aggression by using alternative feeding locations both within and outside food patches. The benefits that could have been obtained by using these alternative sites are referred to as the opportunity costs of choosing to use and contest a particular feeding site (Vogel and Janson 2007). It is predicted that if there are alternative resources available that are similar in value to the contested feeding site, individuals will avoid agonism since the alternative resources decrease the benefit of gaining access to the original resource through fighting, thereby increasing the opportunity costs of aggression (Stephens and Krebs 1986; Vogel and Janson 2007). In this context, we investigated the influence of food patch size and crown energy as measures of the feeding opportunities within a food patch and an "alternative resource score" (see Methods) as a measure of the feeding opportunities in the vicinity of a patch. We predicted that if these variables are measures of the opportunity costs within food patches, they will be negatively related to the frequency of aggression.

Lastly, we investigated mechanisms females may be using to avoid direct competition by looking at cheek pouch use and patterns of co-feeding. We predicted that cheek pouch use should increase with decreasing dominance rank and be more common in food patches that are associated with high levels of contest competition. With regard to patterns of co-feeding we predicted that the frequency with which two females in a dyad feed together in a patch should be linked to their rank distance and the strength of their social bond which was characterized based on a composite sociality index (CSI) (Silk et al. 2006a; Silk et al. 2006b; Silk et al. 2010a). Females are predicted to co-feed more frequently with those individuals they have a strong social bond with or those that are close to them in rank. Additionally, we predicted that dyads with stronger social bonds or a small rank distance would feed together in smaller feeding groups than dyads with weaker social bonds or that are further apart in rank. 
Table 1. Overview of the models used to investigate the frequency of aggression in food patches, female check pouch use and female co-feeding, including response and predictor variables with the predicted direction of the effects

\begin{tabular}{|c|c|c|c|}
\hline Response variable & Predictor variables & Predicted direction of effect & $\begin{array}{l}\text { Error distribution } \\
\text { (link function) }\end{array}$ \\
\hline \multirow{7}{*}{$\begin{array}{l}\text { Number of aggressive } \\
\text { interactions in patch }\end{array}$} & Patch size $(\mathrm{DBH})$ & + (resource value) & Poisson (log) \\
\hline & & - (opportunity costs) & \\
\hline & Total energy in patch (crown energy) & + (resource value) & \\
\hline & & - (opportunity costs) & \\
\hline & Nutritional value food items & + & \\
\hline & No. alternative resources & - & \\
\hline & Feeding group size & + & \\
\hline \multirow[t]{7}{*}{ Cheek pouch volume (0/1) } & Rank & + (larger in lower ranking females) & Binomial (logit) \\
\hline & Rank x Patch size & + (if competition increases with increasing $\mathrm{DBH}$ ) & \\
\hline & & - (if competition decreases with increasing DBH) & \\
\hline & Rank x Total energy in patch & + (if competition increases with increasing crown energy) & \\
\hline & & - (if competition decreases with increasing crown energy) & \\
\hline & Rank $x$ Nutritional value food items & + & \\
\hline & Rank x Aggression in patch & + & \\
\hline \multirow{2}{*}{$\begin{array}{l}\text { Dyadic frequency of co- } \\
\text { feeding in patches }\end{array}$} & Strength of social bond & + & Gaussian (identity) \\
\hline & Rank distance & - & \\
\hline \multirow{2}{*}{$\begin{array}{l}\text { Mean size of feeding groups } \\
\text { dyad feeds in }\end{array}$} & Strength of social bond & - & Gaussian (identity) \\
\hline & Rank distance & + & \\
\hline
\end{tabular}




\section{Methods}

Study site and subjects

This study was conducted at Phu Khieo Wildlife Sanctuary, North-eastern Thailand $\left(16^{\circ} 5^{\prime}-35^{\prime} \mathrm{N}\right.$, $101^{\circ} 20^{\prime}-55^{\prime} \mathrm{E}$ ). The sanctuary covers an area of $1,573 \mathrm{~km}^{2}$ at elevations of $300-1,300 \mathrm{~m}$ above sea level, is part of the 6,500- $\mathrm{km}^{2}$ contiguous Western Isaan Forest Complex (Koenig et al. 2004), and is home to four macaque species, M. arctoides, M. assamensis, M. mulatta, and M. nemestrina leonina (Kumsuk et al. 1999; Borries et al. 2002). The study site within the sanctuary, "Huai Mai Sot Yai" $\left(16^{\circ} 27^{\prime} \mathrm{N}, 101^{\circ} 38^{\prime} \mathrm{E}\right)$, is situated at elevations of $600-800 \mathrm{~m}$ above sea level and comprises mainly hill and dry evergreen forest with bamboo stands (Borries et al. 2002). The annual rainfall averages 1,444 $\mathrm{mm}$ with a distinct dry season from November through March. Mean annual temperature is $21.3^{\circ} \mathrm{C}$ (mean minimum temperature $=18.4{ }^{\circ} \mathrm{C}$, mean maximum temperature $=25.5^{\circ} \mathrm{C}$; Borries et al. 2011) Data were collected from a fully habituated group of wild Assamese macaques that feed naturally. The vegetation at the study site is dense, the terrain hilly, and the study group spends about $60 \%$ of their activity time in the middle and upper strata of the forest (Schülke et al. 2011). The study population breeds seasonally with a mating season between October and January and a birth season between April and July (Fürtbauer et al. 2010).

\section{Behavioural sampling}

Data for this study were collected over two 1-year sampling periods (period 1: October 2007September 2008; period 2: May 2010-April 2011). During these sampling periods, the group consisted of a total of 53 individuals, including 14 adult and 3 subadult males, and 12 adult and 4 subadult females (period 1), and 49 individuals, including 10 adult and 2 subadult males and 15 adult females (period 2). Baseline social and feeding data were collected by recording 30 minute focal observations of all adult females. An effort was made to distribute these observations evenly across both time of day and individuals. In total, $841 \mathrm{~h}$ of focal data were collected during sampling period 1 , with an average of $70 \pm 7 \mathrm{~h}$ per female, and 1,340 $\mathrm{h}$ of focal data were collected during sampling period 2, with an average of $91 \pm 4.6 \mathrm{~h}$ per female. We used continuous sampling to record all affiliative, aggressive, submissive, sexual, solitary and infant directed behaviours, as well as facial displays and vocalizations shown by or directed at the focal female (Altmann 1974). In addition, we used instantaneous sampling (Martin and Bateson 2007) to collect records of positional behaviour and activity at 1-minute intervals.

Dominance hierarchy 
A female dominance hierarchy was established for each sampling period separately using only decided, dyadic agonistic interactions (i.e. bouts of aggression with only aggression on one side and submission on the other or spontaneous signals of submission) recorded during both continuous focal observations and ad libitum sampling. A winner/loser matrix of these interactions was reordered using the I\&SI method as implemented in MATMAN ${ }^{\mathrm{TM}}$ 1.1.4 (Noldus 2003) to give the final female rank order. Female dominance hierarchies for both data collection periods were significantly linear, with a high directional consistency index (period 1-249 interactions: $h^{\prime}=0.92, D C l=0.96,10.6 \%$ unknown relationships, $\mathrm{p}<0.001$; period 2-393 interactions: $h^{\prime}=0.83, \mathrm{DCl}=0.96,12.4 \%$ unknown relationships, $p<0.001$; for details see: Macdonald et al. 2013). Ranks for both data collection periods were standardised to range from 1 (lowest ranking) to 2 (highest ranking), with all females spaced evenly between these two values to enable comparison between the two years.

\section{Focal tree sampling}

The main sampling technique used for this study was the "focal-tree method" adapted from Vogel and Janson (2007). Focal tree data were collected over two periods (period 1: January - September 2008; period 2: July 2010 - April 2011). Focal tree observations were conducted during pre-assigned time blocks (eight seven-hour blocks per month) during which two observers would solely conduct focal tree observations while other observers, if present, would conduct focal animal follows. The advantage of this method is that data can be collected on individuals feeding simultaneously in the same food patch. Here, we define a patch as an individual tree, large shrub or liana with a separate crown or of individuals of the same species with overlapping crowns (Leighton and Leighton 1982; Strier 1989; Phillips 1995; Sterck and Steenbeek 1997). Data were collected by two observers simultaneously, except when focal trees were very small. A focal tree observation started as soon as a monkey was observed entering a patch to feed, or shortly after, and data were taken until the last individual left the patch. The time between the first arrival to the patch (or the first observation in the patch) to the last departure is the "feeding bout length". If there were gaps in feeding during the feeding bout (e.g. all individuals are resting or grooming), the amount of time in which the monkeys did not feed was subtracted from the total feeding bout length.

During focal tree observations we collected data on the number and identity of the individuals in the food patch as well as all agonistic interactions taking place in the patch. During period 1 the number and identity of all monkeys in the patch was recorded at 5-minute intervals, while the exact times at which individuals entered and left the patch were not noted. During period 2 we recorded the time and identity of each monkey entering and leaving the food patch and from this we calculated the 
number and identity of all monkeys in the patch at 5-minutes intervals. The mean number of individuals in the patch throughout the feeding bout was calculated from these 5-minute point samples. All agonistic interactions in the food patch were recorded with, if possible, the identity of the individuals involved. For this study, we only considered interactions that included aggressive behaviour (e.g. physical aggression, threats and chases) towards or by an adult or subadult individual. Spontaneous submission and aggression by or towards juveniles and infants were not considered. Both males and females were included in the calculation of aggression rates and feeding group size as both males and females are expected to compete over food, though food resources are considered to be less important for males. Additionally, during each focal tree observation both observers recorded 1-min focal samples of as many adult females as possible, noting the number of food items ingested, the number of meters moved during that minute and the amount of food a female had stored in her cheek pouches. Cheek pouch volume was scored on a binary scale with 0 including empty and less than half full cheek pouches and 1 including more than half full and full cheek pouches.

\section{Ecological sampling}

The number of food items available within focal trees was estimated visually at the start of each focal tree observation and scored on a logarithmic scale (1=1-9; $2=10-99 ; 3=100-999 ; 4=1,000-9,999$; 5=10,000-99,999; Janson and Chapman 1999b). The Diameter at Breast Height (DBH) of each focal tree was measured at the end of each focal tree observation. We used this as an indicator of patch size as tree crown dimensions are generally well correlated with a tree's DBH (Hemery et al. 2005; Lockhart et al. 2005). When the monkeys were feeding in several overlapping tree crowns these were treated as one food patch and the DBH values of the individual stems were combined. Baseline phenological data were collected at the middle of each month by recording the abundance of foliar items (leaf buds, young leaves, mature leaves) and reproductive items (flower buds, flowers, young fruit, mature fruit, old fruit) of up to 650 trees, shrubs and climbers spread over 20 botanical plots. Abundance of the different items was scored on the same logarithmic scale used during focal tree observations.

\section{Nutritional analysis}

Samples of the most frequently consumed food items were collected preferably from trees in which the monkeys had been observed feeding. These samples were deep-frozen at $-20^{\circ} \mathrm{C}$ and transported to the Department of Animal Science (Kasetsart University, Bangkok), where they were freeze-dried 
and analysed for nutritional content (neutral detergent fibre (NDF), protein, ash, moisture and lipids; for further details see: Heesen et al., 2013). Nutritional information was available for 78 items from 70 species, covering $77.6 \%$ of the average feeding time on plant items.

\section{Nutritional value of food items and crown energy}

In order to give a measure of the nutritional value of the food items available in each focal tree we calculated the energy individuals gain per minute of feeding for each food species (number of kilojoules per item $x$ mean number of items individuals ingested per minute for that species). Mean ingestion rates were based on data collected on all adult females as ingestion rates did not depend on dominance rank (Heesen et al. 2013). Crown energy gives an indication of the total amount of energy available in the focal tree and was calculated by multiplying the median of the values represented by the logarithmic food availability score recorded at the start of a focal tree observation by the nutritional value per food item in kilojoules. Crown energy values ranged from 33.4 to $628,831.4 \mathrm{~kJ}$.

\section{Alternative resource score}

Due to the density of the forest and the large number of tree species the monkeys fed on, it was not feasible to measure the alternative resources available in the vicinity of focal trees directly (Vogel and Janson 2007). Therefore alternative resource scores were calculated based on data from thirteen 1 ha botanical plots ( 1 ha is a good measure of the average spread of the study group calculated from maximum inter-individual distances recorded during group scans; unpublished data). For each calendar month a separate alternative resource score was calculated for each food species focal tree data were collected on during that month. As alternative resources we used the food species the monkeys consumed most during the month when the focal tree observation took place (species representing $\geq 5 \%$ of monthly feeding time based on focal animal sampling)

For each focal tree species, we first selected the plots in which this species was present and based on these plots, we then calculated the mean density of each alternative food species. For each of these alternative food species, we then calculated the mean number of items per tree for that month by taking the mean of the food availability scores (the median of the range of values represented by the logarithmic food availability scores) recorded for this species during phenological sampling. Trees not carrying food items were taken into account here so that the mean number of items per tree was lower when many trees were empty. A measure of the amount of energy provided by each particular alternative food species present within a 1 ha area in the vicinity of an individual of the focal tree 
species was then generated as follows: mean number of food items per tree $\mathrm{x}$ nutritional value per item $x$ mean density of the species.

Values for all alternative food species were then added up to generate an alternative resource score per focal tree species per month. The score varied between 0 and 1,622,204 and increased with the number of important food species present in plots containing the focal tree species and the density, number of food items per tree crown and nutritional value of these important food species.

\section{Social bonds}

Female social relationships were characterized based on a composite sociality index (CSI) promoted by Silk and colleagues (Silk et al. 2006a; Silk et al. 2006b; Silk et al. 2010a). The CSI combines relevant positive social behaviours in such a way that it is possible to assess the strength of the relationship between two individuals relative to the strength of the relationships of all other individuals in the group. Six significantly correlated, behavioural elements were included in the index; the frequency (per hour of observation) of "friendly" approaches (i.e. approaches within $1.5 \mathrm{~m}$ that did not result in aggression or spontaneous submission from either party ), "friendly" body contact (i.e. body contact that did not involve or occur during aggression or spontaneous submission) and grooming and the duration (minutes per hour of observation) of "friendly" approaches, "friendly" body contact and grooming.

Approaches, body contact and grooming are nested behaviours, individuals must approach before making body contact and must make body contact before they can groom. Therefore, in an effort to control for pseudo-replication, friendly approaches were only included in the analysis if there was at least 10 seconds between the initiation of the approach and any other friendly social behaviour, i.e. body contact or grooming. In addition, friendly body contacts were only included in the analysis if the dyad spent at least 10 seconds in body contact before engaging in any other friendly social behaviour, i.e. grooming. Similarly, the duration of any friendly body contact and grooming which occurred during an approach was subtracted from the duration of the approach and the duration of any grooming that occurred during a friendly body contact was subtracted from the duration of the body contact. Friendly approaches that took place in a feeding context (when at least one of the involved individuals was feeding) were not included in the calculation of the CSI to make sure that the cofeeding scores and CSI values are independent.

Co-feeding 
The number of times two females in a dyad $(i, j)$ were observed feeding together in a patch was corrected for the number of times each of the females was present during focal tree observations and calculated as follows:

Corrected co-feeding:

no. of obs. dyad $\mathrm{i}, \mathrm{j}$ is feeding together

no. of obs. ind. $i$ is present + no. of obs. ind. $j$ is present - no. of obs. dyad $i, j$ is feeding together

These values were then standardized by dividing them by the mean value for all dyads (this was done separately for each observation period) so that values above one indicated dyads that feed together more than average and values below one indicated dyads that feed together less than average. In total this resulted in 171 dyadic values (period 1: 66 dyads; period 2: 105 dyads).

\section{Statistical analysis}

In order to assess whether food patches were being depleted, we compared mean food intake rates (number of bites per minute) and feeding effort (distance moved in meters per minute) between the first and last third of a focal tree observation using a Wilcoxon matched pairs test. We included all focal tree observations with a duration of at least 10 minutes and for which food intake rate and feeding effort data were available for both the first and the last third of the observation period. Separate analyses were conducted for all food items combined and for fruit only.

In order to assess how several ecological and social variables influence the frequency of food related aggression in feeding patches we used a generalized linear mixed model (GLMM, Baayen 2008) with Poisson error structure and log link function. As the response variable we used the number of agonistic interactions during a single focal tree observation (aggression involving adult and subadult males and females). Predictor variables were crown energy (measure of the total amount of energy available in a patch), mean number of individuals in the tree (adult and subadult males and females), DBH (measure of the amount of space available in a patch), energy yield in kJ per minute feeding (measure of the energetic value of the food items in the patch), and the alternative resource score. Calendar month and focal tree species were included as random factors and the duration of the focal tree observation was included as an offset variable to control for observation effort. We included all 
focal tree observations that were at least 10 minutes in duration and where at least 2 adult or subadult individuals were present in the tree at the same time for at least part of the observation.

To assess the influence of food patch characteristics, aggression, and rank on female cheek pouch use we ran a GLMM with binomial error structure and logit link function. As binary response variable we included the largest cheek pouch volume recorded for each female that was observed during a particular focal tree observation (0: empty and less than half full cheek pouches; 1 : more than half full and full cheek pouches). Predictor variables were crown energy, DBH, standardized rank, and standardized rate of aggression. Standardized rate of aggression is the number of aggressive interactions per focal tree observation corrected for the number of individuals (adults and subadults) in the tree and the duration of the observation (number of aggressive interactions/ (mean number of individuals in tree $\mathrm{x}$ total duration of focal tree observation)). To assess whether any of these variables affects the strength of the relationship between rank and cheek pouch use we also included the interaction between rank and crown energy, rank and $\mathrm{DBH}$, and rank and standardized aggression as predictor variables. Random factors were female identity and protocol number.

To investigate the influence of rank distance and the strength of social bonds between females on the frequency with which they feed together in food patches, we used a linear mixed model (LMM) with Gaussian error structure and identity link function. As the response variable we used the corrected cofeeding frequency per dyad and the predictor variables were the absolute rank distance between two females in a dyad and the CSI score of the dyad. Observation period ( 1 or 2 ) was included as a predictor variable to control for a potential influence of the data collection period. The identities of both females in a dyad were included as random factors. In addition, we looked at the influence of rank distance and the strength of social bonds between females on the size of the feeding groups in which a dyad was observed feeding together. We ran a LMM with Gaussian error structure and identity link function with the mean number of individuals (adult and subadult males and females) present in focal trees in which a dyad was observed feeding together as the response variable. Predictor variables were the absolute rank distance between two females in a dyad and the CSI score of the dyad. Observation period ( 1 or 2 ) was included as a predictor variable to control for a potential influence of the data collection period. The identities of both females in a dyad were included as random factors.

All (G)LMMs were fitted in $R$ ( $R$, version 2.14.2; R Development Core Team 2012) using the function Imer of the R-package Ime4 (Bates et al. 2012). For all models, we first determined the significance of the full model as compared to the corresponding null model (including the intercept, random effects and offset variable) using a likelihood ratio test (Burnham and Anderson 2002). P values of main 
effects were considered only if these effects were not included in a significant interaction. Likelihood ratio tests were calculated using the $R$ function anova. For the LMMs with Gaussian error structure, $p$ values for the individual effects were based on Markov Chain Monte Carlo sampling (Baayen 2008) and derived using the functions pvals.fnc and aovlmer.fnc of the R package language R (Baayen 2011). For the GLMM's with binomial and Poisson error structure, the significance of the individual fixed effects was determined based on the $z$ and $p$ values provided by Imer. All appropriate assumptions (homogeneity of error variances, multicollinearity, influential cases, absence of overdispersion) were tested for and met in each analysis.

\section{Results}

In total, 355 focal tree observations, with a minimum duration of ten minutes and more than 1 adult or subadult individual present, were included in this study. These observations included 57 different food items (49 fruit (including seeds), 4 flowers, 4 leaves) belonging to 55 species. DBH of focal trees ranged from 2.0 to $277.9 \mathrm{~cm}$ (median=39.9, interquartile range= 23.6-63.0, $\mathrm{n}=336$ ) and mean feeding group size ranged from 0.3 to 12.6 (median=3.3, interquartile range= 2.0-5.4, $n=352$ ). The mean number of aggressive interactions per hour of focal tree observation was 0.56 .

\section{Patch depletion}

Food ingestion rates decreased between the first and the last third of a focal tree observation (Wilcoxon matched pairs test: all items: $V=1787.5, p=0.056, n=76$; fruit only: $V=1695, p=0.017, n=72$ ) while distance moved (feeding effort) did not change significantly (all items: $V=495, p=0.623, n=70$; fruit only: $V=891, p=0.698, n=67)$. This indicates that patches are being depleted by the study group though the effect was more pronounced when looking at fruit patches only, possibly because leaves are more difficult to deplete or because patch depletion may only be evident in preferred food items (Snaith and Chapman 2005). Both the mean number of individuals in a food patch and the duration of feeding bouts were positively correlated with the number of food items available in the patch (Spearman's correlation: mean number of individuals in patch: rho $=0.344, p<0.001$; duration feeding bout: rho $=0.317, p<0.001, n=320$ for both). This indicates that the number of food items in a patch limits the number of individuals feeding in those patches due to patch depletion, and that the food trees used by the study group are not superabundant patches. 


\section{Food patch characteristics and aggression}

Overall, feeding party size and the ecological characteristics of food patches influenced the frequency of aggression in those patches (full model: $\chi^{2}=102.65$, $d f=5, p<0.001, n=289$ ). More specifically, aggression rates increased with increasing numbers of individuals in the patch and with decreasing patch size while aggression rates were not affected by the amount of energy available in the patch (crown energy), the energetic value of the food items in the patch (energy yield in kJ per minute), or the availability of alternative resources outside the food patch (Table 2).

Table 2 The influence of social and ecological variables on the frequency of aggression in food patches (response variable: number of aggressive interactions in food patch). Results of a GLMM with z-transformed predictor variables including month and focal tree species as random variables and group feeding bout duration as offset variable $(n=289)$

\begin{tabular}{lccc}
\hline Predictor variable & Estimate \pm SE & z value & p value \\
\hline Intercept & $-9.09 \pm 0.21$ & -43.76 & $<0.001$ \\
Mean number of adults in patch & $0.88 \pm 0.17$ & 5.28 & $<0.001$ \\
Patch size (DBH) & $-0.63 \pm 0.17$ & -3.68 & $<0.001$ \\
Total energy in patch (crown energy) & $-0.24 \pm 0.17$ & -1.42 & 0.157 \\
Nutritional value food items (kJ/min feeding) & $-0.06 \pm 0.18$ & -0.31 & 0.756 \\
Alternative resource score & $0.03 \pm 0.13$ & 0.22 & 0.825 \\
\end{tabular}

Food patch characteristics, rank and cheek pouch use

The relationship between rank and cheek pouch use was not affected by patch size (interaction rank and DBH: $z=0.14, p=0.889$ ), the total amount of energy available in the patch (interaction rank and crown energy: $z=-0.99, p=0.323$ ), the rate of aggression in the patch (interaction rank and standardized rate of aggression: $z=1.39, p=0.163$ ), or the energetic value of the food items in the patch (interaction rank and energy yield in kJ per minute: $z=-0.59, p=0.555$ ). Therefore we ran the model without the interaction terms and found that overall, rank and food patch characteristics have an influence on cheek pouch use (full model: $\chi^{2}=187.41, d f=5, p<0.001, n=528$ ). More specifically, cheek pouch volume increased with decreasing rank position and with increasing crown energy while it was not influenced by patch size or the energetic value of the food items in the patch. Additionally we 
found a trend indicating that cheek pouch volume may increase with decreasing rates of aggression in the patch (Table 3).

Rank distance, social bonds, and co-feeding

The frequency with which two females were observed feeding together in a food patch increased with decreasing rank distance and with increasing strength of the social bond between the females in the dyad (CSI) (full model: $\chi^{2}=21.81, d f=3, p<0.001, n=171$ dyads, Table 3). Additionally, mean feeding group size decreased with increasing strength of the social bond between the females in a dyad (CSI) while it was not affected by their rank distance (full model: $\chi^{2}=12.65, d f=3, p=0.005, n=171$ dyads, Table 4).

Table 3 The influence of rank and food patch characteristics on female cheek pouch use. Cheek pouch volume is scored as a binary variable: $0=$ empty and less than half full cheek pouches; $1=$ more than half full and full cheek pouches. Results of a GLMM with z-transformed predictor variables and including female ID and protocol number as random variables $(n=528)$

\begin{tabular}{|c|c|c|c|}
\hline Predictor variable & Estimate $\pm S E$ & z-value & p-value \\
\hline Intercept & $1.35 \pm 0.19$ & 7.284 & $<0.001$ \\
\hline Standardized rank ${ }^{a}$ & $-0.39 \pm 0.12$ & -3.11 & 0.002 \\
\hline Patch size (DBH) & $-0.13 \pm 0.21$ & -0.61 & 0.542 \\
\hline Nutritional value food items (kJ/min feeding) & $0.17 \pm 0.17$ & 0.99 & 0.324 \\
\hline Total energy in patch (crown energy) & $0.47 \pm 0.21$ & 2.21 & 0.027 \\
\hline Standardized rate of aggression ${ }^{\mathrm{b}}$ & $-0.41 \pm 0.21$ & -1.94 & 0.052 \\
\hline \multicolumn{4}{|c|}{$\begin{array}{l}{ }^{a} \text { Ranks for both data collection periods are standardised to range from } 1 \text { (lowest ranking) to } 2 \text { (highest ranking) } \\
{ }^{b} \text { number of aggressive interactions per focal tree observation corrected for the number of individuals (adults and } \\
\text { subadults) in the tree and the duration of the observation (number of aggressive interactions/ (mean number of }\end{array}$} \\
\hline
\end{tabular}


Table 4 The influence of rank distance and strength of social bonds (CSI scores) between females on the frequency with which two females in a dyad co-feed in a patch and the mean size of the groups they feed in together. Results of two LMM's with z-transformed predictor variables including the ID's of both females in a dyad and observation period as random variables ( $n=171$ dyads for both)

\begin{tabular}{llccc}
\hline Response variable & Predictor variable & Estimate \pm SE & t-value & $p$-value \\
\hline Co-feeding frequency & Intercept & $1.00 \pm 0.05$ & 20.11 & $<0.001$ \\
& Rank-distance & $-0.06 \pm 0.02$ & -2.93 & 0.004 \\
Mean number of adults in patch & CSI & $0.05 \pm 0.02$ & 2.32 & 0.027 \\
& Intercept & $6.61 \pm 0.15$ & 45.09 & $<0.001$ \\
& Rank-distance & $0.06 \pm 0.05$ & 1.12 & 0.265 \\
& CSI & $-0.12 \pm 0.05$ & -2.33 & 0.021 \\
\hline
\end{tabular}

\section{Discussion}

The results of this study suggest that potential for contest competition exists in the study population and that aggression in food patches is affected by both social and ecological variables. More aggression was observed when more individuals fed together in a patch. This is likely due to an increased opportunity for aggression to occur and has also been observed in other primate species (Saito 1996; Vogel and Janson 2007). Among ecological variables, patch size was the strongest predictor of aggression rates. The frequency of aggression decreased with food patch size indicating that, in this case, patch size is a measure of the opportunity costs of aggression rather than of resource value. In larger patches, more feeding sites are available and therefore it may be less costly to avoid aggression and find another feeding site than to compete over the original site (Sterck and Steenbeek 1997; Vogel and Janson 2007; Hanya 2009). It seems unlikely that contest competition is completely absent in large patches as the study group usually fed in small to medium sized trees (2-69 cm DBH: $79.5 \%$ of focal tree observations) and even large trees ( $\geq 70 \mathrm{~cm}$ DBH: $20.5 \%$ of focal tree observations) did not contain the entire group. Interestingly, the effect of patch size on aggression rates exists independently of the impact of feeding group size even though feeding group size generally increases with patch size. 
The availability of alternative feeding sites within food patches appears to be a more important determinant of aggression than the availability of alternative resources outside patches, possibly because it is easier for the monkeys to assess the availability of alternative feeding opportunities inside patches. It is also possible that we did not fully capture the actual availability of alternative resources as it was calculated based on information from botanical plots and not measured directly around focal trees as suggested by Vogel and Janson (2007). Unfortunately this type of direct measurement was not feasible in our case and will not be feasible in many situations. However, other studies, including one using a more direct measure of alternative resource availability, also found no effect of alternative resources on aggression rates or found that it strongly depended on the scale at which the alternative resources were measured (Vogel and Janson 2007; Hanya 2009; Vogel and Janson 2011). This does not mean that the availability of alternative resources outside feeding patches is not important as it may have an indirect effect on the frequency of aggression by influencing feeding group size (Vogel 2004; Hanya 2009). Contrary to the predictions of socio-ecological theory and findings in several other species (Barton 1993; Saito 1996; Sterck and Steenbeek 1997; Su and Birky 2007), the frequency of aggression in food patches was not affected by ecological variables representing resource value. As similar pattern was observed in white-faced capuchin monkeys (Vogel and Janson 2007) and it appears that in these cases the benefits of avoiding aggression are a more important determinant of aggression than resource value.

As predicted, cheek pouch use increased with decreasing dominance rank, indicating that lower ranking females use their cheek pouches more than higher ranking females. Cheek pouches may help low ranking females to reduce the negative impact of food related aggression by enabling them to harvest food quickly and move to a safer location within or outside the food patch (Lambert and Whitham 2001; Lambert 2005). The relationship between rank and cheek pouch volume did not become more or less pronounced depending on ecological patch characteristics or rates of aggression in food patches. It seems that low ranking females do not increase their cheek pouch use further in situations with a higher aggression risk, possibly because cheek pouch volume can only increase to a certain extent.

All females increased cheek pouch use with increasing crown energy which could be due to the fact that trees with a high crown energy usually contain a high number of food items. One of the advantages of cheek pouches is that it allows individuals to harvest large amounts of food more efficiently because it enables them to harvest food items faster than they can be ingested (Murray 1975; Vander Wall et al. 1998; Lambert 2005). Female cheek pouch use did not change depending on patch size although it was predicted to increase in situations where contest competition is more prevalent. A possible explanation for this is that in certain situations other functions of cheek pouch 
use, such as predator avoidance, may be more important and thereby mask the effect of competition avoidance (Smith et al. 2008).

In addition to using alternative feeding sites within food patches and storing food in cheek pouches, females may also be able to avoid aggression by feeding with individuals they share a strong social bond with. Co-feeding frequencies increased while the mean size of feeding parties a dyad fed in together decreased with the strength of the social bond between two females. This is similar to what has been found in baboons, where females shared food patches more frequently with individuals they had a strong grooming relationship with (King et al. 2011). We have previously shown that in our study population, grooming given is not interchanged for reduced aggression during feeding (Macdonald et al. 2013), contrary to what has been observed in other species (Mitani 2006; Ventura et al. 2006; Carne et al. 2011; Tiddi et al. 2011). Instead of being directly interchanged for other commodities, grooming seems to strengthen the social bond between two females which increases tolerance in a feeding context irrespective of inequalities in grooming exchanges. Benefits of this increased tolerance can include a lower risk of aggression and injury, and less damage to social relationships if aggression does occur. All of these factors are expected to reduce levels of stress (Aureli et al. 1989; Aureli et al. 2002). The finding that more closely bonded dyads feeding together in smaller parties may be related to the fact that smaller parties generally feed in smaller patches where the risk of aggression is higher. Females may try to avoid conflicts in these high risk situations by feeding with individuals that are more likely to tolerate them.

Since data on genetic relatedness are not available for the study group we cannot exclude the possibility that social bonds mainly reflect kinship and that females co-feed with closely bonded individuals because it offers inclusive fitness benefits. However, other studies have found that while grooming bonds affected patterns of co-feeding, genetic relatedness did not, or that grooming affected feeding tolerance independent of kinship (Ventura et al. 2006; King et al. 2011). This makes it plausible that females do not only form strong bonds with kin, that close kin are not always closely bonded, and therefore the benefits of feeding with closely bonded individuals may not be purely based on inclusive fitness. In line with the predictions we also found that females co-feed more frequently with individuals that are close to them in rank, independent of the effect of social bonds. This could reflect females trying to avoid individuals that rank far above them and are, therefore, more likely to show aggression towards them. This would result in females generally feeding with closely ranked individuals, a pattern which is also observed in other species (de Waal 1991; Saito 1996). 
In conclusion, our study shows that in this group of Assamese macaques food patches are being depleted and, therefore, there is a potential for contest competition to occur. The frequency of aggression in food patches is predicted by feeding group size, which affects the opportunity for aggression to occur, and patch size, which affects the opportunity costs of aggression, but not by ecological variables representing resource value. Females appear to try to avoid food related conflicts by using alternative feeding sites within food patches when available, using their cheek pouches, and by feeding with females they have a strong social bond with or that are close to them in rank. This could help explain why levels of aggression in the study group are relatively low (Macdonald et al. 2013) when compared to other cercopithecine species (Wheeler et al. 2013) and why rank does not appear to affect female energy intake (Heesen et al. 2013). The avoidance of open conflict may be able to explain other cases where empirical data do not fit the predictions of the socio-ecological model and should be considered when investigating the relationships between food characteristics, aggression, dominance structure and the fitness benefits of rank (Koenig and Borries 2009; Schülke and Ostner 2012). Our results also inform the debate about the mechanisms generating fitness benefits from strong social bonds (Alberts 2010; Seyfarth and Cheney 2012) by suggesting that by increasing feeding tolerance, social bonds may enhance resource acquisition in situations of contest competition, reduce the risk of injuries and lower levels of agonism related stress. How the benefits of feeding with closely bonded individuals vary with levels of contest competition still requires investigation.

\section{Acknowledgements}

We thank the National Research Council of Thailand (NRCT) and the Department of National Parks, Wildlife and Plant Conservation (DNP) for permission (No. 0004.3/3618; 0002.3/2647) to conduct this study. We are grateful to J. Prabnasuk, K. Nitaya, M. Kumsuk, and K. Kreetiyutanont (Phu Khieo Wildlife Sanctuary) for their cooperation and permission to carry out this research. We thank A. Koenig and C. Borries (Stony Brook University), who developed the field site at Huai Mai Sot Yai. We are very thankful to N. Juntuch, N. Ponganan, D. Bootros, S. Jomhlotwong, T. Kilawit, T. Wisate, P. Saisawatdikul and especially M. Swagemakers for their help in the field. We are also very grateful to W. Nuagchiy and A. Chunchaen for their help with data collection. We thank N. Bhumpakphan, W. Eiadthong (Kasetsart University), and W. Brockelman (Mahidol University) for their support and cooperation. Furthermore we would like to thank two anonymous reviewers for helpful comments on an earlier draft of the manuscript. This work was supported by the Max Planck Society and the University of Göttingen through funding from the German Initiative of Excellence. 


\section{Chapter 3}

\section{Conflict of interest}

The authors declare that they have no conflict of interest.

\section{Ethical standards}

Approval and permission to conduct research was granted by the authorities of Thailand (permit no. 0004.3/3618 and 0002.3/2647), and all research was undertaken in strict accordance with the laws set forth by the National Research Council of Thailand and the regulations of the Department of National Parks, Wildlife and Plant Conservation, Bangkok, as well as the guidelines of the involved institutes. 


\section{Chapter 4}

\section{Ecological and social determinants of group cohesiveness and within-group spatial position in wild Assamese macaques}

Marlies Heesen ${ }^{1}$, Sally Macdonald ${ }^{1}$, Julia Ostner ${ }^{1}$, Oliver Schülke ${ }^{2}$

${ }^{1}$ Primate Social Evolution Group, Courant Research Centre Evolution of Social Behaviour, Georg-August University Göttingen, Kellnerweg 6, 37077, Germany

${ }^{2}$ Courant Research Centre Evolution of Social Behaviour, Georg-August University Göttingen, Kellnerweg 6, 37077, Göttingen, Germany

Ethology (under review) 


\begin{abstract}
Individual spatial positioning plays an important role in mediating the costs and benefits of group living, and as such, shapes different aspects of animal social systems including group structure and cohesiveness. Here, we aim to quantify variation in individual spacing behaviour and its underlying causes in a group of wild Assamese macaques (Macaca assamensis) in north-eastern Thailand which experiences both predation pressure and within-group feeding competition. Data on individual spatial positions were collected during group scans using GPS devices and results suggest that both group cohesiveness and individual spatial positions within a group can be adjusted to mediate the costs and benefits of group living. Individuals had greater nearest neighbour distances and lower numbers of close neighbours when the group was feeding, compared to when main group activity was resting/social or moving. This is likely due to the high costs of proximity associated with feeding competition. Immature individuals and females with young infants which are more vulnerable to predation were located closer to the centre of the group than both adult males and females without infants. This indicates the importance of predation risk in driving individual spatial position. Among adult females, higher ranking individuals occupied more central positions within the group while lower ranking females were more peripheral. It appears that low ranking females trade reduced feeding interference and improved feeding success for increased predation risk. This could help explain why females in the study population do not display a rank related skew in energy intake.
\end{abstract}

Keywords: group spread, inter-individual spacing, predation, feeding competition, spatial structure, dominance rank 


\section{Introduction}

Individual spatial choice plays an important role in mediating the costs and benefits of group living, and as such, shapes different aspects of animal social systems including group structure and cohesiveness (Wrangham 1980; Dunbar 1988; van Schaik 1989; Krause and Ruxton 2002; Hirsch 2007). Reduced predation risk is considered to be one of the major benefits of group living as larger groups benefit from improved predator detection (Kenward 1978), reduced per capita risk of capture (dilution effect: Hamilton 1971), and communal defence against predators (Kenward 1978; van Schaik 1989; Sterck et al. 1997). In addition to reduced predation risk, group living may increase the likelihood of finding food (Ward and Zahavi 1973) and the ability to defend clumped resources (Bertram 1978; Wrangham 1980). At the same time, there are major costs associated with group living, the most widely acknowledged one of which is intragroup feeding competition (Janson 1988a; van Schaik and van Noordwijk 1988; Isbell 1991) which can reduce individual feeding success as a result of both contest (Nicholson 1954; Janson 1985; Janson 1988b; van Schaik 1989) and scramble competition (van Schaik and van Noordwijk 1988; Chapman et al. 1995). Individuals therefore face a trade-off between the costs and benefits of group living. In addition to changing group size, individuals can balance these costs and benefits by adjusting inter-individual spacing and thereby the spatial cohesiveness of the group (Krause and Ruxton 2002; Aureli et al. 2008). As a result, group cohesion is expected to vary both within and between species, depending on factors such as predation risk, the density and distribution of food resources, feeding competition patterns and activity (Wrangham 1980; Isbell 1991; Sogard and Olla 1997). This study investigates variation in individual spacing behaviour and its underlying causes in a group of wild Assamese macaques (Macaca assamensis) in north-eastern Thailand, addressing both group cohesion and individual spatial positioning within the group.

Groups tend to become more cohesive with increasing predation risk as the presence of many close neighbours decreases the chance of being attacked (Chivers et al. 1995; Sterck et al. 1997). At the same time, smaller inter-individual distances are likely to increase feeding interference and foraging animals are therefore likely to space out in an attempt to reduce feeding competition (van Schaik and van Noordwijk 1988; Thouless 1990; Sugiura et al. 2011; Nishikawa et al. 2014). With regard to resource characteristics, groups are predicted to become less cohesive when food resources are scarce because feeding competition intensifies under these conditions which will increase the costs of proximity (Janson 1988a; Schreier and Swedell 2012). Additionally, animals are predicted to adjust their inter-individual distances according to the spatial distribution of their food resources. When food is more clumped, groups are predicted to be more cohesive whereas inter-individual distances will be greater when food is more dispersed (Isbell and Enstam 2002; Wright and Gompper 2005; Hirsch 2007; Sugiura et al. 2011; Bryer et al. 2013). While individuals are predicted to spread out when 
feeding, inter-individual distances are expected to be smaller when individuals are resting or grooming. Travelling can either lead to an increase in cohesion, as it can be considered a risky activity in terms of separation from group members, or a decrease in cohesion as a result of fast movement (Boinski 1987; Cowlishaw 1998; Sugiura et al. 2011; Nishikawa et al. 2014).

In addition to adjusting their distance to group members, individuals can attempt to balance the costs and benefits of group living by altering their spatial position within a group as the relative costs and benefits associated with these positions may differ (Krause and Ruxton 2002). For example, spatial positions can influence individuals' exposure to predators (Hamilton 1971; Tinbergen et al. 1976), access to food (Robinson 1981), and patterns of social interaction with other group members (Baldwin and Baldwin 1972). The major theory used to predict the influence of within-group spatial position on predation risk is the "selfish herd" effect (Hamilton 1971). Its basic premise is that the presence of neighbours reduces an individual's "domain of danger" (the area around an individual where a predator would be closer to the focal prey than to any other individual) and thereby its predation risk (Hamilton 1971). As individuals at the periphery of a group generally have fewer neighbours they experience a higher predation risk than central individuals. Additionally, individuals on the periphery will be encountered first by most predators, making them more likely to be the object of an attack (Vine 1971). This "marginal predation effect" is hypothesized to be the main reason individuals benefit from occupying central spatial positions within groups (Hamilton 1971; Vine 1971) and both theoretical and empirical studies have found increased vigilance, higher per capita attack rates and increased mortality in peripheral compared to central animals (Jennings and Evans 1980; Janson 1990a; Krause 1994; Viscido and Wethey 2002; James et al. 2004; Hirsch and Morrell 2011).

While individuals in central spatial positions may experience a lower predation risk, the higher density of individuals in the centre may increase feeding interference and therefore reduce food intake in central individuals (Robinson 1981; Janson 1990b; Krause 1994; Di Bitetti and Janson 2001; Krause and Ruxton 2002). Alternatively, especially when food sources are monopolisable and groups experience within-group contest competition, central individuals may be able to occupy the best food sources, leading to a higher food intake in central individuals (Robinson 1981; van Schaik and van Noordwijk 1986; van Schaik and van Noordwijk 1988; Janson 1990a; Barton 1993; Grant et al. 2002). Due to the varying costs and benefits of different spatial positions, animals are predicted to engage in risksensitive foraging, meaning that they have to balance a trade-off between feeding and avoiding danger (Lima and Dill 1990; Miller 2002). The outcome of this trade-off is affected by factors such as resource availability, predation risk and an individual's hunger state (Milinski and Heller 1978; Heller and Milinski 1979; Werner et al. 1983; Milinski 1984). For example, individuals that are more vulnerable to predation such as juveniles or females with infants are often found closer to the centre 
of the group where they are safer from predation but may experience lower feeding rates (Rhine et al. 1980; Busse 1984; Collins 1984).

Differences in spatial position between individuals are usually not only determined by the trade-off between predation costs and feeding benefits but also by social factors such as dominance or age. High ranking individuals may use their rank to gain access to and actively exclude lower ranking from preferred positions or high ranking individuals may use preferred spatial positions and low ranking individuals avoid competition with dominants by using less preferred positions (Hall and Fedigan 1997; Hirsch 2011). Both mechanisms are predicted to lead to high ranking individuals occupying central positions which are associated with a lower predation risk while low ranking individuals occupy more risky peripheral positions. This correlation between dominance rank or size and spatial position has been observed in a wide range taxa, including mammals (van Schaik and van Noordwijk 1986; Janson 1990b; Ron et al. 1996; Hall and Fedigan 1997; Hirsch 2011), birds, fish (Krause 1994) and spiders (Rayor and Uetz 1990).

This study aims to quantify variation in individual spacing behaviour and its underlying causes in a group of wild Assamese macaques in north-eastern Thailand. Several predator species are present in the home range of the study group, including leopards (Pantera pardus), clouded leopards (Neofelis nebulosa) and Asian golden cats (Catopuma temminickii) (Grassman et al. 2005). These predators have been observed in close vicinity of the study group and there are cases of suspected predation (Schülke and Ostner, unpublished data). Evidence of arboreal primate remains has been found in the scats of clouded leopards and Asian golden cats in the study area (Grassman et al. 2005). Assamese macaques are highly frugivorous and females exhibit contest competition for food resources (Heesen et al. 2013; Heesen et al. in revision), indicating that individuals will have to balance the costs associated with both predation risk and feeding competition and may adjust their spatial position to do so. While the determinants of group cohesiveness have been frequently studied in primate species with high fission-fusion dynamics it has rarely been quantified in species, like Assamese macaques, which have relatively stable group membership and do not split up into subunits (Robinson 1981; Boinski 1987; Sugiura et al. 2011).

First, we describe the variation in spatial cohesiveness in the study population and examine factors that may influence this variability. We explore the influence of group activity and food resource characteristics (food tree density and size) on group cohesiveness, measured as mean nearest neighbour distance and mean number of neighbours within 5 meters. We predict that the group will be least cohesive when individuals are feeding and more cohesive when the group is resting, engaging in social behaviour or moving. Group cohesiveness is also predicted to increase with increasing food 
tree density and size. Next, we investigate how an individual's distance from the centre of the group is influenced by its age-sex class, predicting that juveniles will be more central due to their greater vulnerability to predation. Then, we focus in on females specifically since access to food has a greater impact on their fitness and they are therefore predicted to be more strongly affected by feeding competition than males (Trivers 1972). We examine how dominance rank and reproductive state affect a female's distance from the centre of the group and how activity and food tree size and density affect the relationship between female rank and spatial position. Low ranking females are predicted to occupy more peripheral positions where feeding interference is lower but predation risk may be higher, a relationship which is expected to be stronger in situations with more intense feeding competition. We also predict that lactating females are closer to the centre of the group as they may be more vulnerable to predation.

\section{Methods}

\section{Study site and subjects}

This study was conducted at Phu Khieo Wildlife Sanctuary in north-eastern Thailand $\left(16^{\circ} 5^{\prime}-35^{\prime} \mathrm{N}\right.$, $101^{\circ} 20^{\prime}-55^{\prime} \mathrm{E}$ ). The sanctuary covers an area of $1573 \mathrm{~km}^{2}$ at elevations of $300-1300 \mathrm{~m}$ above sea level, is part of the ca. $6500 \mathrm{~km}^{2}$ contiguous Western Isaan Forest Complex (Koenig et al. 2004) and is home to a diverse animal community including Asian elephants, Asian forest bisons, clouded leopards, Asian golden cats, raptors, pythons, and 7 diurnal primate species (Kumsuk et al. 1999; Borries et al. 2002; Grassman et al. 2005). The study site “Huai Mai Sot Yai" $\left(16^{\circ} 27^{\prime} \mathrm{N}, 101^{\circ} 38^{\prime} \mathrm{E}, 600-800 \mathrm{~m}\right.$ a.s.l.) consists mostly of dry evergreen forest with bamboo stands (Borries et al. 2002). The annual rainfall averages 1,444 $\mathrm{mm}$ with a distinct dry season from November through March and the mean annual temperature is $21.3^{\circ} \mathrm{C}$ (Borries et al. 2011). We collected data from one group of fully habituated wild Assamese macaques that were individually recognised. Group size varied from 45 to 49 individuals (910 adult males, 15 adult females and 20-25 immatures) due to births and one disappearance. The study site is characterised by dense vegetation and the study group spends about $60 \%$ of their activity time in the middle and upper strata of the forest (Schülke et al. 2011). The study population breeds seasonally with a mating season between October and January and a birth season between April and July (Fürtbauer et al. 2010).

\section{Behavioural sampling}


Data for this study were collected between May 2010 and April 2011. We collected data on social and feeding behaviour by recording 30 minute focal animal observations of all adult females, resulting in a total of $1,340 \mathrm{~h}$ of focal animal data with an average of $91 \pm 4.6 \mathrm{~h}$ per female. An effort was made to distribute these observations evenly across both time of day and individuals. We used continuous sampling to record all affiliative, aggressive, submissive, sexual, solitary and infant directed behaviours, as well as facial displays and vocalizations shown by or directed at the focal female (Altmann 1974). In addition, we used instantaneous sampling (Martin and Bateson 2007) to collect records of positional behaviour and activity at 1-minute intervals.

\section{Spatial cohesiveness}

Data on individual spatial positions were collected by conducting group scans ("scan sampling", Martin and Bateson 2007). We attempted to conduct one group scan per day evenly spread out across different time blocks. Scans were not conducted when the majority of the group was travelling fast as it was not possible to record the animals' positions accurately under these conditions. Group scans were conducted by at least 2 and up to 5 observers simultaneously and had a total duration of 15 minutes. During this time the observers walked in opposite directions through the group recording the geographical coordinates of the location of each monkey they encountered by taking a waypoint with a handheld GPS (Garmin GPSmap 60CSx), standing either directly underneath the individual (Assamese macaques spend almost $90 \%$ of their time off the ground: Schülke et al. 2011) or as closely to the individual as possible if it was on the ground. In addition to the location, the identity of the individual, its activity (resting, feeding, social or travelling) and its vertical distance from the ground were recorded. After a waypoint was taken for a particular individual, the area was scanned for any monkeys present within 10 meters of this individual in any direction. Such small inter-individual distances were difficult to record by GPS because the average measurement error provided by the GPS was $7.4 \mathrm{~m}$ (based on a test series of 4257 points: Schülke et al. 2014). Instead, we recorded the direction (compass bearing) and horizontal distance of each individual from the location of the individual the waypoint was taken for, as well as its vertical distance from the ground (distances were estimated visually after training of all observers). Based on this information the coordinates of these individuals were calculated. Coordinates were recorded in MGRS. In case several observers recorded a location for same individual, only the first recorded location was used.

Based on the $x, y$ and $z$ coordinates of each individual the 3-dimensional inter-individual distances (IID's) between all individuals in a scan were calculated. Additionally we calculated each individual's horizontal distance from the centre of the group. For this, the coordinates were converted to 
rectangular coordinates using the Universal Traverse Mercator (UTM) projection. The centre of the group was determined for each group scan by calculating the mean of the $\mathrm{x}$ and $\mathrm{y}$ coordinates of all individuals included in the scan.

\section{Density and size of food trees}

For each group scan we determined what plant food species the monkeys fed on during the day the group scan was recorded by examining the feeding data recorded during focal animal sampling. For some scans no plant feeding data were available either because the monkeys fed on animal matter only or because no feeding behaviour was observed during focal animal sampling that day. For each group scan feeding data were available for we calculated the mean density and DBH (diameter at breast height) of the plant food species the monkeys fed on that day. We used DBH as an indicator of the size of food patches as tree crown dimensions are generally well correlated with DBH (Hemery et al. 2005; Lockhart et al. 2005). Calculations were based on 13 1-ha botanical plots situated throughout the home range of the study group. Within these plots the identity and DBH of all 7498 trees $\geq 10 \mathrm{~cm}$ DBH and climbers $\geq 5 \mathrm{~cm}$ DBH has been recorded (for details see: Heesen et al. 2013).

\section{Dominance hierarchy}

A female dominance hierarchy was established using only decided, dyadic agonistic interactions (i.e. bouts of aggression with only aggression on one side and submission on the other or spontaneous signals of submission) recorded during both continuous focal observations and ad libitum sampling. A winner/loser matrix of these interactions was reordered using the I\&SI method as implemented in MATMAN $^{\text {TM }}$ 1.1.4 (Noldus 2003) to give the final female rank order. The female dominance hierarchy was significantly linear, with a high directional consistency index (393 interactions: $h^{\prime}=0.83, D C l=0.96$, $12.4 \%$ unknown relationships, $p<0.001$; for details see: Macdonald et al. 2013).

\section{Statistical analysis}

For the analyses only group scans which included at least 50 percent of the group ( 25 individuals) were used. The remaining 84 group scans ( $7 \pm 3$ scans per month) included on average two-thirds of both all individuals and all adults, yielding at total of 41,130 inter-individual distances (9222 of these IID's are between adults). As a measure of group spread we used the maximum distance recorded between two adult individuals in a scan. Additionally, we calculated both the mean nearest neighbour distance 
and the mean number of neighbours within 5 meters for each group scan as measures of cohesiveness. All these measures are based on adult individuals only as immature individuals are thought to play a minor role in both predator defence and feeding competition (Cowlishaw 1994; Hirsch 2007). Individual activity was divided into three categories: resting/social, feeding and moving (moving does not included high speed travel as groups scans were not conducted when the group was travelling). For each scan, the overall activity of the group was determined as the activity of the majority of the individuals and divided into the same three categories (resting/social, feeding and moving).

In order to assess which factors influenced group cohesiveness we ran a multiple regression with the mean nearest neighbour distance across all adult individuals in a scan as response variable. Predictor variables were group activity, mean food tree density and mean food tree size (DBH). Additionally we ran a negative binomial regression analysis with the mean number of neighbours within 5 meters recorded per group scan as response variable. This type of analysis was used as the number of neighbours is an over-dispersed count variable. Response variables were the same as in the previous analysis. To investigate whether individual distance from the centre of the group depended on the age-sex class of the individual and individual activity, we ran a linear mixed model (LMM) with distance from the centre of the group in meters as response variable. Predictor variables were age-sex class (adult male, adult female, immature) and maximum IID, which was included to control for the effect of group spread on individual distance from the centre of the group. The immature age category included only individuals $\geq 6$ months. Young infants ( $<6$ months) are not included here as their location will often depend entirely on that of their mothers. As random factors we included individual identity and group scan number.

In order to assess what determines the spatial position of adult females in particular we ran a LMM with female distance from the centre of the group in meters as response variable. As predictor variables we used female dominance rank and female lactation status (yes /no, yes includes the first 6 months of lactation). We included interactions between rank and activity, rank and food tree density, rank and food tree size and rank and lactation status as predictors as these variables may affect the relationship between rank and distance from the centre of the group. Individual identity and group scan number were included as random factors. Additionally, we tested the relationship between mean distance from the centre of the group and mean number of neighbours within 5 meters as well as the relationship between rank and rate of aggression received during focal observations for all adult females using Spearman's correlation. 
All statistical tests were conducted in $R$ ( $R$, version 2.14.2; $R$ Development Core Team 2012). LMM's were fitted using the function Imer of the R-package Ime4 (Bates et al. 2012). For both LMM's we first determined the significance of the full model as compared to the corresponding null model (including the intercept and random effects) using a likelihood ratio test (Burnham and Anderson 2002). P values of main effects were considered only if these effects were not included in a significant interaction. Likelihood ratio tests were calculated using the $R$ function anova. $P$ values for the individual effects were based on Markov Chain Monte Carlo sampling (Baayen 2008) and derived using the functions pvals.fnc and aovlmer.fnc of the $R$ package languageR (Baayen 2011). All appropriate assumptions (homogeneity of error variances, multicollinearity, influential cases) were tested for and met in each analysis.

\section{Results}

\section{Group cohesiveness}

During the study period, mean group spread (maximum distance between two adult individuals in a scan) was $107.7 \pm 39.4 \mathrm{~m}$ (mean $\pm S \mathrm{D}, \mathrm{n}=84$ scans), ranging from $48.1 \mathrm{~m}$ to $214.3 \mathrm{~m}$. The mean nearest neighbour distance across all adult individuals in a scan was $9.8 \pm 3.6 \mathrm{~m}$ (mean $\pm \mathrm{SD}, \mathrm{n}=84$ scans), ranging from $3.1 \mathrm{~m}$ to $20.3 \mathrm{~m}$ and the mean number of neighbours within $5 \mathrm{~m}$ was $0.5 \pm 0.4$, ranging from 0 to 1.9 (mean $\pm S D, n=84$ scans). Mean nearest neighbour distance was greater when the group was feeding compared to when the group was resting/social or moving while there was no significant difference between resting/social and moving (Fig. 1). Mean nearest neighbour distance was not influenced by mean food tree size or density (Table 1). The mean number of adult neighbours within 5 meters was smaller when the main group activity was feeding than when the group was resting/social or moving (Fig. 2) while it did not differ significantly between scans where the main activity was resting/social and scans where the main activity was moving. Mean number of neighbours within 5 meters was also not significantly influenced by mean food tree size or density (Table 2). 


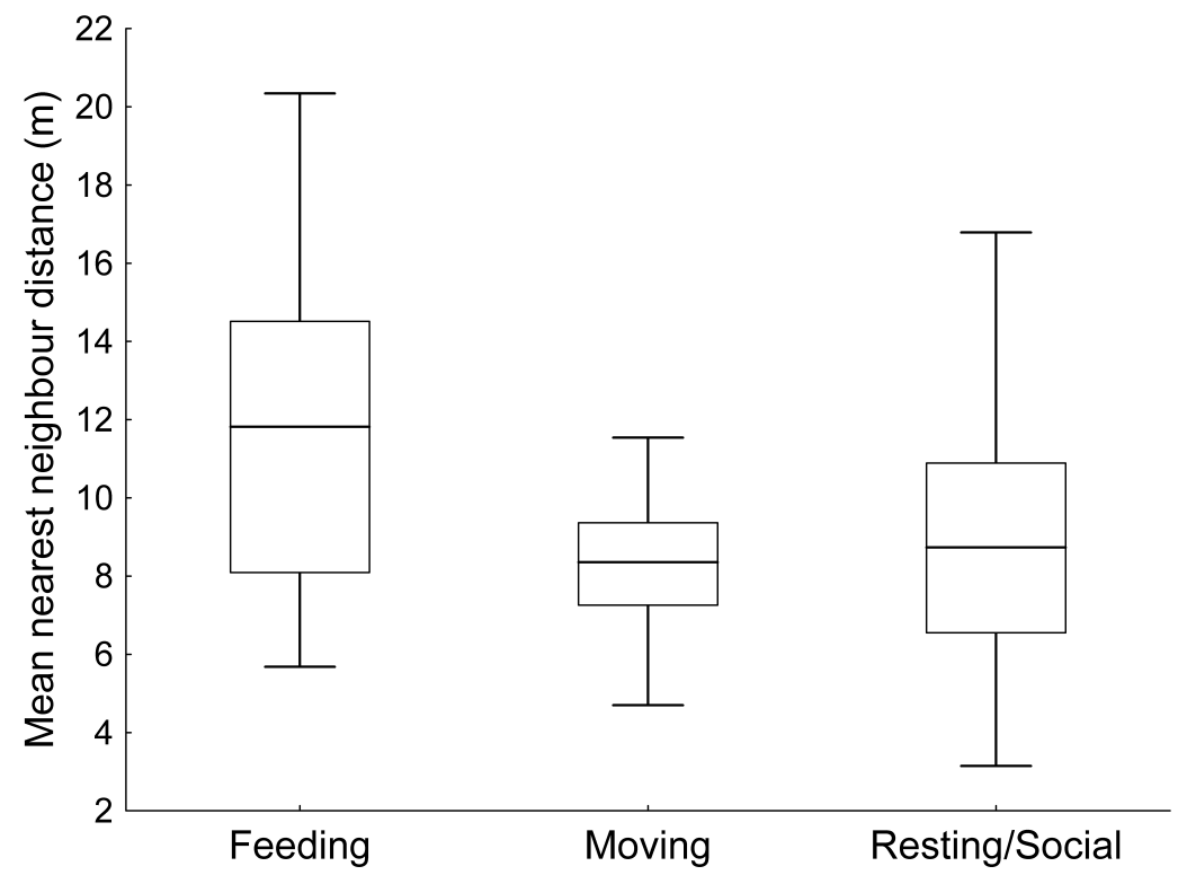

Fig. 1 Mean nearest neighbour distance in meters across all adult individuals in scans where the main group activity was either, feeding, moving or resting/social. Distance during feeding was significantly greater compared to when the group was moving $(p=0.016)$ or resting/social $(p=0.047), n=71$

Table 1. The influence of group activity, mean food tree size and mean food tree density on mean nearest neighbour distance across all adults in a scan. Results of a multiple regression with z-transformed continuous predictor variables $(n=71)$.

\begin{tabular}{lccc}
\hline Predictor variable & Estimate \pm SE & t-value & $p$-value \\
\hline Intercept & $3.30 \pm 0.11$ & 29.09 & $<0.001$ \\
Rest/social vs feed & $-0.29 \pm 0.14$ & -2.03 & 0.047 \\
Moving vs feed & $-0.45 \pm 0.18$ & -2.47 & 0.016 \\
Moving vs rest/social & $-0.16 \pm 0.16$ & -0.98 & 0.332 \\
Food tree size (DBH) & $-0.06 \pm 0.06$ & -0.86 & 0.392 \\
Food tree density & $-0.11 \pm 0.06$ & -1.68 & 0.098 \\
\hline
\end{tabular}




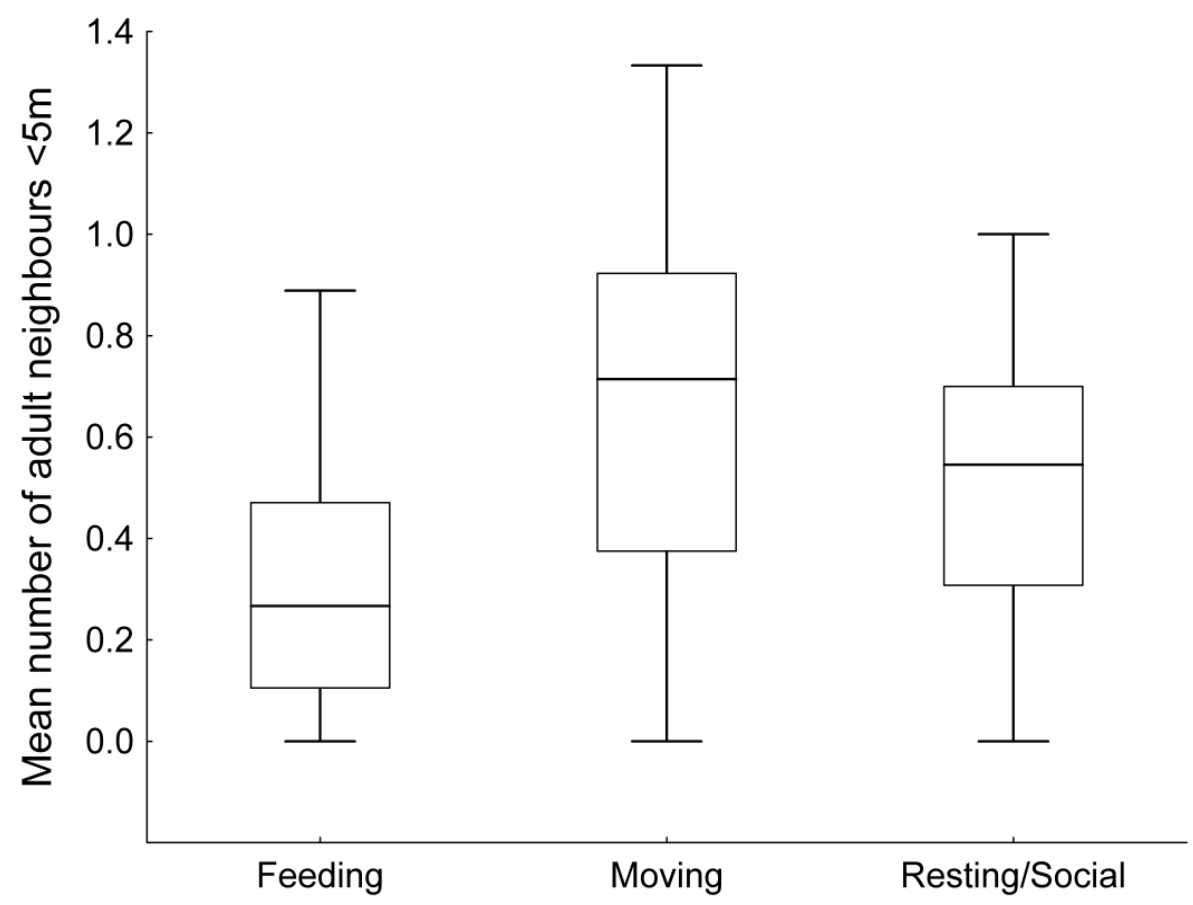

Fig. 2 Mean number of adult neighbours within 5 meters across all adults in scans where the main group activity was, feeding, moving or resting/social. The mean number of neighbours was significantly lower when the group was feeding compared to when the group was moving ( $p=0.002)$ or resting/social ( $p=0.019), n=71$

Table 2. The influence of group activity, mean food tree size and mean food tree density on the mean number of adult neighbours within 5 meters across all adult individuals in a scan. Results of a negative binomial multiple regression with $z$-transformed continuous predictor variables $(n=71)$.

\begin{tabular}{lcrr}
\hline Predictor variable & Estimate \pm SE & z-value & $p$-value \\
\hline Intercept & $-1.10 \pm 0.17$ & -6.59 & $<0.001$ \\
Rest/social vs feed & $0.48 \pm 0.20$ & 2.36 & 0.019 \\
Moving vs feed & $0.79 \pm 0.25$ & 3.16 & 0.002 \\
Moving vs rest/social & $0.31 \pm 0.21$ & 1.45 & 0.148 \\
Food tree size (DBH) & $0.02 \pm 0.09$ & 0.25 & 0.805 \\
Food tree density & $0.12 \pm 0.09$ & 1.34 & 0.180 \\
\hline
\end{tabular}




\section{Individual spatial position}

Overall, individual distance from the centre of the group differed between age-sex classes (full model: $\chi^{2}=15.29, \mathrm{df}=2, \mathrm{p}<0.001, \mathrm{n}=2479$ ). Immatures (infants $>6 \mathrm{mo}$ and juveniles; distance (mean $\pm \mathrm{SD}$ ): $29.3 \pm 18.9 \mathrm{~m}$ ) were closer to the centre of the group than both adult males (distance: $33.5 \pm 21.3 \mathrm{~m}$ ) and females (distance: $34.9 \pm 23.8 \mathrm{~m}$ ) while there was no difference between adult males and females. Adult males vs immatures: estimate $=-0.41, \mathrm{SE}=0.12, \mathrm{t}=-3.37, \mathrm{p}=0.001$; adult females vs immatures: estimate $=-0.35, \mathrm{SE}=0.10, \mathrm{t}=-3.45, \mathrm{p}=0.001$; adult males vs adult females: estimate $=0.057, \mathrm{SE}=0.13$, $t=0.44, p=0.652$.

\section{Female spatial position}

The relationship between female rank and distance from the centre of the group was not affected by activity, mean food tree density, mean food tree size or whether females were lactating or not (interaction rank and activity: likelihood ratio test comparing the full model with a model not comprising the interaction between rank and activity: $\chi^{2}=2.06, \mathrm{df}=2, \mathrm{p}=0.357$; interaction rank and food tree density: $t=0.48, p=0.654$; interaction rank and food tree size: $t=-1.05, p=0.322$; interaction rank and lactation: likelihood ratio test comparing the full model with a model not comprising the interaction between rank and lactation: $\left.\chi^{2}=0.52, \mathrm{df}=1, \mathrm{p}=0.469\right)$. Therefore, the interaction terms were removed from the model and the results discussed below refer to a model including only rank and lactation status (maximum IID was included as a control variable). Overall, rank and lactation status influenced female distance from the centre of the group (full model: $\chi^{2}=17.84, d f=2, p<0.001, n=680$ ). Female distance from the centre of the group increased with decreasing dominance rank with the highest ranking female being on average $12 \mathrm{~m}$ closer to the centre than the lowest ranking female (estimate $\pm \mathrm{SE}=0.26 \pm 0.05, \mathrm{t}=4.84, \mathrm{p}<0.001$; Fig. 3 ) and lactating females (first 6 months of lactation) were closer to the centre of the group compared to non-lactating females (estimate $\pm \mathrm{SE}=-0.33 \pm 0.13$, $t=-2.48, p=0.010$ ). The number of adult neighbours within 5 meters of an adult female decreased with increasing distance from the centre of the group (Spearman's correlation: rho=-0.69, $p=0.005, n=15$, Fig. 4). Additionally, among adult females the rate of aggression received per hour of focal observation increased with decreasing dominance rank (Spearman's correlation: rho=0.78, $p<0.001, n=15$ ). 


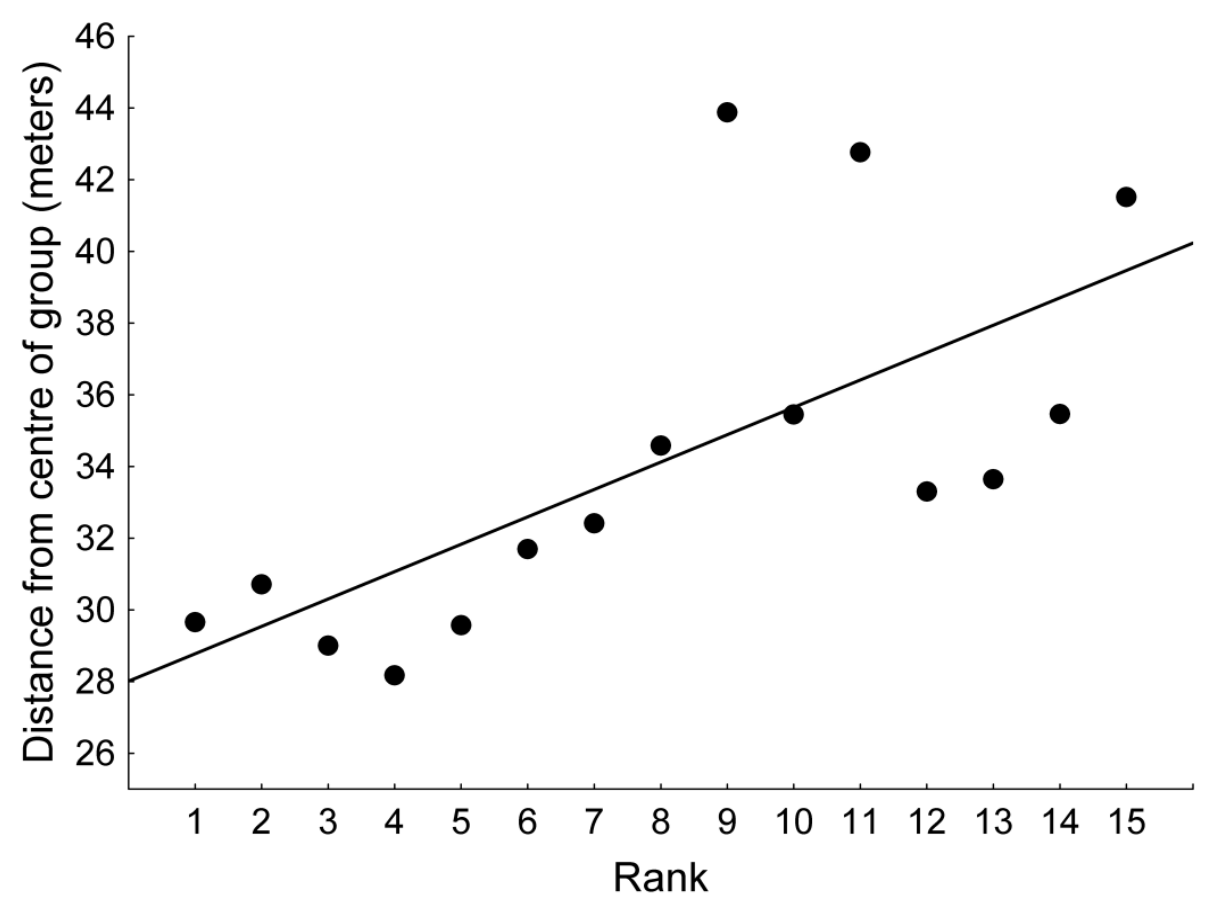

Fig. 3 Distance from the centre of the group increased with decreasing rank position (1= highest rank) in adult females (estimate $\pm S E=0.26 \pm 0.05, t=4.84, p<0.001, n=680$ ) 


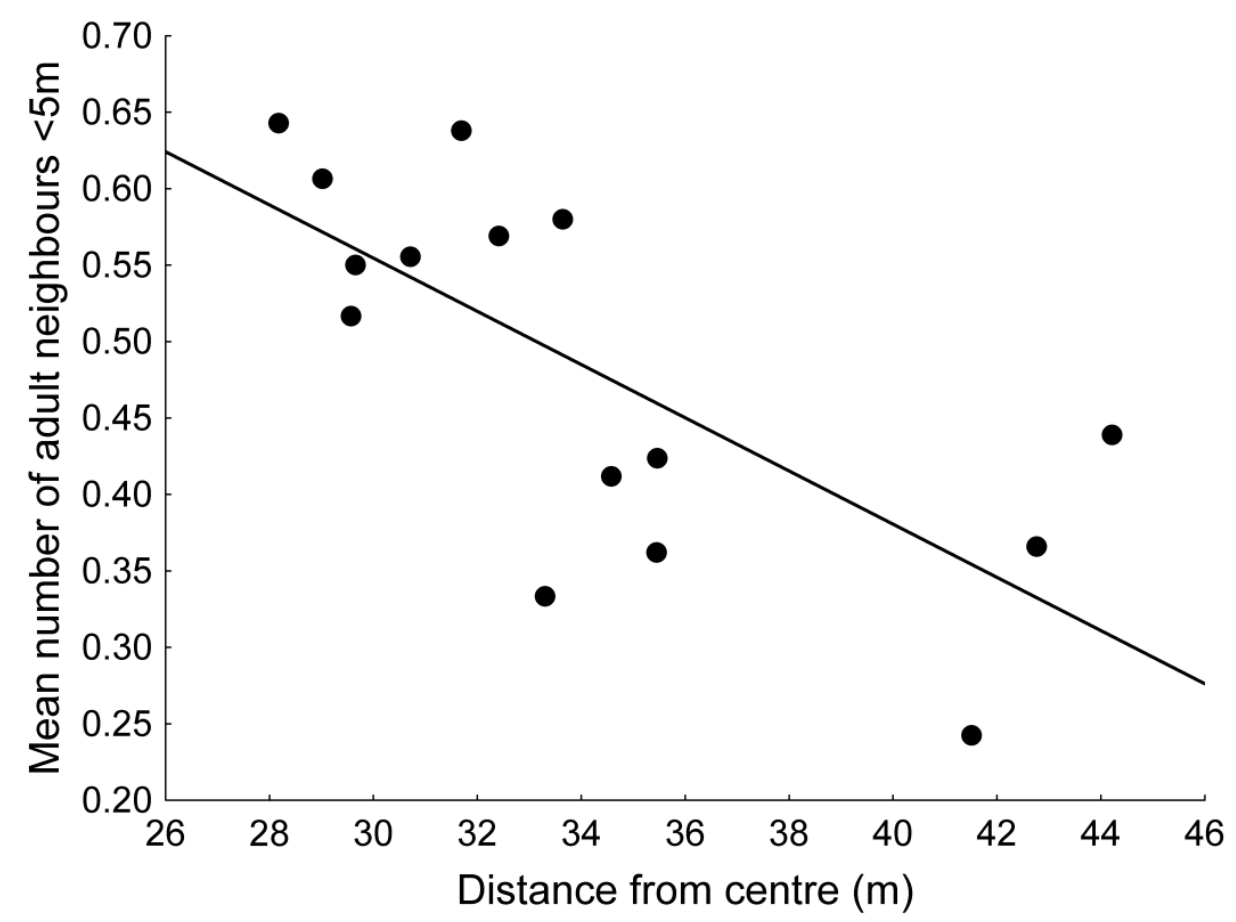

Fig. 4 The number of adult individuals within 5 meters of an adult female decreased with increasing distance from the centre of the group (Spearman's rho=-0.69, $p=0.005, n=15$ )

\section{Discussion}

The results of our study indicate that group cohesiveness can be variable over time in groups with stable membership and therefore may be adjusted flexibly to balance the costs and benefits of group living. The maximum observed group spread of 214 meters is smaller than the maximum observed for Japanese macaques (Macaca fuscata) (280 m, Kinkazan island, 31-39 individuals: Sugiura et al. 2011) and Siberut macaques (Macaca siberu) (418.5 m, 29 individuals: C. Richter, pers. comm.) living on islands without predators. This suggests that predation risk constrains the degree to which individuals can spread out in the study population. At the same time individuals do spread out over rather large distances (mean group spread: $108 \mathrm{~m}$ ) indicating an additional influence of feeding competition on inter-individual spacing.

As predicted, mean nearest neighbour distance was greater and the mean number of close neighbours was smaller when the group was feeding compared to when the overall group activity was resting and socialising or moving. This partly follows the patterns observed in other species and indicates that individuals are adjusting their inter-individual spacing to reduce feeding interference and thereby the 
costs associated with feeding competition (Sugiura et al. 2011; Nishikawa et al. 2014). It also indicates that individuals are more vulnerable to predation when they are foraging and that the benefits in terms of reduced feeding competition are greater than the costs associated with predation risk.

As social behaviour and resting often occur together and social behaviour requires close proximity between group members it is not surprising that individuals have more close neighbours while engaged in these activities compared to when they are feeding. Proximity while individuals were moving was similar to when they were resting or engaging in social behaviour. Several species actually show an increase in inter-individual distances during travelling (Cowlishaw 1999; Sugiura et al. 2011; Nishikawa et al. 2014), however, we did not collect spatial data when the group was travelling at high speed and therefore the category moving only includes low speed movement which is not expected to lead to increased distances between individuals. Another possible explanation is that moving is perceived as a risky activity, as individuals risk losing group members and may be more likely to encounter predators (Cowlishaw 1998), and individuals are therefore more likely to stay close together. During resting, socialising and moving the costs of proximity are expected to be lower than when individuals are feeding and individual spacing during these activities may therefore be driven primarily by predation risk.

Neither nearest neighbour distances nor the number of close neighbours around individuals was influenced by mean food tree size or density. One possible reason for this is that our measures of resource size and density did not capture the exact conditions the individuals were experiencing while the group scan took place. We did find a trend indicating that mean nearest neighbour distance decreased with increasing food tree density, as was predicted. When food tree density is higher it is likely that more food will be available per unit space and individuals will be able to feed more closely together without reducing each other's food intake. It is possible that this effect will become more pronounced in a larger dataset.

With regard to individual spatial positions within the group, immature individuals (older than 6 months) were found to be closer to the centre of the group than adults while there was no difference between adult males and females. The more central position of immature individuals may be due to the fact that they are more vulnerable to predation, indicating that individual spatial position is affected by predation pressure. Infants and smaller individuals are preferentially found in the centre of groups in a large number of species (Robinson 1981; Collins 1984; van Schaik and van Noordwijk 1986; Pereira 1988; van Noordwijk et al. 1993). In addition to protection from predators, a central location might provide immature individuals with other benefits such as protection from infanticidal males, an increased numbers of playmates and more learning opportunities (Hirsch 2007). The fact that adult 
males and females do not differ in their distance from the centre of the group could indicate that their nutritional requirements (Ross 1992) and predation risk are similar despite differences in body size or that other determinants of spatial position (e.g. dominance) are more important.

Among adult females, distance from the centre of the group increased with decreasing rank position, meaning that lower ranking females are more peripheral while higher ranking females hold more central positions within the group. This relationship between dominance status and spatial position has been observed in several species, including mammals, birds, fish and spiders (van Schaik and van Noordwijk 1986; Janson 1990b; Rayor and Uetz 1990; Barton 1993; Krause 1994; Ron et al. 1996; Hall and Fedigan 1997; Hirsch 2011). Central positions are often associated with increased feeding success leading to a higher food intake in high ranking compared to low ranking individuals (Robinson 1981; Janson 1990a; Grant et al. 2002). In the study group however, female dominance rank does not predict energy intake (Heesen et al. 2013). Instead, it appears that lower ranking females gain an equal energy intake to higher ranking females by foraging at more peripheral positions, thereby reducing feeding interference at the cost of increased predation risk. This is similar to the pattern observed in long-tailed macaques (Macaca fascicularis) where low ranking females use peripheral positions or positions away from the main party to avoid feeding competition the cost of increased mortality (van Noordwijk and van Schaik 1987). Although we have no data on vigilance as a measure of perceived predation risk, predation risk is predicted to be directly related to both an individual's distance from the centre of the group and the density of neighbours around it (Hamilton 1971; Vine 1971; Busse 1984). Since in the study group more peripheral individuals also had fewer neighbours we may assume these individuals experience a higher predation risk.

Spatial assortment by rank may result from active exclusion of subordinates from preferred central positions by dominant individuals (Robinson 1981; Janson 1990b; Saito 1996). Alternatively, subordinates may avoid dominant individuals located at more central positions and therefore end up at the periphery of the group. If active exclusion plays a role, individuals are expected to experience more aggression in the centre of the group than on the periphery (Hall and Fedigan 1997). Unfortunately we do not have the data to directly link female spatial position to aggression but we do know that lower ranking females are both more peripheral and receive more aggression than higher ranking females. Though we do not know whether lower ranking females receive more aggression when they are in the centre of the group it is probable that active exclusion plays a role in female spatial assortment. At the same time, the study group exhibits low overall rates of aggression and females appear to avoid food related conflicts instead of engaging in direct competition when possible (Heesen et al. in revision). This makes it likely that female spatial assortment is more strongly influenced by avoidance than by active exclusion. The relationship between female rank and distance 
from the centre of the group was not affected by activity, female lactation status, mean food tree size or mean food tree density. It is possible that changes in the intensity of feeding competition and/or predation risk take place on a very short time scale which we did not capture with our data.

Lactating females with infants younger than 7 months are situated closer to the centre of the group than females in other reproductive stages. Similar patterns where lactating females occupy more central positions or maintain a closer proximity to others have been observed in other species (Busse 1984; Cowlishaw 1999; Hirsch 2011). This could be due to an increase in the females' vulnerability to predation while carrying their infants and the vulnerability of the infants themselves. Being in the centre of the group is expected to increase the amount of feeding interference females experience which could provide an explanation for the reduced feeding time and energy intake observed in lactating females in the study population compared to females in other reproductive stages (Heesen et al. 2013). It is possible that females with young infants follow an energy saving strategy and trade safety for reduced food intake. It is not likely that this pattern drives the observed relationship between rank and spatial position as the females that had young infants during the study period occupied very different rank positions.

In summary, we found evidence that group cohesion can be flexible in species that do not form subgroups. During feeding, individuals had larger nearest neighbour distances and smaller numbers of close neighbours, indicating that the costs of gregariousness are increased during feeding and individuals adjust their inter-individual spacing to reduce the costs of feeding competition. Immature individuals who are more vulnerable to predation were closer to the centre of the group than both adult males and females, indicating the importance of predation risk in driving individual spatial position. Among adult females, distance from the centre of the group increased with decreasing rank. This spatial positioning is likely the result of both active exclusion of low ranking individuals from central locations and avoidance of high ranking individuals by lower ranking individuals. It appears that females use spatial positioning to reduce the costs of feeding competition and low ranking females trade reduced feeding interference for increased predation risk. These results could help explain the absence of a rank related skew in female energy intake in the study population (Heesen et al. 2013). Females with young infants appear to trade a reduced food intake for safer positions in the centre of the group as under these conditions the benefits associated with reduced predation risk are likely to be greater than the costs associated with increased feeding competition. These findings suggest that both group cohesiveness and individual positions within a group can be adjusted to mediate the costs and benefits of group living. The degree of spatial cohesiveness is important as it influences communication within a group, which is essential for collective decisions and group coordination (Conradt and Roper 2005; Jacobs 2010). Additionally, group cohesiveness can influence the frequency 
of social interactions within groups so that increases in group spread due increased feeding competition may result in reduced social behaviour (Alberts et al. 2005).

\section{Acknowledgements}

We thank the National Research Council of Thailand (NRCT) and the Department of National Parks, Wildlife and Plant Conservation (DNP) for permission (No. 0004.3/3618) to conduct this study. We are grateful to J. Prabnasuk, K. Nitaya, M. Kumsuk, and K. Kreetiyutanont (Phu Khieo Wildlife Sanctuary) for their cooperation and permission to carry out this research. We thank A. Koenig and C. Borries (Stony Brook University), who developed the field site at Huai Mai Sot Yai. We are very thankful to N. Juntuch, N. Ponganan, S. Jomhlotwong, T. Wisate, P. Saisawatdikul, W. Nuagchiyo and especially M. Swagemakers for their help in the field. We thank N. Bhumpakphan, W. Eiadthong (Kasetsart University), and W. Brockelman (Mahidol University) for their support and cooperation. This project was supported with funds from the Max Planck Society, the National Geographic Society, and the University of Göttingen through funding from the German Initiative of Excellence. 



\section{Chapter 5}

\section{General discussion}

The overall aim of this thesis was to broaden our understanding of the relationships between food resource characteristics, proximate mechanisms of feeding competition and female fitness. By combining ecological, spatial and behavioural data, I examined social and ecological influences on female feeding competition, linking food characteristics to aggression, energy intake and reproduction in a wild unprovisioned primate population.

In this general discussion I will first briefly summarise the main findings of my study (section 5.1). I will then discuss my findings in the context of proximate mechanisms of feeding competition and especially food related aggression (section 5.2), the role of competition reducing mechanisms (section 5.3), including the function of social bonds in feeding tolerance (section 5.4) and finally I discuss the fitness consequences of feeding competition (section 5.5) and relate my findings to what is known about social structure in female Assamese macaques (section 5.6) before providing a brief general conclusion and outline some ideas for future research (section 5.7).

\subsection{Summary of results}

In mammals, female reproduction is strongly influenced by nutritional status and females are therefore predicted compete more intensively for food resources than males (Sadleir 1969; Gilmore and Cook 1981; Lee 1987; Wade et al. 1996). In chapter 2 I therefore first characterised the diet of females in the study group and found that it largely consisted of fruit with a smaller proportion of animal matter, leaves and flowers. I then continued by showing that both female energy intake and conception rates increased with food availability, indicating that food is indeed a limiting resource for the study population and females are therefore predicted to compete for access to food resources (Koenig 2002). The influence of nutritional status on female fitness was especially apparent during the lactation period which is considered to be one of the most energetically costly parts of the reproductive cycle in female mammals (Lee 1987). I found that female Assamese macaques follow an energy conserving strategy during this period, trading-off an increase in time spent resting for reduced feeding time. Energy conservation was not sufficient though as the physical condition of lactating females was lower than that of non-lactating females. 
My findings also indicate that the degree to which females can compensate for the costs of lactation affects whether they are able to attain a high enough physical condition to be able to conceive again. Firstly, females that gave birth earlier during the birth season were more likely to conceive during the subsequent mating season than females that gave birth later in the season. Secondly, the probability a female conceived seemed to increase with increasing physical condition during the mating season. These findings combined suggest that food availability during energetically demanding periods such as peak lactation can constrain female reproduction. Though my study showed that food availability was highly variable both within and between years, the annual peak in food availability generally occurred during the peak lactation period. The fact that reproduction in Assamese macaques is strictly seasonal while at the same time the probability a female conceived appeared to be condition dependent indicates that conception is timed by both exogenous and endogenous cues. This and the fact that, unlike in strict income breeders, birth rates varied between years depending on food availability, classifies Assamese macaques as relaxed income breeders (Brockman and van Schaik 2005).

Surprisingly, despite the fact that the study population is highly frugivorous, food is a limiting resource and females exhibit strict linear dominance hierarchies (Macdonald et al. 2013), I did not find evidence for a rank related skew in energy intake or reproduction. Females also did not exhibit rank related differences in activity budgets, indicating that low ranking females are not compensating for reduced food intake rates by feeding or foraging longer. The relationships between female rank and either energy intake or activity did not change depending on overall fruit abundance or the nutritional quality, patch size or density of the most consumed food items.

While in chapter 2, resource characteristics were calculated on a monthly basis based on botanical plot data, in chapter 3 I zoomed in to the level of individual food patches to further elucidate the relationship between resource characteristics and mechanisms of feeding competition. I found that the frequency of food related aggression in feeding patches was influenced by both social and ecological factors. Aggression rates increased with increasing feeding group size and decreasing patch size while they were not affected by ecological variables representing resource value. While this indicates that females exhibit contest competition of food resources they also appeared to employ several mechanisms to avoid direct conflicts. These mechanisms included the use of alternative feeding sites within food patches, storing food in cheek pouches and co-feeding with closely bonded individuals. Conflict avoidance may be partially responsible for the absence of a rank related skew in female energy intake in the study population (chapter 2 ).

In chapter 4, I investigated how individuals adjust their inter-individual spacing to mediate the costs and benefits of gregariousness in terms of predation risk and feeding competition which are both 
likely to be strong selective pressures for the study population. Inter-individual spacing among adults was greatest when the group was feeding, which is when the costs of close proximity are thought to be highest due to feeding competition. Though greater inter-individual distances will also increase individual predation risk, the benefits of reduced feeding interference appear to be greater than the costs of increased predation risk. During resting, socialising and moving group cohesiveness was greater, indicating that individuals increase proximity to reduce predation risk when the costs of proximity are low. Immature individuals and females with young infants which are likely to be more vulnerable to predation occupied more central positions within the group which are associated with a lower predation risk. In adult females, dominance rank predicted an individual's distance from the centre of the group with higher ranking individuals occupying more central positions while lower ranking females were more peripheral. It appears that for low ranking females, the benefits of reduced feeding interference outweigh the costs associated with increased predation risk.

\subsection{Proximate mechanisms of feeding competition}

In the study population, food availability limits female reproduction which is a prerequisite for feeding competition to occur (chapter 2, Koenig 2002). The way females compete over such limiting resources is thought to be the result of different patterns of food distribution, abundance and quality (van Schaik 1989). The main components of the diet of the study population (fruit, leaves and flowers) all occur in discrete patches (trees, shrubs or lianas) which are rarely large enough to accommodate the whole group (chapter 3 ). These patches are being depleted (chapter 3 ) and an increase in feeding group size with food patch size indicates that patches are not superabundant and can be monopolised (chapter 3, Sterck 1995; Koenig et al. 1998; Schülke 2003). Many of the food items consumed by the study population have a high nutritional value though there is a great variation between different food items in the diet (chapter 2). Such limiting food sources with a high nutritional value and which occur in patches that are of intermediate size compared to group size are associated with strong within-group contest competition (van Schaik 1989; Isbell 1991; Sterck et al. 1997; Koenig 2002). This type of competition is predicted to select for traits that increase a female's access to high-quality resources and is therefore associated with high aggression rates as individuals stand to gain or lose a lot depending on the outcome of agonistic interactions (Janson 1985; Isbell and Pruetz 1998; Koenig 2000; Vogel 2005; Robbins 2008).

Though many species exhibit higher rates of aggression over more contestable resources (Mitchell et al. 1991; Saito 1996; Sterck and Steenbeek 1997; Pruetz and Isbell 2000; Su and Birky 2007) aggression is not always related to resource characteristics in such predictable ways. My study provides an 
example of a case where, contrary to predictions from socio-ecological models, aggression rates are low while food resources predict within-group contest competition (chapter 3, Deutsch and Lee 1991; Gore 1993; Sterck and Steenbeek 1997; Isbell and Pruetz 1998). These discrepancies between food resources and aggression rates have been attributed to inaccurate measurement of resource characteristics and more specifically the use of gross dietary categories as indicators of modes of feeding competition (Isbell and Young 2002; Koenig and Borries 2006; Snaith and Chapman 2007; Vogel and Janson 2007). For example, aggression rates are often predicted to be higher in frugivorous species compared to those that rely more on leaves or insects because fruit is assumed to occur in discrete, high-value patches that can be defended against conspecifics (Wrangham 1980; van Schaik 1989; Clutton-Brock and Janson 2012).

Although the use of gross dietary categories is problematic as leaves as well as fruit can occur in monopolizable high quality patches, meaning that contest competition may occur in both folivores and frugivores (Snaith and Chapman 2007), my study reveals that even when fruit does indeed occur in monopolizable high quality patches aggression rates may be low (chapter 3 ). This adds to the accumulating evidence that frugivory is not necessarily associated with high levels of aggression (Chancellor and Isbell 2009; Wheeler et al. 2013) and that rates of food related aggression are influenced by many other factors such as competitor density, degree of arboreality, the availability of alternative resources and the individuals' hunger state (chapter 3, Janson and Vogel 2006; Vogel and Janson 2007; Vogel and Janson 2011; Wheeler et al. 2013).

Individual aggression rates are predicted to increase with increasing group or party size (in fissionfusion societies) (Goss-Custard 1980; van Schaik et al. 1983; Watts 1985; De Ruiter 1986; Janson 1988b; Blumstein et al. 1999; Koenig and Borries 2006; Wheeler et al. 2013). As group size increases, the density of local competitors for limited resources increases (Janson and van Schaik 1988) which means that individuals are more likely to encounter each other. My study demonstrates that this effect is also present at the level of individual food patches, leading to an increase in aggression rates with feeding group size (chapter 3, Saito 1996; Vogel and Janson 2007). This stresses the fact that social as well as ecological factors need to be considered when investigating feeding competition. Additionally, my finding that aggression rates increase with decreasing patch size indicates that rates of aggression are influenced by the opportunity costs of aggression (chapter 3, Vogel and Janson 2007). For example, in larger patches more feeding sites are available and therefore it may be less costly to avoid aggression and find another feeding site than to compete over the original site. In other words, the opportunity costs of aggression are higher in larger patches, resulting in a linear decline of aggression rates with food patch size (chapter 3, Sterck and Steenbeek 1997; Vogel and Janson 2007; Hanya 2009). The availability of alternative resources (feeding sites) outside food patches is predicted 
to have a similar effect on aggression rates within patches (Vogel and Janson 2007; Vogel and Janson 2011). In my study, however, the availability of alternative resources outside food patches did not influence aggression rates within those patches, indicating that an individual's willingness to fight may be mainly affected by the availability of alternative feeding sites within food patches (chapter 3 ). This could be affected by visibility and individual's knowledge of the environment.

The linear relationships between aggression rates in food patches and both patch size and feeding group size found for the study population are not in accordance with resource defence theory. This theory predicts that aggression rates depend on the energetic value of the food in relation to the energetic costs of aggression, resulting in a hyperbolic relationship between aggression rates and both food abundance and competitor density (Brown 1964; Emlen and Oring 1977; Grant 1993). Instead my findings concur with hawk-dove models (Sirot 2000) which predict that the frequency of aggressive individuals (hawks) in the population (or feeding group) increases with competitor density and decreases with increased food abundance. This will result in a linear increase in the frequency of aggression with competitor density and a linear decrease with increased food abundance, a pattern which has been observed in several taxa including birds (Kotrschal et al. 1993; Johnson et al. 2004) and fish (Gregory and Wood 1999). Together with these findings, the results of my study may help explain some cases where, counter to predictions from socio-ecological models, clumped resources were associated with decreased aggression rates (Deutsch and Lee 1991; Gore 1993). It is likely that when food is clumped more alternative feeding sites will be available within or near food patches, thereby increasing the opportunity costs of aggression (chapter 3, Janson 1985; Janson 1988b; Vogel and Janson 2007). Another important factor influencing aggression rates is the fact that individuals may be more likely to avoid direct aggressive encounters instead of initiating them due to the risk of injury, energetic costs and increased social and ecological stress associated with aggression (van Schaik and van Noordwijk 1988; Sterck and Steenbeek 1997; Aureli et al. 2002; Koenig 2002; Harris 2007). This will be discussed in more detail below.

\subsection{The role of competition reducing mechanisms}

Competition is often particularly intense among individuals of the same sex because they require the same limited resources to increase their reproductive success (Stockley and Bro-Jørgensen 2011). While much research effort has been focussed on male-male competition, understanding of intrasexual competition among females has been slow to develop (Stockley and Campbell 2013). One of the most obvious sex differences in intrasexual competition is that males usually show more overt aggression than females, an effect which is also observed in humans and non-human primates 
(Clutton-Brock 2007; Stockley and Campbell 2013). An important factor underlying these sex differences in competitive strategies is thought to be the greater reproductive investment usually made by females (Clutton-Brock 2007; Clutton-Brock 2009). Females consequently face a trade-off between investment in aggression and reproduction which may constrain investment in costly competitive behaviour, weaponry or signals (Fitzpatrick et al. 1995). This could explain why in Assamese macaques, as in many species, females use relatively low-risk competitive strategies and avoid direct aggression (chapter 3, Stockley and Campbell 2013). Since food is considered one of the most important limiting resources female mammals compete for, conflict reducing mechanisms are likely to play an important role in feeding competition.

There are many mechanisms which animals may employ to reduce the risk of food related conflicts. Certain species have developed morphological adaptations which can reduce feeding competition such as an enlarged caecum and colon, which enables hindgut fermentation of leaves and allows for greater dietary flexibility. This may enable individuals to avoid contests over foods that are in high demand (Lambert 2002; Lawes et al. 2013). Additionally, species which have cheek pouches may be able to use these to reduce conflict by quickly storing food and leaving feeding patches before aggression occurs (Hill 1966; Murray 1973; Lambert 2005; Smith et al. 2008). This can manifest itself as an increase in cheek pouch use in situations of increased contest competition as well as greater cheek pouch use in particular individuals (e.g. low ranking females) which are more likely to receive aggression during feeding (chapter 4, Lambert and Whitham 2001; Lambert 2005). As discussed above, individuals can also avoid aggression by choosing alternative feeding sites when available (chapter 3 , Vogel and Janson 2007). In some species individuals form small subunits to reduce feeding competition (Symington 1988; Asensio et al. 2008) while in species with relatively stable group membership individuals may increase inter-individual distances during feeding (chapter 4, Sugiura et al. 2011; Nishikawa et al. 2014). My finding that a female's distance from the centre of the group was related to dominance rank corroborates observations on a variety of species and suggests that low ranking females may attempt to avoid aggression by feeding at the periphery of the group (van Schaik and van Noordwijk 1986; Janson 1990b; Rayor and Uetz 1990; Krause 1994; Ron et al. 1996; Hall and Fedigan 1997; Hirsch 2011). Thus, my results show that female Assamese macaques exhibit low food related aggression rates and at the same time employ a variety of conflict reducing mechanisms (chapter 3,4 ). This highlights the importance of such mechanisms for the study of feeding competition and suggests that conflict avoidance may be especially important for lower ranking females

Another way in which individuals may attempt to avoid direct conflicts is by feeding together with those group-mates who are likely to show the greatest tolerance and willingness to share food patches with them. These group-mates might be those with whom an individual shares a strong social 
bond and/or those to whom an individual is closely related (chapter 3, Saito 1996; King et al. 2009; King et al. 2011).

\subsection{Social bonds and feeding tolerance}

Feeding tolerance can be of great importance in the context of feeding competition since it can both reduce the costs of aggression and provide lower ranking individuals with an alternative means to obtain resources (de Waal 1986b; Stahl and Kaumanns 2003). Degrees of feeding tolerance are likely to be affected by social bonds, kin relationships and rank (chapter 4, de Waal 1991; Saito 1996; King et al. 2009; King et al. 2011). In primates, social bonds are primarily formed through the exchange of grooming (Dunbar 1991; Schino 2001). Grooming has been associated with reduced aggression during feeding, increased co-feeding frequencies and close proximity and frequent approaches during feeding, all of which are measures of increased feeding tolerance (Ventura et al. 2006; Dubuc and Chapais 2007; Carne et al. 2011; King et al. 2011; Tiddi et al. 2011). Additionally, grooming relationships can affect decisions to join group mates at food patches (King et al. 2008; King et al. 2009). While grooming given is often directly exchanged for increased feeding tolerance (Mitani 2006; Ventura et al. 2006; Carne et al. 2011; Tiddi et al. 2011), this does not seem to be the case in Assamese macaques (Macdonald et al. 2013). In chapter 3, I show that females preferentially co-feed with individuals they share a strong social bond with. This finding suggests that, instead of being directly interchanged for other commodities, grooming may function to strengthen the social bond between two females which increases tolerance in a feeding context irrespective of inequalities in grooming exchanges.

Feeding tolerance may also be driven by kinship; either due to the inclusive fitness benefits associated with tolerating close kin or because individuals preferentially form strong bonds with close kin due to the fitness benefits of such bonds in themselves, resulting in increased feeding tolerance among relatives (Hamilton 1963; Hamilton 1964a; Hamilton 1964b; Silk et al. 2003; Silk 2007a). Although matrilineal kinship is the most important factor affecting the development of long-term bonds in animals (Seyfarth and Cheney 2012), several studies have found that patterns of co-feeding, patch joining decisions or feeding rates were affected by grooming bonds but not by genetic relatedness, or that grooming affected feeding tolerance independent of kinship (Matsumura and Okamoto 1997; Ventura et al. 2006; King et al. 2009; King et al. 2011). This absence of kin effects on co-feeding could be due to the fact that kinship may only be important at high levels of relatedness (parentoffspring/full-sibling) (Sklepkovych 1997; Belisle and Chapais 2001; Rossiter et al. 2002; Nystrand 2006) and there may be few dyads with such high levels of relatedness among adult individuals in a 
group (King et al. 2011). Additionally, it has become clear that females do not only form strong bonds with kin (Langergraber et al. 2009; Silk et al. 2010b) and that close kin are not always closely bonded (Assamese macaques: personal observation). This makes it unlikely that the benefits of feeding with closely bonded individuals are purely based on inclusive fitness (Cameron et al. 2009).

Like several other female primates (Silk et al. 2010a; Silk et al. 2012), female Assamese macaques form strong differentiated social bonds (i.e. there is a wide variation between the frequencies and durations of affiliation exchanged within dyads, resulting in (generally) a few strong and many weak relationships) which remain stable over time, despite changes in social and ecological conditions (Macdonald et al. in prep). Such social bonds have been associated with improved fitness, including greater longevity, increased offspring survival and improved health, in a wide range of taxa (Berkman and Glass 2000; Taylor et al. 2000; Silk 2007a; Smith and Christakis 2008; Yee et al. 2008; Cameron et al. 2009; Langergraber et al. 2009; Silk et al. 2010b). However, the mechanisms relating sociality and social bonds to fitness outcomes are still largely unknown (Silk 2007a; Alberts 2010). In chapter 3, I show that in female Assamese macaques co-feeding frequency increased with increasing strength of the social bond between individuals and that more closely bonded females fed together more often in patches associated with a high aggression risk (i.e. small patches) compared to weakly bonded females. Potential benefits of increased feeding tolerance include a reduced risk of aggression and injury, reduced damage to social relationships if aggression does occur, and increased access to food. In turn, all of these factors are expected to reduce levels of stress (Aureli et al. 1989; Aureli et al. 2002). This suggest that the benefits associated with increased feeding tolerance may provide one of the missing links between sociality and fitness as social bonds may improve resource acquisition, reduce aggression related stress and lower costs from wounding.

While rank is generally considered as an important determinant of female fitness via its impact on feeding success (Whitten 1983; van Noordwijk and van Schaik 1987; Barton 1993), in recent years the focus has shifted to the importance of social bonds as determinants of female fitness (Silk 2007b). In baboons, dominance rank and the quality of close social bonds have independent effects on female longevity. Both high-ranking females and females who form stronger and more stable social bonds live longer and have more surviving offspring than lower-ranking females and females who form weaker and less stable relationships (Silk et al., 2003, 2010). My study suggests that the impact of social bonds on female fitness may also be related to feeding success (chapter 3 ). Therefore the effects of rank and social bonds on feeding success can operate simultaneously and the development of strong and consistent social bonds may partially offset fitness costs due to low dominance rank (Silk et al., 2003). In Assamese macaques an interaction between rank and social bonds could have contributed to the absence of rank related differences in energy intake. 


\subsection{Ultimate consequences of feeding competition}

Socio-ecological models predict that different types of feeding competition will result in specific relationships between individual net energy gain or fitness and either group size or dominance rank (Janson and van Schaik 1988; Koenig 2002). Several primate species that experience within-group contest competition display the expected positive relationship between female rank and food intake or fitness (Whitten 1983; Janson 1985; Bulger and Hamilton 1987; van Noordwijk and van Schaik 1987; Barton and Whiten 1993; Saito 1996; Altmann and Alberts 2003; Vogel 2005). There are however, many empirical studies which do not support model predictions, including those where resources predict predominantly within-group scramble competition but fitness is not affected by group size (Crockett and Janson 2000; Robbins et al. 2007) and those where resources predict strong withingroup contest competition but energy gain or fitness are not affected by rank (Deutsch and Lee 1991; Roberts and Cords 2013). In chapters 2 and 3, I show that female Assamese macaques are an example of the latter case as they use high quality resources which occur in patches of intermediate size in relation to group size but they do not display a rank related skew in energy intake or reproduction. This lack of rank effects may reflect the behavioural strategies individuals employ to reduce food related aggression and suggests that apart from reducing aggression, these strategies may enable low ranking females to maintain a similar energy intake to that of high ranking individuals.

Feeding competition also does not necessarily affect both individual energy intake and fitness in the same way. For example, rank can affect reproductive performance in the absence of rank related differences in food or energy intake (Deutsch and Lee 1991). In general, evidence for a rank effect on reproduction is mixed (Ellis 1995; Stockley and Bro-Jørgensen 2011), suggesting that, in addition to the influence of competition on energy intake, other social or environmental factors play a role in explaining reproductive variance within social groups. These factors include physiological stress which is expected to be higher in low ranking females as they generally receive more aggression during feeding (Deutsch and Lee 1991). Also, some of the strategies lower ranking females can use to reduce the costs of feeding competition and increase their food intake carry fitness costs. For example, increased feeding or foraging time reduces the time available for other activities and may increase energy expenditure (Wright et al. 2014) while foraging at the periphery of a group or in smaller subgroups has been suggested to increase predation risk (Hamilton 1971; van Schaik and van Noordwijk 1986).

It is also possible that group size or dominance related differences in net energy gain match resource characteristics but this does not translate into differential reproductive success (Koenig 2000; Schülke 
2003). This could be due to confounding variables such as infanticide by males, which may influence the relationship between group size, dominance rank and birth rates (Isbell 1991; Crockett and Janson 2000). Additionally, spatial and temporal variation in food availability can lead to variation in the strength of within-group contest competition and as a result rank may affect reproduction only during certain parts of the year (Woodroffe and MacDonald 1995; Beehner et al. 2006; Foerster et al. 2011). This effect may be particularly strong in seasonal breeders such as Assamese macaques where, as I show in chapter 2 , food availability during a very restricted time period has a strong impact on female reproduction (Koenig 2000).

\subsection{Feeding competition and social structure}

The link between ecological conditions and social structure is the part of socio-ecological models that is currently least well understood (Koenig 2002; Schülke and Ostner 2012; Koenig et al. 2013). Here I will link my findings on feeding competition and its fitness consequences to what is currently known about the social structure of female Assamese macaques. Females in the study population form steep, linear dominance hierarchies that are stable over time, agonism is usually unidirectional within dyads and rates of counter-aggression are low (Macdonald et al. 2013). In addition, Assamese macaques use the silent-bared teeth display as a formalised signal of submission (Bernstein and Cooper 1999). These characteristics are all predicted to result from high levels of within-group contest competition. Thus, so far, the dominance aspect of female social structure matches what would be predicted based on the characteristics of food resources used by the study population. However, the apparent absence of a rank related bias in energy intake or fitness (chapter 2) raises the question: which fitness benefits associated with high rank have led to the formation of such strict stable hierarchies? A possible answer lies in the influence of rank on female spatial position. In chapter 4, I show that lower ranking females occupy more peripheral positions than higher ranking females. This suggests that lower ranking females trade-off improved feeding conditions for increased predation risk while higherranking females can both obtain sufficient food resources and occupy safe positions within a group. If this is the case it is likely that rank does influence female fitness in the study population but more long term data may be needed to reveal this effect.

Although food patches used by the study population are generally large enough to accommodate more than one individual at a time female coalitions are very rare (chapter 3, Macdonald et al. 2013). This is a characteristic associated with low levels of within-group contest competition. The important role of competition reducing mechanisms indicated by the results of my study could also clarify the absence of female coalitions as the formation of coalitions may be unbeneficial when conflict 
avoidance plays a greater role in feeding competition than aggression. Other studies in species where females experience within-group contest competition have also found coalition formation among females to be rare (Cercopithecus mitis: Cords 2002) or non-existent (Papio ursinus: Barrett et al. 1999). This suggests that coalitions may not be as important to female intragroup feeding competition as socio-ecological models predict.

Since information on kinship is not available for the study population, it is not yet known whether female hierarchies are nepotistic, though this is common in macaque species. Where females are philopatric, individuals are expected to accrue benefits of coalition formation with close-kin; however, this does not seem to be the case in the study population. This supports the suggestion that female dispersal patterns cannot easily be predicted by competition for resources and should be omitted from socio-ecological models (Robbins et al. 2007; Koenig and Borries 2009). Although our knowledge on female social structure in the study population is not yet complete it most resembles the resident nepotistic class which is predicted to develop when females experience strong within-group contest competition (Sterck et al. 1997). One aspect which does not fit with this classification is the absence of female coalitions which could be explained by the importance of competition reducing mechanisms.

Among macaques suites of behaviours covary between species in different lineages. This correlated character evolution is seen as evidence against a flexible reaction of social traits to changes in ecological factors (Thierry 2007). It is more likely, however, that social structure will represent a combination of adaptation to the current environment and phylogenetic inertia (Chapman and Rothman 2009). In Assamese macaques dispersal patterns appear to be highly constrained while aggression and female coalition formation seem to be more flexible. The influence of adaptations to the present environment and phylogenetic inertia may be teased apart by comparing groups of the same population that inhabit different ecological conditions or distantly related species that have similar social structures (Chapman and Rothman 2009).

Self-organisation is suggested as another alternative explanation for variation in social structure as several characteristics of despotic and egalitarian societies can be generated in an artificial model system by changing the intensity or frequency of aggression (Hemelrijk 1999). However, selforganisation cannot explain how these differences in aggressions develop in the first place which is important considering that aggression is a costly behaviour and my findings suggest that females are more likely to avoid direct conflicts (chapter 3 ). Although aggression rates are low in female Assamese macaques, they still display many characteristics of a despotic society which suggests there are many factors besides aggression rates alone that influence social structure. 


\subsection{Outlook}

This thesis unites information on the relationships between resource characteristics, behavioural mechanisms of feeding competition and ultimate fitness consequences in female Assamese macaques, creating a detailed picture of the social and ecological influences on female feeding competition and fitness. Resource characteristics predicted within-group contest competition and females did exhibit food related aggression though aggression levels were lower than predicted. This was probably due to the influence of conflict reducing mechanisms and the fact that aggression rates may be more strongly affected by patch size and feeding group size than by food density, quality and distribution per se. The competitive regime (i.e. relationship between rank and fitness measures) did not match predictions based on resource characteristics. Here, again, competition reducing mechanisms are important as they may enable low ranking females to enhance their access to food resources. In addition, competition for safe positions can interact with the influence of food characteristics on individual fitness. The structure of female social relationships was beyond the scope of this study but what is currently known partly corresponds with the social structure that is predicted to emerge when withingroup contest competition is strong while some aspects may be constrained by phylogeny or affected by competition reducing mechanisms.

These findings provide mixed support for the internal consistency of socio-ecological models, suggesting that, rather than constituting a comprehensive theory of ecological influences on social structure, the main value of socio-ecological models is that they provide testable hypotheses about relationships between resources, competition, fitness and social structure. Even when there appear to be no fitness consequences associated with feeding competition, as is the case in this study, the models still have a predictive value as the lack of fitness consequences may be due to conflict avoidance mechanisms which have developed in response to selective pressures which are part of the models. Since originally socio-ecological models did not consider any constraints and ecological factors were considered as the sole determinants of social structure, they function as a type of 'null model' (Thierry 2013). By testing the hypotheses provided by socio-ecological models we can gain insight into the kinds of data still needed to answer questions about the relationships between ecological factors, competition and social structure as well as genetic, behavioural, developmental and social factors that may constrain social behaviour (Kappeler et al. 2013; Koenig et al. 2013).

My findings stress the importance of distinguishing between aggression rates and energetic and fitness consequences of competition as they may not respond to food characteristics in the same way. This also emphasizes that aggression rates should not be used as indicators of modes of feeding competition or as predictors of competitive regimes or social structure as they may not be predictably 
linked to either of these factors. The availability of alternative feeding sites in food patches and feeding group size may interact with measures of food density, quality and distribution and as such could explain some of the discrepancies that have been found between resource characteristics and aggression or competitive regimes as predicted by socio-ecological models. Conflict reducing adaptations can affect the relationship between resource characteristics and aggression as well as the energetic and fitness consequences of competition. Competition for safety (or other limiting resources) can interact with feeding competition to influence female fitness. This also indicates that feeding competition can have different effects on energy intake, survival and reproduction and ideally all these variables should be measured to assess the fitness consequences of competition.

For true tests of the internal consistency of socio-ecological models more studies are needed which incorporate accurate measurements of resource characteristics, energetic and fitness measures, conflict reducing adaptations as well as competition for limiting resources other than food. This would enable a comparative assessment of all model predictions and assumptions which is currently still lacking. For Assamese macaques specifically, long-term fitness data may be able to clarify if and how rank influences female fitness while relatedness data are needed to elucidate the role of kinship in social structure and feeding tolerance. Furthermore, measures of physiological stress could reveal further costs and benefits associated with rank.

Other interesting avenues of future research include the potential role of social bonds in feeding tolerance which could help elucidate the mechanisms by which social bonds enhance fitness in gregarious animals and the influence of animal personalities on the emergence of animal social structures. Individuals in a variety of species show consistent differences in behaviour across a variety of social and ecological contexts which constitute a personality trait or behavioural syndrome (Sih et al. 2004; Dingemanse and Wolf 2010). It is suggested that individuals may select certain situations or be prepared to engage in certain kinds of interaction, and avoid others, depending on their personality (Montiglio et al. 2013). It seems likely that social groups will be composed of individuals with varying personalities such that the social system is an emergent property of these dynamic social interactions rather than a uniform entity (Barrett et al. 2013). Feeding competition may be particularly interesting in this respect as behavioural consistency can reduce conflict among conspecifics because it reduces niche overlap between individuals using the same resources. Increased levels of competition may therefore result in an increase in personality types (Bergmüller et al. 2010; Montiglio et al. 2013). 



\section{Bibliography}

Alberts S, Hollister-Smith J, Mututua R, Sayialel S, Muruthi P, Warutere J, Altmann J (2005) Seasonality and long-term change in a savanna environment. In: Brockman D, van Schaik C (eds) Seasonality in primates. Cambridge University Press, Cambridge, pp 157-196

Alberts S (2010) Primatology: "A faithful friend is the medicine of life". Current Biology 20:R632-R634

Alexander RD (1974) The evolution of social behavior. Annual Review of Ecology and Systematics 5:325-382

Altmann J (1974) Observational study of behavior: sampling methods. Behaviour 49:227-267

Altmann J (1980) Baboon mothers and infants. Harvard University Press, Cambridge

Altmann J, Hausfater G, Altmann SA (1988) Determinants of reproductive success in savannah baboons, Papio cynocephalus. In: Clutton-Brock TH (ed) Reproductive success. University of Chicago Press, Chicago, pp 403-418

Altmann J, Alberts S (2003) Variability in reproductive success viewed from a life-history perspective in baboons. American Journal Of Human Biology 15:401-409

Andersson M, Wicklund CG (1978) Clumping versus spacing out: experiments on nest predation in fieldfares (Turdus pilaris) Animal Behavior:1207-1212

Asensio N, Korstjens AH, Schaffner CM, Aureli F (2008) Intragroup aggression, fission-fusion dynamics and feeding competition in spider monkeys. Behaviour 145:983-1001

Aureli F, van Schaik CP, Van Hooff JARAM (1989) Functional aspects of reconciliation among captive long-tailed macaques (Macaca fascicularis). American Journal of Primatology 19:39-51

Aureli F (1992) Post-conflict behaviour among wild long-tailed macaques (Macaca fascicularis). Behavioral Ecology and Sociobiology 31:329-337

Aureli F, Cords M, van Schaik CP (2002) Conflict resolution following aggression in gregarious animals: a predictive framework. Animal Behaviour 64:325-343

Aureli F, Schaffner CM, Boesch C, Bearder SK, Call J, Chapman CA, Connor R, Di Fiore A, Dunbar RIM, Henzi SP, Holekamp K, Korstjens AH, Layton R, Lee P, Lehmann J, Manson JH, RamosFernández G, Strier KB, van Schaik CP (2008) Fission-fusion dynamics: new research frameworks. Current Anthropology 49:627- 654

Baayen RH (2008) Analyzing linguistic data. Cambridge University Press, Cambridge

Baayen RH (2011) R package languageR. $\mathrm{R}$ package version 1.4 http://CRAN.Rproject.org/package=language $R$

Baldwin JD, Baldwin JI (1972) The ecology and behavior of squirrel monkeys (Saimiri oerstedi) in a natural forest in Panama. Folia Primatologica:161-184

Barrett L, Henzi S, Weingrill T, Lycett J, Hill R (1999) Market forces predict grooming reciprocity in female baboons. Proceedings of the Royal Society London B 266:665-670

Barrett L, Halliday J, Henzi SP (2006) The ecology of motherhood: the structuring of lactation costs by chacma baboons. Journal of Animal Ecology 75:875-886

Barrett L, Blumstein DT, Clutton-Brock TH, Kappeler PM (2013) Taking note of Tinbergen, or: the promise of a biology of behaviour. Philosophical Transactions of the Royal Society B: Biological Sciences 368 
Barton RA, Whiten A, Strum SC, Byrne RW, Simpson AJ (1992) Habitat use and resource availability in baboons. Animal Behaviour 43:831-844

Barton RA (1993) Sociospatial mechanisms of feeding competition in female olive baboons, Papio anubis. Animal Behaviour 46:791-802

Barton RA, Whiten A (1993) Feeding competition among female olive baboons, Papio anubis. Animal Behaviour 46:777-789

Barton RA, Byrne RW, Whiten A (1996) Ecology, feeding competition and social structure in baboons. Behavioural Ecology and Sociobiology 38:321-329

Bates D, Maechler M, Bolker B (2012) Ime4 - linear mixed effects models using S4 classes. R package version 0.999999-0. http://CRAN.R-project.org/package=Ime4

Beehner J, Onderdonk D, Alberts S, Altmann J (2006) The ecology of conception and pregnancy failure in wild baboons. Behavioral Ecology 17:741 - 750

Belisle P, Chapais B (2001) Tolerated co-feeding in relation to degree of kinship in Japanese macaques. Behaviour 138:487-509

Bercovitch FB (1987) Female weight and reproductive condition in a population of olive baboons (Papio anubis). American Journal of Primatology 12:189-195

Bercovitch FB, Strum SC (1993) Dominance rank, resource availability, and reproductive maturation in female savanna baboons. Behavioral Ecology and Sociobiology 33:313-318

Bergmüller R, Schürch R, Hamilton IM (2010) Evolutionary causes and consequences of consistent individual variation in cooperative behaviour. Philosophical Transactions of the Royal Society B: Biological Sciences 365:2751-2764

Berkman LF, Glass T (2000) Social integration, social networks, social support, and health. In: Berkman LF, Kawachi I (eds) Social Epidemiology. Oxford University Press, New York, pp 137-173

Berman CM, Schwartz S (1988) A nonintrusive method for determining relative body fat in freeranging monkeys. American Journal of Primatology 14:53-64

Bernstein I, Cooper M (1999) Dominance in Assamese macaques (Macaca assamensis). American Journal of Primatology 48:283- 289

Bertram BCR (1978) Living in groups: predators and prey. In: Krebs JR, Davies NB (eds) Behavioural Ecology: An Evolutionary Approach. Blackwell Scientific Publications, Oxford, pp 64-96

Blumstein DT, Evans CS, Daniel JC (1999) An experimental study of behavioural group size effects in tammar wallabies, Macropus eugenii. Animal Behavior 58:351-360

Boinski S (1987) Habitat use by squirrel monkeys (Saimiri oerstedi) in Costa Rica. Folia Primatologica:151-167

Boinski S (1999) The social organizations of squirrel monkeys: implications for ecological models of social evolution. Evolutionary Anthropology 8:101-112

Borries C (1993) Ecology of female social relationships: hanuman langurs (Presbytis entellus) and the van Schaik model. Folia Primatologica 61:21-30

Borries C, Koenig A, Winkler P (2001) Variation of life history traits and mating patterns in female langur monkeys (Semnopithecus entellus). Behavioral Ecology and Sociobiology 50:391-402

Borries C, Larney E, Kreetiyutanont K, Koenig A (2002) The diurnal primate community in a dry evergreen forest in Phu Khieo Wildlife Sanctuary, Northeast Thailand. Natural History Bulletin of the Siam Society 50:75-88

Borries C, Lu A, Ossi-Lupo K, Larney E, Koenig A (2011) Primate life histories and dietary adaptations: A comparison of Asian colobines and macaques. American Journal Of Physical Anthropology 144:286-299 
Bradbury JW, Vehrencamp SL (1977a) Social organization and foraging in emballonurid bats. II. A model for the determination of group size. Behavioral Ecology and Sociobiology 1:383-404

Bradbury JW, Vehrencamp SL (1977b) Social organization and foraging in emballonurid bats. III. Mating systems. Behavioral Ecology and Sociobiology 2:1-17

Brockman DK, van Schaik CP (2005) Seasonality and reproductive function. In: Brockman DK, Van Schaik CP (eds) Seasonality in Primates: Studies of Living and Extinct Human and non-human Primates. Cambridge University Press, Cambridge, pp 269-305

Brown JL (1964) The evolution of diversity in avian territorial systems. Wilson Bulletin:160-169

Bryer MAH, Chapman C, Rothman J, Rothman JM (2013) Diet and polyspecific associations affect spatial patterns among redtail monkeys (Cercopithecus ascanius). Behaviour 150:1-17

Bulger J, Hamilton WJ (1987) Rank and density correlates of inclusive fitness measures in a natural chacma baboon (Papio ursinus) troop. International Journal of Primatology 8:635-650

Bumann D, Krause J, Rubenstein D (1997) Mortality risk of spatial positions in animal groups: the danger of being in the front. Behaviour 134:1063-1076

Burnham KP, Anderson DR (2002) Model Selection and Multimodel Inference, 2 edn. Springer, Berlin

Busse CD (1984) Spatial structure of chacma baboon groups. International Journal of Primatology 5:247-261

Cameron E, Setsaas T, Linklater W (2009) Social bonds between unrelated females increase reproductive success in feral horses. Proceedings of the National Academy of Sciences USA 106:13850

Carne C, Wiper S, Semple S (2011) Reciprocation and interchange of grooming, agonistic support, feeding tolerance, and aggression in semi-free-ranging Barbary macaques. American Journal of Primatology 73:1127-1133

Carnegie SD, Fedigan LM, Melin AD (2011) Reproductive seasonality in female capuchins (Cebus capucinus) in Santa Rosa (Area de Conservación Guanacaste), Costa Rica. International Journal of Primatology

Chancellor RL, Isbell LA (2009) Food site residence time and female competitive relationships in wild gray-cheeked mangabeys (Lophocebus albigena). Behavioral Ecology and Sociobiology 63:1447-1458

Chapman C, Rothman J (2009) Within-species differences in primate social structure: evolution of plasticity and phylogenetic constraints. Primates 50:12-22

Chapman CA, Wrangham RW, Chapman LJ (1995) Ecological constraints on group size: an analysis of spider monkey and chimpanzee subgroups. Behavioral Ecology and Sociobiology 36:59-70

Chapman CA, Rothman JM, Lambert JE (2012) Food as a selective force in primates. In: Mitani JC, Call J, Kappeler PM (eds) The Evolution of Primate Societies. The University of Chicago Press, Chicago, pp 149-168

Chivers DP, Brown GE, Smith RJF (1995) Familiarity and shoal cohesion in fathead minnows (Pimephales promelas)-implications for antipredator behavior. Canadian Journal of Zoology:955-960

Clutton-Brock TH (1974) Primate social organization and ecology. nature 250:539-542

Clutton-Brock TH (1989) Mammalian mating systems. Proceedings of the Royal Society London B 236:339-372

Clutton-Brock TH, Parker GA (1992) Potential reproductive rates and the operation of sexual selection. The Quarterly Review of Biology 67:437-456

Clutton-Brock TH (2007) Sexual selection in males and females. Science 318:1882-1885 
Clutton-Brock TH (2009) Sexual selection in females. Animal Behaviour 77:3-11

Clutton-Brock TH, Janson C (2012) Primate socioecology at the crossroads: Past, present, and future. Evolutionary Anthropology: Issues, News, and Reviews 21:136-150

Coelho AM (1986) Time and Energy Budgets Comparative Primate Biology In: Mitchell G, Erwin J (eds) Vol. 2A: Behaviour, Conservation and Ecology Alan R. Liss, Inc., New York

Collins DA (1984) Spatial pattern in a troop of yellow baboons (Papio cynocephalus) in Tanzania. Animal Behaviour 32:536-553

Conradt L, Roper T (2005) Consensus decision making in animals. Trends in Ecology and Evolution 20:449- 456

Cords M (2000) Agonistic and afilliative relationships in a blue monkey group. In: Whitehead P, Jolly C (eds) Old World Monkeys. Cambridge University Press, Cambridge, pp 453-479

Cords M (2002) Friendship among adult female blue monkeys (Cercopithecus mitis). Behaviour 139:291-314

Cords M (2012) The behavior, ecology, and social evolution of cercopithecine monkeys. In: Mitani JC, Call J, Kappeler PM, Palombit RA, Silk JB (eds) The Evolution of Primate Societies. The University of Chicago Press, Chicago

Cowlishaw G (1994) Vulnerability to predation in baboon populations. Behaviour 131:293-304

Cowlishaw G (1997) Trade-offs between foraging and predation risk determine habitat use in a desert baboon population. Animal Behaviour 53:667-686

Cowlishaw $\mathrm{G}$ (1998) The role of vigilance in the survival and reproductive strategies of desert baboons. Behaviour 135:431-451

Cowlishaw G (1999) Ecological and social determinants of spacing behaviour in desert baboon groups. Behavioral Ecology and Sociobiology 45:67-77

Crockett CM, Rudran R (1987) Red howler monkey birth data 1: seasonal variation. American Journal of Primatology 13:347-368

Crockett CM, Janson CH (2000) Infanticide in red howlers: female group size, male membership, and a possible link to folivory. In: van Schaik $\mathrm{CP}$, Janson $\mathrm{CH}$ (eds) Infanticide by males and its implications. Cambridge University Press, Cambridge, pp 75-98

Crook JH, Gartlan JC (1966) Evolution of primate societies. nature 210:1200-1203

Cunninham E, Janson C (2007) A socioecological perspective on primate cognition, past and present. Animal Cognition 10:273-281

Darwin C (1859) On the origin of species. Murray, London

Dasilva G (1992) The western black-and-white colobus as a low-energy strategist: Activity budgets, energy expenditure and energy intake. The Journal of Animal Ecology 61:79-91

Davies NB, Krebs JR, West SA (2012) An Introduction to Behavioural Ecology. Wiley-Blackwell

De Ruiter D (1986) The Influence of group size on predator scanning and foraging behaviour of wedgecapped capuchin monkeys (Cebus olivaceus). Behaviour 98:240-258

de Waal F (1986a) The integration of dominance and social bonding in primates. The Quarterly Review of Biology 61:459-479

de Waal FB (1986b) Class structure in a rhesus monkey group: the interplay between dominance and tolerance. Animal Behavior 34:1033-1040

de Waal FBM, Luttrell LM (1989) Toward a comparative socioecology of the genus Macaca: Different dominance styles in rhesus and stumptail monkeys. American Journal of Primatology 19:83109 
de Waal FBM (1991) Rank distance as a central feature of rhesus monkey social organization: a sociometric analysis. Animal Behaviour 41:383-395

Deutsch JC, Lee PC (1991) Dominance and feeding competition in captive rhesus monkeys. International Journal of Primatology 12:615-625

Di Bitetti MS, Janson CH (2000) When will the stork arrive? Patterns of birth seasonality in neotropical primates. American Journal of Primatology 50:109-130

Di Bitetti MS, Janson CH (2001) Social foraging and the finder's share in capuchin monkeys, Cebus apella. Animal Behaviour 62:47-56

Di Fiore A (2004) Diet and feeding ecology of wooly monkeys in a western Amazonian rain forest. International Journal of Primatology 25:767-801

Dias LD, Strier KBS (2003) Effects of group size on ranging patterns in Brachyteles arachnoides hypoxanthus. International Journal of Primatology 24:209-221

Dingemanse NJ, Wolf M (2010) Recent models for adaptive personality differences: a review. Philosophical Transactions of the Royal Society B: Biological Sciences 365:3947-3958

Drent R, Daan S (1980) The prudent parent: Energetic adjustments in avian breeding. Ardea 68:225252

Dubois F, Giraldeau L-A, Grant JWA (2003) Resource defense in a group-foraging context. Behavioral Ecology 14:2-9

Dubuc C, Chapais B (2007) Feeding competition in Macaca fascicularis: An assessment of the early arrival tactic. International Journal of Primatology 28:357-367

Dunbar R (1980) Demographic and lifehistory variables of a population of gelada baboons. Journal of Animal Ecology 49:485-506

Dunbar R (1991) Functional significance of social grooming in primates. Folia Primatologica 57:121131

Dunbar RIM (1988) Primate social systems. Cornell University Press, Ithaca

Dunbar RIM, Dunbar P (1988) Maternal time budgets of gelada baboons. Animal Behaviour 36:970980

Duncan P, Vigne N (1979) The effect of group size in horses on the rate of attacks by blood-sucking flies. Animal Behavior:623-625

Ellis L (1995) Dominance and reproductive success among nonhuman animals: a cross-species comparison. Ethology and Sociobiology 16:257-333

Emlen ST (1966) The role of time and energy in food choice. American Naturalist 100:611-617

Emlen ST, Oring LW (1977) Ecology, sexual selection, and the evolution of mating systems. Science 197:215-223

Fashing P (2001) Activity and ranging patterns of guerezas in the Kakamega forest: intergroup variation and implications for intragroup feeding competition. International Journal of Primatology 22:549-577

Fitzpatrick S, Berglund A, Rosenqvist G (1995) Ornaments or offspring-costs to reproductive success restrict sexual selection processes. Biological Journal of the Linnean Society 55:251-260

Foerster S, Cords M, Monfort SL (2011) Social behavior, foraging strategies, and fecal glucocorticoids in female blue monkeys (Cercopithecus mitis): potential fitness benefits of high rank in a forest guenon. American Journal of Primatology 73:870-882

Fretwell SD, Lucas HL (1969) On territorial behavior and other factors influencing habitat distribution in birds. I. Theoretical Development. Acta Biotherica:16-36.

Fretwell SD (1972) Populations in a Seasonal Environment. Princeton University Press, Princeton, NJ 
Fürtbauer I, Schülke O, Heistermann M, Ostner J (2010) Reproductive and life history parameters of wild female Assamese macaques (Macaca assamensis). International Journal of Primatology 31:501-517

Gilmore D, Cook B (1981) Environmental factors in mammal reproduction. MacMillan, London

Gittleman JL, Thompson SD (1988) Energy allocation in mammalian reproduction. American Zoologist 28:863-875

Goering HK, Van Soest PJ (1970) Forage Fiber Analysis (apparatus, reagents, procedures and some applications). USDA Agricultural Handbook No. 379.

Goldberg JL, Grant JWA, Lefebvre L (2001) Effects of the temporal predictability and spatial clumping of food on the intensity of competitive aggression in the Zenaida dove. Behavioral Ecology 12:490-495

Gore MA (1993) Effects of food distribution on foraging competition in rhesus monkeys, Macaca mulatta, and hamadryas baboons, Papio hamadryas. Animal Behaviour 45:773-786

Goss-Custard JD (1980) Competition for food and interference among waders. Ardea 68:52

Grant JWA (1993) Whether or not to defend? the influence of resource distribution. Marine Behaviour and Physiology 23:137-153

Grant JWA, Girard IL, Breau C, Weir LK (2002) Influence of food abundance on competitive aggression in juvenile convict cichlids. Animal Behaviour 63:323-330

Grassman LI, Tewes ME, Silvy NJ, Kreetiyutanont K (2005) Ecology of three sympatric felids in a mixed evergreen forest in north-central Thailand. Journal of Mammalogy 86:29-38

Gregory TR, Wood CM (1999) Interactions between individual feeding behaviour, growth, and swimming performance in juvenile rainbow trout (Oncorhynchus mykiss) fed different rations. Canadian Journal of Fisheries and Aquatic Sciences 56:479-486

Hall CL, Fedigan LM (1997) Spatial benefits afforded by high rank in white-faced capuchins. Animal Behaviour 53:1069-1082

Hamilton WD (1963) The evolution of altruistic behavior. The American Naturalist 97:354-356

Hamilton WD (1964a) The genetical evolution of social behaviour. I. Journal of Theoretical Biology 7:116

Hamilton WD (1964b) The genetical evolution of social behaviour. II. Journal of Theoretical Biology 7:17-52

Hamilton WD (1971) Geometry for the selfish herd. Journal of Theoretical Biology 31:295-311

Hanya $G$ (2009) Effects of food type and number of feeding sites in a tree on aggression during feeding in wild Macaca fuscata. International Journal of Primatology 30:569-581

Harcourt AH (1989) Environment, Competition and Reproductive Performance of Female Monkeys. Trends in Ecology and Evolution 4:101-105

Harper DGC (1982) Competitive foraging in Mallards: 'ideal free ducks' Animal Behavior:575-584

Harris T (2007) Testing mate, resource and infant defence functions of intergroup aggression in nonhuman primates: issues and methodology. Behaviour 144:1521-1535

Heesen M, Rogahn S, Ostner J, Schülke O (2013) Food abundance affects energy intake and reproduction in frugivorous female Assamese macaques. Behavioral Ecology and Sociobiology 67:1053-1066

Heesen M, Rogahn S, Macdonald S, Ostner J, Schülke O (in revision) Predictors of food related aggression in wild Assamese macaques and the role of conflict avoidance. Behavioral Ecology and Sociobiology 
Heller R, Milinski M (1979) Optimal foraging of sticklebacks on swarming prey. Animal Behavior:11271141

Hemelrijk C (1999) An individual-orientated model of the emergence of despotic and egalitarian societies. Proceedings of the Royal Society London B 266:361-369

Hemery GE, Savill PS, Pryor SN (2005) Applications of the crown diameter-stem diameter relationship for different species of broadleaved trees. Forest Ecology and Management 215:285-294

Hill WCO (1966) Primates: comparative anatomy and taxonomy (volume VI; Catarrhini, Cercopithecoidea, Cercopithecinae). Edinburgh University Press, Edinburgh

Hinde R (1976) Interactions, relationships and social structure. Man 11:1-17

Hirsch BT (2007) Costs and benefits of within-group spatial position: A feeding competition model. Quarterly Review of Biology 82:9-27

Hirsch BT (2011) Within-group spatial position in ring-tailed coatis: balancing predation, feeding competition, and social competition. Behavioral Ecology and Sociobiology 65:391-399

Hirsch BT, Morrell LJ (2011) Measuring marginal predation in animal groups. Behavioral Ecology 22:648-656

Holand O, Weladji R, Gjostein J, Kumpula J, Smith M, Nieminen M, Roed K (2004) Reproductive effort in relation to maternal social rank in reindeer (Rangifer tarandus). Behavioral Ecology and Sociobiology 57:69-76

Holekamp KE, Dloniak SM (2010) Intraspecific variation in the behavioral ecology of a tropical carnivore, the spotted hyena. Advances in the Study of Behavior Volume 42:189-229

Isbell L, Pruetz J (1998) Differences between vervets (Cercophitecus aethiops) and patas monkeys (Erythrocebus patas) in agonistic interactions between adult females. International Journal of Primatology 19:837-855

Isbell L, Pruetz J, Young T (1998) Movements of vervets (Cercopithecus aethiops) and patas monkeys (Erythrocebus patas) as estimators of food resource size, density, and distribution. Behavioral Ecology and Sociobiology 42:123-133

Isbell L (2004) Is there no place like home? Ecological bases of female dispersal and philopatry and their consequences for the formation of kin groups. In: Chapais B, Berman C (eds) Kinship and Behavior in Primates. Oxford University Press, Oxford, pp 71-108

Isbell LA (1991) Contest and scramble competition: patterns of female aggression and ranging behavior among primates. Behavioral Ecology 2:143-155

Isbell LA, Enstam KL (2002) Predator (in)sensitive foraging in sympatric female vervets (Cercopithecus aethiops) and patas monkeys (Erythrocebus patas): A test of ecological models of group dispersion. In: Miller LE (ed) Eat or Be Eaten: Predator Sensitive Foraging Among Primates. Cambridge University Press, New York, pp 154-168

Isbell LA, Young TP (2002) Ecological models of female social relationships in primates: similarities, disparities, and some directions for future clarity. Behaviour 139:177-202

Jacobs A (2010) Group cohesiveness during collective movements: travelling apart together. Behavioural Processes:678-680

James R, Bennet PG, Krause J (2004) Geometry for mutualistic and selfish herds: the limited domain of danger. Journal of Theoretical Biology:107-113

Janson C, Chapman C (1999a) Resources and primate community structure. In: Fleagle J, Janson C, Reed J (eds) Primate communities. Cambridge University Press, Cambridge, pp 237-267

Janson C, Chapman CA (1999b) Resources and primate community structure. In: Fleagle JG, Janson CH, Reed KE (eds) Primate Communities. Cambridge University Press, Cambridge, pp 237-267 
Janson C (2000) Primate socio-ecology: The end of a golden age. Evolutionary Anthropology 9:73-86 Janson C, Verdolin J (2005) Seasonality of primate births in relation to climate. In: Brockman DK, Van Schaik CP (eds) Seasonality in Primates: Studies of Living and Extinct Human and non-human Primates. Cambridge University Press, Cambridge, pp 307-350

Janson C, Vogel E (2006) Hunger and aggression in capuchin monkeys. In: Hohmann G, Robbins M, Boesch C (eds) Feeding ecology in apes and other primates - ecological, physical, and behavioral aspects. Cambridge University Press, Cambridge, pp 285-312

Janson CH (1985) Aggressive competition and individual food consumption in wild brown capuchin monkeys (Cebus apella). Behavioral Ecology and Sociobiology 18:125-138

Janson CH (1988a) Intra-specific food competition and primate social structure: a synthesis. Behaviour 105:1-17

Janson CH (1988b) Food competition in brown capuchin monkeys (Cebus apella): Quantitative effects of group size and tree productivity. Behaviour 105:53-76

Janson CH, van Schaik CP (1988) Recognizing the many faces of primate food competition: methods. Behaviour 105:165-186

Janson CH (1990a) Ecological consequences of individual spatial choice in foraging groups of brown capuchin monkeys, Cebus apella. Animal Behaviour:922-934

Janson $\mathrm{CH}$ (1990b) Social correlates of individual spatial choice in foraging groups of brown capuchin monkeys, Cebus apella. Animal Behaviour 40:910-921

Janson CH (1992) Evolutionary ecology of primate social structure. In: Smith EA, Winterhalder B (eds) Evolutionary Ecology and Human Behavior. Aldine de Gruyter, New York, pp 95-130

Janson CH (1998) Testing the predation hypothesis for vertebrate sociality: prospects and pitfalls. Behaviour 135:389-410

Jarman PJ (1974) The social organisation of antelope in relation to their ecology. Behaviour 48:215-256

Jennings T, Evans SM (1980) Influence of position in the flock and flock size on vigilance in the starling, Sturnus vulgaris. Animal Behaviour 28:634-635

Johnson CA, Grant JWA, Giraldeau L-A (2004) The effect of patch size and competitor number on aggression among foraging house sparrows. Behavioral Ecology 15:412-418

Kappeler PM, van Schaik CP (2002) The evolution of primate social systems. International Journal of Primatology 23:707-740

Kappeler PM, Barrett L, Blumstein DT, Clutton-Brock TH (2013) Constraints and flexibility in mammalian social behaviour: introduction and synthesis. Philosophical Transactions of the Royal Society B: Biological Sciences 368

Kenward RE (1978) Hawks and doves: factors affecting success and selection in goshawk attacks on wood-pigeons. Journal of Animal Ecology:449-460

King A, Douglas C, Huchard E, Isaac N, Cowllshaw G (2008) Dominance and affiliation mediate despotism in a social primate. Current Biology 18:1833- 1838

King AJ, Isaac NJB, Cowlishaw G (2009) Ecological, social, and reproductive factors shape producerscrounger dynamics in baboons. Behavioral Ecology 20:1039-1049

King AJ, Clark FE, Cowlishaw G (2011) The dining etiquette of desert baboons: the roles of social bonds, kinship, and dominance in co-feeding networks. American Journal of Primatology 73:768-774

Koenig A, Borries C, Chalise MK, Winkler P (1997) Ecology, nutrition, and timing of reproductive events in an Asian primate, the Hanuman langur (Presbytis entellus). Journal of Zoology, London 243:215-235 
Koenig A, Beise J, Chalise M, Ganzhorn J (1998) When females should contest for food - testing hypotheses about resource density, distribution, size, and quality with hanuman langurs (Presbytis entellus). Behavioral Ecology and Sociobiology 42:225-237

Koenig A (2000) Competitive regimes in forest-dwelling Hanuman langur females (Semnopithecus entellus). Behavioral Ecology and Sociobiology 48:93-109

Koenig A, Borries C (2001) Socioecology of Hanuman langurs: the story of their success. Evolutionary Anthropology 10:122-137

Koenig A (2002) Competition for resources and its behavioral consequences among female primates. International Journal of Primatology 23:759-783

Koenig A, Borries C, Suarez S, Kreetiyutanont K, Prabnasuk J (2004) Socio-ecology of Phayre's leaf monkeys (Trachypithecus phayrei) at Phu Khieo Wildlife Sanctuary. Journal of Wildlife in Thailand 12:150-163

Koenig A, Borries C (2006) The predictive power of socioecological models: a reconsideration of resource characteristics, agonism, and dominance hierarchies. In: Hohmann G, Robbins M, Boesch C (eds) Feeding ecology in apes and other primates - ecological, physical, and behavioral aspects. Cambridge University Press, Cambridge, pp 263-284

Koenig A, Borries C (2009) The lost dream of ecological determinism: Time to say goodbye? ... Or a White Queen's proposal? Evolutionary Anthropology 18:166-174

Koenig A, Scarry CJ, Wheeler BC, Borries C (2013) Variation in grouping patterns, mating systems and social structure: what socio-ecological models attempt to explain. Philosophical Transactions of the Royal Society B: Biological Sciences 368

Kotrschal K, Hemetsberger J, Dittami J (1993) Food exploitation by a winter flock of greylag geese: behavioral dynamics, competition and social status. Behavioral Ecology and Sociobiology 33:289-295

Krause J (1983) The relationship between foraging and shoal position in a mixed shoal of roach (Rutilus rutilus) and chub (Leuciscus Leuciscus): a field study Oecologia:356-359

Krause J (1994) Differential fitness returns in relation to spatial position in groups. Biological Reviews 69:187-206

Krause J, Ruxton GD (2002) Living in groups. Oxford University Press, Oxford

Krebs J, Davies N (1987) Natural selection, ecology and behaviour. In: An Introduction to Behavioural Ecology. Blackwell Scientific Publications, Oxford

Kruuk H (1964) Predators and anti-predator behaviour of the black headed gull, Larus ridibundus. Behaviour (suppl.):1-129

Kuester J, Paul A (1984) Female reproductive characteristics in semifree-ranging Barbary Macaques (Macaca sylvanus L. 1758). Folia Primatologica 43:69-83

Kumsuk M, Kreetiyutanont K, Suvannakorn V, Sanguanyat N (1999) Diversity of wildlife vertebrates in Phu Khieo Wildlife Sanctuary, Chaiyaphum Province. In. Phu Khieo Wildlife Sanctuary, Wildlife Conservation Division, Natural Resources Conservation Office, Royal Forest Department, Bangkok, pp 124

Lambert J (2002) Resource switching and species coexistence in guenons: A community analysis of dietary flexibility. In: Glenn ME, \& Cords, M. (ed) The Guenons: Diversity and Adaptation in African Monkeys. Kluwer Academic/ Plenum Publishers, New York, pp 309-323

Lambert JE, Whitham J (2001) Cheek pouch use in Papio cynocephalus. Folia Primatologica 72:89-91 
Lambert JE (2005) Competition, predation, and the evolutionary significance of the cercopithecine cheek pouch: The case of Cercopithecus and Lophocebus. American Journal Of Physical Anthropology 126:183-192

Langergraber K, Mitani J, Vigilant L (2009) Kinship and social bonds in female chimpanzees (Pan troglodytes). American Journal of Primatology 71:840-851

Lappan S (2009) The effects of lactation and infant care on adult energy budgets in wild siamangs (Symphalangus syndactylus). American Journal Of Physical Anthropology 140:290-301

Lawes M, Cords M, Lehn C (2013) Cercopithecus mitis species profile. In: Butynski TM, Kingdon J, Kalina $\mathrm{J}$ (eds) Primates of Africa, vol II of the mammals of Africa. Bloomsbury, London, pp 354-362

Lee PC (1987) Nutrition, fertility and maternal investment in primates. Journal of Zoology (London) 213:409-422

Leighton M, Leighton DR (1982) The relationship of size of feeding aggregate to size of food patch: howler monkeys (Alouatta palliata) feeding in Trichilia cipo fruit trees on Barro Colorado island. Biotropica 14:81-90

Lewis R, Kappeler P (2005) Are Kirindy sifaka capital or income breeders? It depends. American Journal of Primatology 67:365-369

Lima SL, Dill LM (1990) Behavioral decisions made under the risk of predation: a review and prospectus. Canadian Journal of Zoology 68:619-640

Lockhart BR, Robert C, Weih JR, Keith MS (2005) Crown radius and diameter at breast height relationships for six bottomland hardwood species. Journal of the Arkansas Acadamy of Sciences 59:110-115

Lomnicki A (1988) Population Ecology of Individuals. Princeton University Press, Princeton, N.J.

Loudon ASI, Racey PA (1987) Reproductive Energetics in Mammals. Clarendon Press, Oxford

MacArthur RH, Pianka ER (1966) On optimal use of a patchy environment. American Naturalist 100:603-609

Macdonald S, Schülke O, Ostner J (2013) The absence of grooming for rank-related benefits in female Assamese macaques (Macaca assamensis). International Journal of Primatology 34:571-584

Majolo B, Lehmann J, de Bortoli Vizioli A, Schino G (2012) Fitness-related benefits of dominance in primates. American Journal Of Physical Anthropology 147:652-660

Martin P, Bateson P (2007) Measuring Behaviour, Third edn. Cambridge University Press, Cambridge

Matsumura S, Okamoto K (1997) Factors affecting proximity among members of a wild group of Moor macaques during feeding, moving, and resting. International Journal of Primatology 18:929940

Maynard Smith J, Price GR (1973) The logic of animal conflict. nature 246:15-18

Maynard Smith J (1974) The theory of games and the evolution of animal conflicts. Journal of Theoretical Biology 47:209-221

Maynard Smith J (1976) Evolution and the theory of games. American Scientist 64:41-45

Milinski M, Heller R (1978) Influence of a predator on the optimal foraging behaviour of sticklebacks (Gasterosteus aculeatus). nature:642-644

Milinski M (1984) A predator's cost of overcoming the confusion effect of swarming prey. Animal Behavior:1157-1162

Miller KE, Bales KL, Ramos JH, Dietz JM (2006) Energy intake, energy expenditure, and reproductive costs of female wild golden lion tamarins (Leontopithecus rosalia). American Journal of Primatology 68:1037-1053 
Miller LE (2002) Eat or be eaten - risk sensitive foraging among primates. Cambridge University Press, Cambridge

Mitani JC (2006) Reciprocal exchange in chimpanzees and other primates. In: Kappeler P, van Schaik C (eds) Cooperation in primates and humans. Springer, Heidelberg, pp 107-120

Mitchell CL, Boinski S, van Schaik CP (1991) Competitive regimes and female bonding in two species of squirrel monkeys (Saimiri oerstedi and S. sciureus). Behavioral Ecology and Sociobiology 28:5560

Montiglio P-O, Ferrari C, Réale D (2013) Social niche specialization under constraints: personality, social interactions and environmental heterogeneity. Philosophical Transactions of the Royal Society B: Biological Sciences 368

Mori A (1979) Analysis of population changes by measurement of body weight in the Koshima troop of Japanese monkeys. Primates 20:71-397

Murray C, Eberly L, Pusey A (2006) Foraging strategies as a function of season and rank among wild female chimpanzees (Pan troglodytes). Behavioral Ecology 17:1020-1028

Murray P (1973) The anatomy and functional significance of cheek pouches (bursae buccales) in the Cercopithecinae, Cercopithecoidea. University of Chicago

Murray P (1975) The role of cheek pouches in cercopithecine monkey adaptive strategy. In: Tuttle RH (ed) Primate functional morphology and evolution. Mouton Publishers, The Hague, pp 151-194

Nicholson AJ (1954) An outline of the dynamics of animal populations. Australian Journal of Zoology 2:9-65

Nievergelt CM, Martin RD (1999) Energy intake during reproduction in captive common marmosets (Callithrix jacchus). Physiology and Behavior 65:849-854

Nishikawa M, Suzuki M, Sprague DS (2014) Activity and social factors affect cohesion among individuals in female Japanese macaques: A simultaneous focal-follow study. American Journal of Primatology DOI: 10.1002/ajp.22263

Noldus (2003) MatMan 1.1.

Nunn CL, Altizer S (2006) Infectious Disease in Primates: Behavior, Ecology and Evolution. Oxford University Press, Oxford

Nystrand M (2006) Influence of age, kinship, and large-scale habitat quality on local foraging choices of Siberian jays. Behavioral Ecology 17:503-509

Ostner J, Heistermann M, Schülke O (2008) Dominance, aggression and physiological stress in wild male Assamese macaques (Macaca assamensis). Hormones and Behavior 54:613-619

Parker G (2000) Scramble in behaviour and ecology. Proceedings of the Royal Society London B 355:1637-1645

Parker GA, Sutherland WJ (1986) Ideal free distributions when individuals differ in competitive ability: phenotype-limited ideal free models. Animal Behavior:1222-1242

Pereira ME (1988) Effects of age and sex on intragroup spacing behaviour in juvenile savannah baboons, Papio cynocaphalus cynocephalus. Animal Behaviour:184-204

Pereira ME (1993) Seasonal adjustment of growth rate and adult body weight in ringtailed lemurs. In: Kappeler PM, Ganzhorn JU (eds) Lemur social systems and their ecological basis. Plenum Press, New York, pp 205-221

Perry G, Pianka ER (1997) Animal foraging: past, present and future. Trends in Ecology \& Evolution 12:360-364

Phillips KA (1995) Resource patch size and flexible foraging in white-faced capuchins (Cebus capucinus). International Journal of Primatology 16:509-519 
Pierce WC, Haenisch EL (1947) Quantitative analysis. Wiley, London

Pruetz JD, Isbell LA (2000) Correlations of food distribution and patch size with agonistic interactions in female vervets (Chlorocebus aethiops) and patas monkeys (Erythrocebus patas) living in simple habitats. Behavioral Ecology and Sociobiology 49:38-47

Pyke GH, Pulliam HR, Charnov EL (1977) Optimal foraging: A selective review of theory and tests. Quarterly Review of Biology 52:137-154

$R$ Development Core Team (2012) A language and environment for statistical computing. $R$ foundation for statisical computing, Vienna, Austria

Rayor LS, Uetz GW (1990) Trade-offs in foraging success and predation risk with spatial position in colonial spiders. Behavioral Ecology and Sociobiology:77-85

Rhine RJ, Hendy HM, Stillwell-Barnes R, Westlund BJ, Westlund HD (1980) Movement patterns of yellow baboons (Papio cynocephalus): Central positioning of walking infants. American Journal Of Physical Anthropology 53:159-167

Richard AF, Dewar RE, Schwartz M, Ratsirarson J (2000) Mass change, environmental variability and female fertility in wild Propithecus verreauxi. Journal Of Human Evolution 39:381-391

Robbins M, Robbins A, Gerald-Steklis N, Steklis H (2005) Long-term dominance relationships in female mountain gorillas: strength, stability and determinants of rank. Behaviour 142:779-809

Robbins M, Robbins A, Gerald-Steklis N, Steklis H (2007) Socioecological influences on the reproductive success of female mountain gorillas (Gorilla beringei beringei). Behavioral Ecology and Sociobiology 61:919-931

Robbins M (2008) Feeding competition and agonistic relationships among Bwindi Gorilla beringei. International Journal of Primatology 29:999-1018

Roberts S, Cords M (2013) Group size but not dominance rank predicts the probability of conception in a frugivorous primate. Behavioral Ecology and Sociobiology 67:1995-2009

Roberts SB, Cole TJ, Coward WA (1985) Lactational performance in relation to energy intake in the baboon. The American Journal of Clinical Nutrition 41:1270-6

Robinson JG (1981) Spatial structure in foraging groups of wedge-capped capuchin monkeys Cebus nigrivittatus. Animal Behaviour 29:1036-1056

Robinson MR, Kruuk LEB (2007) Function of weaponry in females: the use of horns in intrasexual competition for resources in female Soay sheep. Biology Letters:651-654

Ron T, Henzi SP, Motro U (1996) Do female chacma baboons compete for a safe spatial position in a southern woodland habitat? Behaviour 133:475-490

Ross C (1992) Basal metabolic rate, body weight and diet in primates: an evaluation of the evidence. Folia Primatologica 58:7-23

Rossiter S, Jones G, Ransome R, Barratt E (2002) Relatedness structure and kin-biased foraging in the greater horseshoe bat (Rhinolophus ferrumequinum). Behavioral Ecology and Sociobiology 51:510-518

Sadleir RMF (1969) The ecology and reproduction in wild and domestic mammals. Methuen, London

Saito C (1996) Dominance and feeding success in female Japanese macaques, Macaca fuscata: effects of food patch size and inter-patch distance. Animal Behaviour 51:967-980

Sawada A, Sakaguchi E, Hanya G (2011) Digesta passage time, digestibility, and total gut fill in captive Japanese macaques (Macaca fuscata): effects food type and food intake level. International Journal of Primatology 32:390-405

Schino G (2001) Grooming, competition and social rank among female primates: a meta-analysis. Animal Behavior 62:265-271 
Schoener TW (1971) Theory of feeding strategies. Annual Review of Ecology and Systematics 2:369404

Schreier AL, Swedell L (2012) Ecology and sociality in a multilevel society: Ecological determinants of spatial cohesion in hamadryas baboons. American Journal Of Physical Anthropology 148:580588

Schülke O (2003) To breed or not to breed: food competition and other factors influencing female reproductive decisions in the pair-living nocturnal fork-marked lemur (Phaner furcifer). Behavioral Ecology and Sociobiology 55:11-21

Schülke O, Chalise M, Koenig A (2006) The importance of ingestion rates for estimating food quality and energy intake. American Journal of Primatology 68:951-965

Schülke O, Ostner J (2008) Male reproductive skew, paternal relatedness, and female social relationships. American Journal of Primatology 70:1-4

Schülke O, Pesek D, Whitman B, Ostner J (2011) Ecology of Assamese macaques (Macaca assamensis) at Phu Khieo Wildlife Sanctuary. Journal of Wildlife in Thailand

Schülke O, Ostner J (2012) Ecological and social influences on sociality. In: Mitani J, Call J, Kappeler P, Palombit R, Silk J (eds) The Evolution of Primate Societies. University of Chicago Press, Chicago, pp 193-219

Schülke O, Heistermann M, Ostner J (2014) Lack of evidence for energetic costs of mate-guarding in wild male Assamese macaques (Macaca assamensis). International Journal of Primatology:124

Seyfarth RM, Cheney DL (2012) The evolutionary origins of friendship. Annual Review of Psychology 63:153-177

Sih A, Bell A, Johnson JC (2004) Behavioral syndromes: an ecological and evolutionary overview. Trends in Ecology \& Evolution 19:372-378

Silk JB (2002) Females, Food, Family, and Friendship. Evolutionary Anthropology 11:85-87

Silk JB, Alberts SC, Altmann J (2003) Social bonds of female baboons enhance infant survival. Science 302:1231- 1234

Silk JB, Alberts SC, Altmann J (2006a) Social relationships among adult female baboons (Papio cynocephalus) II. Variation in the quality and stability of social bonds. Behavioral Ecology and Sociobiology 61:197-204

Silk JB, Altmann J, Alberts SC (2006b) Social relationships among adult female baboons (Papio cynocephalus) I. Variation in the strength of social bonds. Behavioral Ecology and Sociobiology 6:183-195

Silk JB (2007a) The adaptive value of sociality in mammalian groups. Philosophical Transactions of the Royal Society B: Biological Sciences 362:539-559

Silk JB (2007b) Social components of fitness in primate groups. Science 317:1347-1351

Silk JB, Beehner J, Bergman T, Crockford C, Engh A, Moscovice L, Wittig R, Seyfarth R, Cheney D (2010a) Female chacma baboons form strong, equitable, and enduring social bonds. Behavioural Ecology and Sociobiology 64:1733-1747

Silk JB, Beehner JC, Bergman TJ, Crockford C, Engh AL, Moscovice LR, Wittig RM, Seyfarth RM, Cheney DL (2010b) Strong and consistent social bonds enhance the longevity of female baboons. Current Biology 20:1359-1361

Silk JB, Alberts SC, Altmann J, Cheney DL, Seyfarth RM (2012) Stability of partner choice among female baboons. Animal Behaviour 83:1511-1518

Simmons LW (2014) 25 years of Behavioral Ecology. Behavioral Ecology 25:1-3 
Sirot E (2000) An evolutionarily stable strategy for aggressiveness in feeding groups. Behavioral Ecology 11:351-356

Sklepkovych B (1997) The influence of kinship on foraging competition in Siberian jays. Behavioral Ecology and Sociobiology 40:287-296

Skogland T (1985) The effect of density-dependent resource limitation on the demography of wild reindeer. Journal of Animal Ecology:359-374

Smith KP, Christakis NA (2008) Social networks and health. Annual Review of Sociology 34:405-429

Smith LW, Link A, Cords M (2008) Cheek pouch use, predation risk, and feeding competition in blue monkeys (Cercopithecus mitis stuhlmanni). American Journal Of Physical Anthropology 137:334-341

Snaith T, Chapman C (2005) Towards an ecological solution to the folivore paradox: patch depletion as an indicator of within-group scramble competition in red colobus monkeys (Piliocolobus tephrosceles). Behavioral Ecology and Sociobiology 59:185-190

Snaith TV, Chapman CA (2007) Primate group size and interpreting socioecological models: Do folivores really play by different rules? Evolutionary Anthropology: Issues, News, and Reviews 16:94-106

Snaith TV, Chapman CA (2008) Red colobus monkeys display alternative behavioral responses to the costs of scramble competition. Behavioral Ecology 19:1289-1296

Sogard SM, Olla BL (1997) The influence of hunger and predation risk on group cohesion in a pelagic fish, walleye pollock Theragra chalcogramma. Environmental Biology of Fishes:405-413

Soumah AG, Yokota N (1991) Female rank and feeding strategies in a free-ranging provisioned troop of Japanese macaques. Folia Primatologica 57:191-200

Stahl D, Kaumanns W (2003) Food competition in captive female sooty mangabeys (Cercocebus torquatus atys). Primates 44:203-216

Stearns S (1992) The evolution of life histories. Oxford University Press, New York

Steenbeek R (2000) Infanticide by males and female choice in wild Thomas's langurs. In: van Schaik C, Janson C (eds) Infanticide by males and its implications. Cambridge University Press, Cambridge, pp 153-197

Stephens DW, Krebs JR (1986) Foraging theory. Princeton University Press, Princeton

Sterck EHM (1995) Females, foods and fights. A socio-ecological comparison of the sympatric Thomas langur and long-tailed macaque. Utrecht University

Sterck EHM, Steenbeek R (1997) Female dominance relationships and food competition in the sympatric Thomas langur and long-tailed macaque. Behaviour 134:749-774

Sterck EHM, Watts DP, van Schaik CP (1997) The evolution of female social relationships in nonhuman primates. Behavioral Ecology and Sociobiology 41:291-309

Stockley P, Bro-Jørgensen J (2011) Female competition and its evolutionary consequences in mammals. Biological Reviews 86:341-366

Stockley P, Campbell A (2013) Female competition and aggression: interdisciplinary perspectives. Philosophical Transactions of the Royal Society B: Biological Sciences 368

Strier KB (1989) Effects of patch size on feeding associations in muriquis (Brachyteles arachnoides). Folia Primatologica 52:70-77

Strum SC, Western JD (1982) Variations in fecundity with age and environment in olive baboons (Papio anubis). American Journal of Primatology 3:61-76.

Su H, Birky W (2007) Within-group female-female agonistic interactions in Taiwanese macaques (Macaca cyclopis). American Journal of Primatology 69:199-211 
Sugiura H, Shimooka Y, Tsuji Y (2011) Variation in Spatial Cohesiveness in a Group of Japanese Macaques (Macaca fuscata). International Journal of Primatology:1-19

Suzuki S, Noma N, Izawa K (1998) Inter-annual variation of reproductive parameters and fruit availability in two populations of Japanese macaques. Primates 39:313-324

Symington MM (1988) Food competition and forgaging party size in the black spider monkey (Ateles paniscus chamek). Behaviour 105:117-184

Takahashi H (2002) Female reproductive parameters and fruit availability: factors determining onset of estrus in Japanese macaques. American Journal of Primatology 57:141-153

Taylor SE, Cousino L, Lewis BP, Gruenewald TL, Gurung RAR, Updegraff JA (2000) Biobehavioral responses to stress in females: tend-and-befriend, not fight-or-flight. Psychological Review 107:411-429

Terborgh J (1983) Five new world primates: a study in comparative ecology. Princeton University Press, Princeton, NJ

Thierry B (1985) Patterns of agonistic interactions in three species of macaque (Macaca mulatta, $M$ fascicularis, $M$ tonkeana). Aggressive Behavior 11:223-233

Thierry B (2007) Unity in diversity: Lessons from macaque societies. Evolutionary Anthropology: Issues, News, and Reviews 16:224-238

Thierry B (2008) Primate socioecology, the lost dream of ecological determinism. Evolutionary Anthropology 17:93-96

Thierry B (2013) Identifying constraints in the evolution of primate societies. Philosophical Transactions of the Royal Society B: Biological Sciences 368

Thouless CR (1990) Feeding competition between grazing red deer hinds. Animal Behaviour 40:105111

Tiddi B, Aureli F, Polizzi di Sorrentino E, Janson CH, Schino G (2011) Grooming for tolerance? Two mechanisms of exchange in wild tufted capuchin monkeys. Behavioral Ecology 22:663-669

Tinbergen N, Impekoven M, Franck D (1976) An experiment on spacing out as defence against predators. Behaviour:307-321

Tregenza T (1995) Building on the ideal free distribution. Advances in Ecological Research 26:253-302

Trivers RL (1972) Parental investment and sexual selection. In: Campbell B (ed) Sexual selection and the descent of man, 1871-1971. Heinemann, London, pp 136-179

van Noordwijk MA, van Schaik CP (1987) Competition among female long-tailed macaques, Macaca fascicularis. Animal Behaviour 35:577-589

van Noordwijk MA, Hemelrijk CK, Herremans LAM, St (1993) Spatial position and behavioral sex differences in juvenile long-tailed macaques. In: Pereira ME, Fairbanks LA (eds) Juvenile Primates - Life History, Development, and Behavior. Oxford University Press, Oxford, pp 77-85

van Noordwijk MA, van Schaik CP (1999) The effects of dominance rank and group size on female lifetime reproductive success in wild long-tailed macaques, Macaca fascicularis. Primates 40:105-130

van Schaik CP (1983) Why are diurnal primates living in groups? Behaviour 87:120-144

van Schaik CP, van Noordwijk MA, de Boer RJ, Tonkelaar I (1983) The effect of group size on time budgets and social behaviour in wild long-tailed macaques (Macaca fascicularis). Behavioral Ecology and Sociobiology 13:173-181

van Schaik CP, van Noordwijk MA (1985) Interannual variability in fruit abundance and the reproductive seasonality in Sumatran long-tailed macaques (Macaca fascicularis). Journal of Zoology (London) 206:533-549 
van Schaik CP, van Noordwijk MA (1986) The hidden costs of sociality: intra-group variation in feeding strategies in Sumatran long-tailed macaques (Macaca fascicularis). Behaviour 99:296-315

van Schaik CP, van Noordwijk MA (1988) Scramble and contest in feeding competition among female long-tailed macaques (Macaca fascicularis). Behaviour 105:77-98

van Schaik CP (1989) The ecology of social relationships amongst female primates. In: Standen V, Foley RA (eds) Comparative socioecology: The behavioural ecology of humans and other mammals. Blackwell Scientific Publications, Oxford, pp 195-218

van Schaik CP (1996) Social evolution in primates: the role of ecological factors and male behaviour. Proceedings of the British Academy 88:9-31

Van Soest PJ, Robertson JB (1980) Systems of analysis for evaluating fibrous feeds. In: Pigden WJ, Balch CC, Graham M (eds) Standardization of Analytical Methodology in Feeds. International Research Development Center, Ottawa, Canada

Vander Wall SB, Longland WS, Pyare S, Veech JA (1998) Cheek pouch capacities and loading rates of heteromyid rodents. Oecologia 113:21-28

Vehrencamp SL (1983) A model for the evolution of despotic versus egalitarian societies. Animal Behaviour 31:667-682

Ventura R, Majolo B, Koyama NF, Hardie S, Schino G (2006) Reciprocation and interchange in wild Japanese macaques: grooming, cofeeding, and agonistic support. American Journal of Primatology 68:1138-1149

Vine I (1971) Risk of visual detection and pursuit by a predator and the selective advantage of flocking behaviour. Journal of Theoretical Biology:405-422

Viscido SV, Wethey DS (2002) Quantitative analysis of fiddler crab flock movement: evidence for 'selfish herd' behaviour. Animal Behaviour:735-741

Vogel E (2004) The ecological basis of aggression in white-faced capuchins monkeys, Cebus capucinus, in a Costa Rican dry forest. Dissertation, Stony Brook University

Vogel E (2005) Rank differences in energy intake rates in white-faced capuchin monkeys, Cebus capucinus: the effects of contest competition. Behavioral Ecology and Sociobiology 58:333-344

Vogel E, Janson C (2007) Predicting the frequency of food-related agonism in white-faced capuchin monkeys (Cebus capucinus), using a novel Focal-Tree Method. American Journal of Primatology 69:533-550

Vogel E, Janson C (2011) Quantifying primate food distribution and abundance for socioecological studies: an objective consumer-centered method. International Journal of Primatology 32:737754

Wade GN, Schneider JE, Li HY (1996) Control of fertility by metabolic cues. American Journal of Physiology Endocrinology and Metabolism 270:E1-E19

Ward P, Zahavi A (1973) The importance of certain assemblages of birds as "information centres" for food finding. Ibis 115:517-534

Watts DP (1985) Relations between group size and composition and feeding competition in mountain gorilla groups. Animal Behaviour 33:72-85

Watts DP (1989) Infanticide in mountain gorillas: new cases and a reconsideration of the evidence. Ethology 81:18

Werner EE, Gilliam JF, Hall DJ, Mittelbach GE (1983) An experimental test of the effects of predation risk on habitat use in fish. Ecology:1540-1548

Wheeler BC, Scarry CJ, Koenig A (2013) Rates of agonism among female primates: a cross-taxon perspective. Behavioral Ecology 
White FJ, Overdorff DJ, Keith-Luca T, Rasmussen MA, Kallan WE, Forward Z (2007) Female dominance and feeding priority in a prosimian primate: experimental manipulation of feeding competition. American Journal of Primatology 69:295-304

Whitten PL (1983) Diet and dominance among female vervet monkeys (Cercopithecus aethiops). American Journal of Primatology 5:139-159

Williams GC (1966) Adaptation and natural selection. Princeton University Press, Princeton

Wittig R, Boesch C (2003) Food competition and linear dominance hierarchy among female chimpanzees of the Tai National Park. International Journal of Primatology 24:847-867

Woodroffe R, MacDonald DW (1995) Female/female competition in European badgers Meles meles: effects on breeding success. Animal Ecology 64:12-20

Wrangham RW (1979) On the evolution of ape social systems. Social Sciences Information 18:335-368

Wrangham RW (1980) An ecological model of female-bonded primate groups. Behaviour 75:262-300

Wright AN, Gompper ME (2005) Altered parasite assemblages in raccoons in response to manipulated resource availability. Oecologia:148-156

Wright $E$, Robbins A, M, Robbins M, M (2014) Dominance rank differences in the energy intake and expenditure of female Bwindi mountain gorillas. Behavioral Ecology and Sociobiology:DOI: 10.1007/s00265-014-1708-9

Yee JR, Cavigelli SA, Delgado B, McClintock MK (2008) Reciprocal affiliation among adolescent rats during a mild group stressor predicts mammary tumors and lifespan. Psychosomatic Medicine 70:1050-1059 



\section{Acknowledgements}

This thesis would not have been possible without the great help of many people. First of all I would like to thank Julia Ostner and Oliver Schülke for their great supervision and constructive comments on my manuscripts. Thank you for your guidance and support and special thanks to Oliver for the many enthusiastic ecological discussions and for always having an open door when I needed advice.

I am thankful to Peter Kappeler for his support as the co-supervisor of my thesis. I further thank Julia Fischer, Eckhard Heymann, and Bernhard Fink for agreeing to be members of my evaluation committee.

The fieldwork in Thailand would not have been possible without the support and assistance from many people. I wish to thank the National Research Council of Thailand (NRCT) and the Department of National Parks, Wildlife and Plant Conservation (DNP) for permission to conduct research in Thailand. Many thanks go to Carola Borries and Andreas Koenig who developed the field site and to J. Prabnasuk, K. Nitaya, K. Kumsuk and K. Kreetiyutanont for their cooperation and permission to carry out this project.

This study would not have been possible without the funding provided by Max-Planck Society and the German Initiative of Excellence to the Georg-August University Göttingen.

I am very grateful to all members of "Team Macaque". In particular, I wish to thank Miranda for making all of our lives so much easier by being an amazing camp manager and field researcher (a.k.a. superwoman), for keeping us all going despite torrential rain, leaches, ticks and motorbike crashes and not in the least for the late night chats in the kitchen about the good old days in Utrecht and for making sure I did not forget how to speak Dutch while in the field. Many thanks go to Khun Piya, Khun Sayaan, Khun Tam, Khun Wet, Khun Mee, Khun Aim, Khun Wat and Khun Moo for their great help with data collection, for the fun times and for making me feel at home in Thung Ka Mang. Special thanks go to Piya for collecting phenology data with me every month while discussing windmills, wooden shoes and Dutch politics and Wet for helping me with tree focal observations, even if they lasted for several hours, and singing the whole time. A special thanks to Sebastian Rogahn for his substantial contribution to data collection.

I am very grateful to Sally for sharing the highs and lows of both fieldwork and life in general, the fun movie nights with (too much) Sangsom, teaching me to appreciate whisky, making sure I actually found my way out of the forest every day and being a great travel companion on our amazing trips across South-East Asia. You will always be my "adopted" sister. 
I like to thank all current and former members of my research group: Christin R, Chris, Sally, Ines, Miranda, Mathias, Annie, Nadine, Josi, Andreas, Christin M, Markus, and Barbora for discussions, advice, comments and cake and for creating a great work environment.

I would like to thank my Dutch biology friends and especially Stephan and Roelof for putting a roof over my head when I was in The Netherlands, the many fun weekends in Utrecht, Bonn and Göttingen and for dancing like nobody's watching (especially while doing the dishes). A special thanks to Roelof for many years of friendship across several continents, for the long talks, dinners and whisky evenings, for being supportive and for sometimes knowing me better than I know myself.

I am very grateful to my friends in Göttingen for the many great memories, serious and hilarious conversations and for making me feel at home. Special thanks to Adeelia, Anni, Cédric, Christof, Chris, Christin M, Fede, Gisela (and mini Gisi), Ines, Josi, Julie, Matthis, Miranda, Pascal, Rebecca, Sally, Steffi and Tabby for zombies, movie nights, outdoor yoga, dancing till sunrise, BBQ's, lots of unfug and the occasional omnishambles. Thanks to Levin for many shared bottles of wine, great conversations and for sometimes admitting that you are wrong and I am right.

Special thanks to Cédric and Chris for their helpful comments on this thesis, Frederic for translating my summary into German and to all for the pep-talks, hugs and attempts to distract me during the final phases of my PhD and making it so much more bearable.

I am deeply grateful to my dad and my entire family for their understanding and for supporting my choices, even if that meant I disappeared to the other side of the planet for years at a time. Thank you for all the emails and cards and for shipping boxes of Sinterklaas presents to Thailand every year so I never felt too far away from home. In the last few years you have proven to be an invaluable and much needed support network and I am very lucky to have you all in my life. Special thanks my brother Milan and my sister Asha for being the best little family unit anyone could wish for. 